\title{
Design, Synthesis and Anti-RNA Virus Activity of 6 -Fluorinated-aristeromycin Analogues
}

Ji-seong Yoon, ${ }^{1, \#}$ Gyudong Kim,,${ }^{1,2, \#}$ Dnyandev B. Jarhad, ${ }^{1}$ Hong-Rae Kim, ${ }^{1}$ Young-Sup Shin, ${ }^{1}$ Shuhao Qu, ${ }^{1}$ Pramod K. Sahu, ${ }^{3}$ Hea Ok Kim, ${ }^{3}$ Hyuk Woo Lee, ${ }^{3}$ Su Bin Wang, ${ }^{4}$ Yun Jeong Kong, ${ }^{4}$ Tong-Shin Chang, ${ }^{4}$ Natacha S. Ogando, ${ }^{5}$ Kristina Kovacikova, ${ }^{5}$ Eric J. Snijder, ${ }^{5}$ Clara C. Posthuma, ${ }^{5}$ Martijn J. van Hemert, ${ }^{5}$ Lak Shin Jeong ${ }^{1, *}$

${ }^{1}$ Research Institute of Pharmaceutical Sciences, College of Pharmacy, Seoul National University, Seoul 151-742, Korea, ${ }^{2}$ College of Pharmacy and Research Institute of Drug Development, Chonnam National University, Gwangju 500-757, Korea, ${ }^{3}$ Future Medicine Co., Ltd, Seoul 06665, Korea, ${ }^{4}$ College of Pharmacy, Ewha Womans University, Seoul 120 750, Korea and ${ }^{5}$ Department of Medical Microbiology, Leiden University Medical Center, Albinusdreef 2, 2333ZA Leiden, The Netherlands

lakjeong@snu.ac.kr

${ }^{\#}$ Contributed equally to this work

Keywords: 6 -Fluorinated-ariseromycin, S-Adenosylhomocysteine hydrolase, Anti-RNA virus activity, Zika, MERS-CoV, Chikungunya, SARS-CoV 


\section{Abstract}

The 6'-fluorinated aristeromycin analogues $\mathbf{2} \mathbf{a}-\mathbf{j}$ and the phosphoramidate prodrugs $\mathbf{3 a - c}$ were designed as dual-target antiviral compounds aimed at inhibiting both the viral RNA-dependent RNA polymerase (RdRp) and the host cell $S$-adenosyl-homocysteine (SAH) hydrolase, which would indirectly target capping of viral RNA. These novel compounds were synthesized, using the electrophilic fluorination of silyl enol ether with Selectfluor as the key step. The adenosine and $N^{6}$-methyladenosine analogues 2 a-e potently inhibited the activity of SAH hydrolase, while only the adenosine derivatives $\mathbf{2 a - c}$ exhibited potent antiviral activity against MERScoronavirus, SARS-coronavirus, chikungunya virus and/or Zika virus. The introduction of a fluorine at the 6 '-position enhanced the inhibition of SAH hydrolase and the activity against RNA viruses. The 6 - $-\beta$-fluoroaristeromycin (2a) was $\sim 4$-fold more potent $\left(\mathrm{IC}_{50}=0.37 \mu \mathrm{M}\right.$ ) in its inhibition of SAH hydrolase than the control compound, (-)-aristeromycin. $6^{\prime}, 6^{\prime}-$ Difluoroaristeromycin (2c) exhibited a strong inhibitory effect on the replication of all tested RNA viruses, including MERS-CoV $\left(\mathrm{EC}_{50}=0.2 \mu \mathrm{M}\right)$, SARS-CoV $\left(\mathrm{EC}_{50}=0.5 \mu \mathrm{M}\right), \mathrm{CHIKV}$ $\left(\mathrm{EC}_{50}=0.13 \mu \mathrm{M}\right)$ and $\mathrm{ZIKV}\left(\mathrm{EC}_{50}=0.26 \mu \mathrm{M}\right)$. In viral load reduction assays this compound reduced infectious progeny titers up to $2.5 \mathrm{log}$. The phosphoramidate prodrug $3 \mathrm{a}$ also demonstrated potent broad-spectrum antiviral activity, possibly by inhibiting the viral RdRp. This study shows that $6^{\prime}$-fluorinated aristeromycin analogues can serve as starting points for the development of broad-spectrum antiviral agents that target RNA viruses. 


\section{Introduction}

Over the past 15 years outbreaks of a number of emerging positive-stranded RNA (+RNA) viruses, ${ }^{1}$ such as the severe acute respiratory syndrome coronavirus (SARS-CoV), ${ }^{2}$ Middle East respiratory syndrome coronavirus (MERS-CoV), ${ }^{3}$ chikungunya virus (CHIKV), ${ }^{4}$ and Zika virus $(\mathrm{ZIKV})^{5}$ have seriously threatened human health and have had a substantial socioeconomic impact. SARS-CoV and MERS-CoV cause serious respiratory diseases ${ }^{6}$ that can be fatal in approximately $10 \%$ and $35 \%$ of cases, respectively. CHIKV is transmitted by mosquitoes and causes a painful arthritis that can persist for months. ${ }^{7}$ ZIKV is also transmitted by mosquitoes ${ }^{8}$ although sexual transmission ${ }^{8}$ occurs as well. This virus usually causes mild disease, but can cause neurological complications in adults and fetal death or severe complications, including microcephaly in infants when women are infected during pregnancy. ${ }^{9}$ CHIKV and ZIKV have caused massive outbreaks, totaling millions of infections over the past decade. Currently, there are no effective chemotherapeutic agents or vaccines that can prevent or cure infections of any of these four serious pathogens.

The aforementioned viruses belong to the +RNA virus group (Baltimore class IV), ${ }^{1}$ which indicates that their genomic RNA has the same polarity as mRNA and can be directly translated by host ribosomes upon release into the cytoplasm of a host cell. After infection, the genomes of these viruses are translated into polyproteins that are subsequently cleaved into individual proteins by viral and/or host proteases. The nonstructural proteins (nsps) of these viruses harbour a variety of enzymatic activities that are required for the replication of the viral RNA, and invariably include a RNA-dependent RNA polymerase $(\mathrm{RdRp})^{10}$, an enzyme which is not present in uninfected cells. The RdRp transcribes the genomic RNA into a complementary negative-stranded RNA that subsequently serves as the template for the synthesis of new 
positive-stranded RNA.

Many +RNA viruses (including coronaviruses, CHIKV and ZIKV) also encode methyltransferases (MTases) ${ }^{11}$ that are required for methylation of viral mRNA cap structures. ${ }^{12}$ Since this capping is crucial for stability and translation of the viral RNA, and evasion of the host innate immune response, the viral MTases are considered promising targets for the development of antiviral therapy. ${ }^{12}$ Inhibition of MTases can be indirectly achieved by the inhibition of $S$-adenosyl-L-homocysteine (SAH) hydrolase. ${ }^{13}$ The SAH hydrolase catalyzes the interconversion of SAH into adenosine and L-homocysteine. Inhibition of this enzyme leads to the accumulation of SAH in the cell, which in turn inhibits $S$-adenosyl-L-methionine (SAM)-dependent transmethylase reactions by feedback inhibition. ${ }^{13,14}$ Most of the viral methyltransferases are dependent on SAM as the only methyl donor. Compounds that target cellular proteins might exhibit a broader spectrum of activity, are less likely to lead to drugresistance, but have a higher likelihood of toxicity. Compounds that are specifically aimed at viral proteins are expected to be less cytotoxic, but might have a more narrow spectrum of antiviral activity and might have a lower barrier antiviral drug-resistance ${ }^{14}$ Thus, the approach of targeting cellular proteins such as SAH hydrolase can be considered as a promising strategy for the development of broad-spectrum antiviral agents. ${ }^{14}$

A number of compounds have been reported to act as SAH hydrolase inhibitors. ${ }^{14}$ Type I inhibitors act through inactivation of the $\mathrm{NAD}^{+}$cofactor, and their inhibitory effect on the catalytic activity of the enzyme can be reversed by the addition of excess $\mathrm{NAD}^{+} .{ }^{14}$ Type II inhibitors are irreversible inhibitors of the SAH hydrolase that form covalent bonds with amino acid residues in the active site of the enzyme. This irreversible inhibition cannot be reversed by the addition of $\mathrm{NAD}^{+}$or adenosine or by dialysis. ${ }^{14}$

Since both the viral RdRp and host SAH hydrolase are critical for virus replication, we 
aimed to design broad-spectrum nucleoside analogue inhibitors that could directly target RdRp activity and/or indirectly inhibit the methylation of viral RNA through their effect on the host SAH hydrolase. Modified nucleosides are usually taken up by the cell via nucleoside transporters, and can be successively converted into mono-, di-, and triphosphates by cellular kinases. ${ }^{15}$ Then. these modified nucleoside triphosphates (NTPs) can compete with natural NTPs during RNA synthesis or can be incorporated into the nascent viral RNA, leading to chain termination or detrimental mutations. ${ }^{15}$
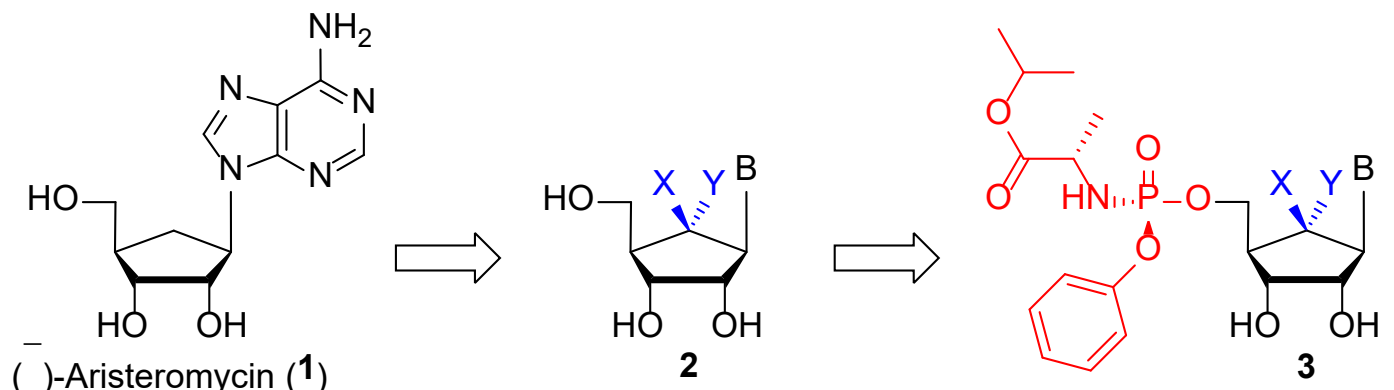

Figure 1.

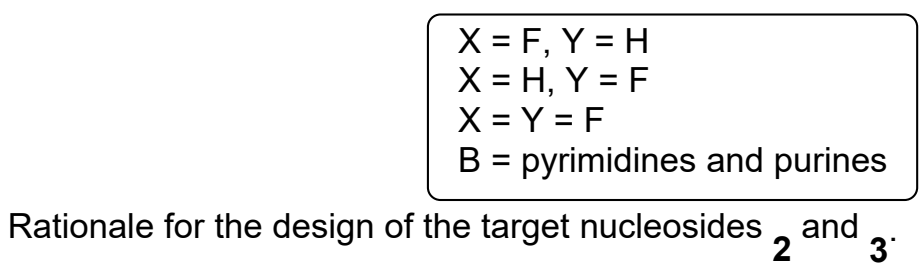

(-)-Aristeromycin (1) is a naturally occurring carbocyclic nucleoside, that was originally identified as a metabolite of Streptomyces citricolor in $1967 .{ }^{16 a}$ The first synthesis of $\mathbf{1}$ as racemate was reported by Clayton and his co-worker, ${ }^{16 \mathrm{~b}-\mathrm{d}}$ and its asymmetric syntheses have since been reported. ${ }^{16-h}$ It is a type I SAH hydrolase inhibitor and exhibits potent antiviral activity against many viruses. ${ }^{14 a}$ However, it could not be further advanced into clinical development because of its cytotoxicity. ${ }^{17}$ Compound 1 was found to be toxic at low concentrations in both adenosine kinase positive $\left(\mathrm{AK}^{+}\right)$and $\mathrm{AK}^{-}$cells. $\mathrm{AK}^{+}$cells were presumably killed by the 5 -phosphorylated form of $\mathbf{1}$, while the toxicity in $\mathrm{AK}^{-}$cells was caused by 1 itself. ${ }^{17}$ However, this compound is also metabolized into a triphosphate form and 
has been observed to exert a variety of metabolic effects. ${ }^{17}$ We aimed to use $\mathbf{1}$ as a prototype for the design of dual-target compounds intended at directly inhibiting the viral RdRp and indirectly inhibiting the capping process through targeting of cellular SAH hydrolase.

Since the introduction of a fluorine at the 6'-position of carbocyclic nucleosides has been known to affect biological activities to a significant extent, ${ }^{18}$ we aimed to synthesize the 6 fluorinated-aristeromycin analogues 2 by introducing fluorine at the 6'-position of 1 (Figure 1). Prisbe and his co-workers ${ }^{18 a}$ have reported the synthesis of $( \pm)-6-\alpha-$ and $( \pm)-6-\beta$-fluorinated aristeromycins and their inhibitory activity on SAH hydrolase, but the synthesis and biological activity of ( \pm )-6,6 -difluoroaristeromycin was not reported, despite the fact that the structure was claimed in the patent. ${ }^{18 \mathrm{~b}}$ Thus, we set out to synthesize the 6 -fluorinated-aristeromycin analogues $\mathbf{2}$ in the optically pure D-forms since biological activity can generally be attributed to one enantiomer, the D-isomer. Schneller and co-workers ${ }^{18 c}$ reported the elegant synthesis of optically pure (-)-6'- $\beta$-fluoro-aristeromycin, but its biological activity was not reported. Their synthetic route involved the 6- $\beta$-fluoroazide as the key intermediate, which was synthesized by employing $\mathrm{S}_{\mathrm{N}} 2$ fluorination of the 6- $\alpha$-triflic azide with tris(dimethylamino)sulfur (trimethylsilyl)difluoride (TASF), whereas our current approach ${ }^{19}$ included the stereoselective electrophilic fluorination of silyl enol ether with Selectfluor ${ }^{\circledR}$ as the fluorine source. In addition to the adenosine analogues, aimed at inhibiting SAH hydrolase and/ or RdRp, we have also synthesized 6'-fluorinated purine and pyrimidine nucleosides (changes in B the structure shown in fig 1), which could interfere with viral RNA synthesis by targeting the viral RdRp after their phosphorylation by cellular kinases. ${ }^{15}$ To bypass the first and rate-limiting 5 '-phosphorylation step, we have also synthesized a phosphoramidate prodrug $\mathbf{3}$ of nucleoside $\mathbf{2}$, using the McGuigan ProTides. ${ }^{20}$ Herein, we report the synthesis of the 6 -fluoro-aristeromycin analogues 
$\mathbf{2}$ and $\mathbf{3}$ and a preliminary characterization of their effect on several +RNA viruses, which provided insight into structure-activity relationships (SARs).

\section{Results and Discussion}

Chemistry. For the synthesis of the target nucleosides 2, the key fluorosugars 8a-c were synthesized from D-ribose via electrophilic fluorination, as shown in Scheme 1.

Scheme 1. ${ }^{\text {syntnesıs or b- }} \beta$-Fluoro-, 6- ${ }^{\alpha}$-Fluoro-, and 6-Difluorosugar 8a-c

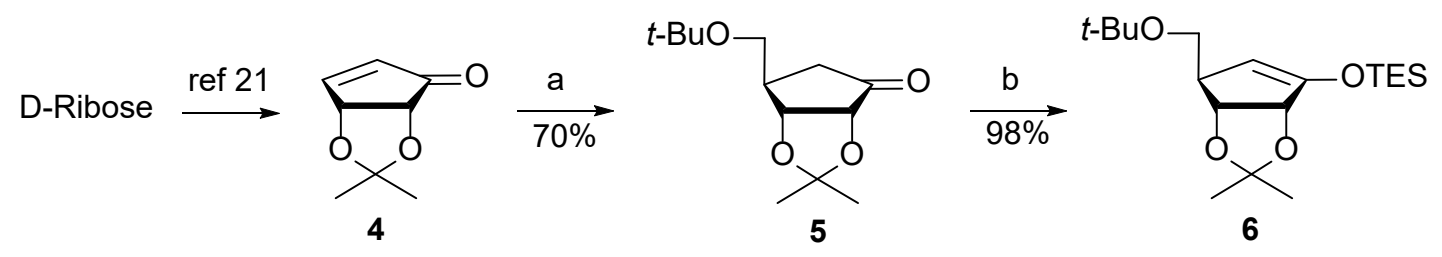

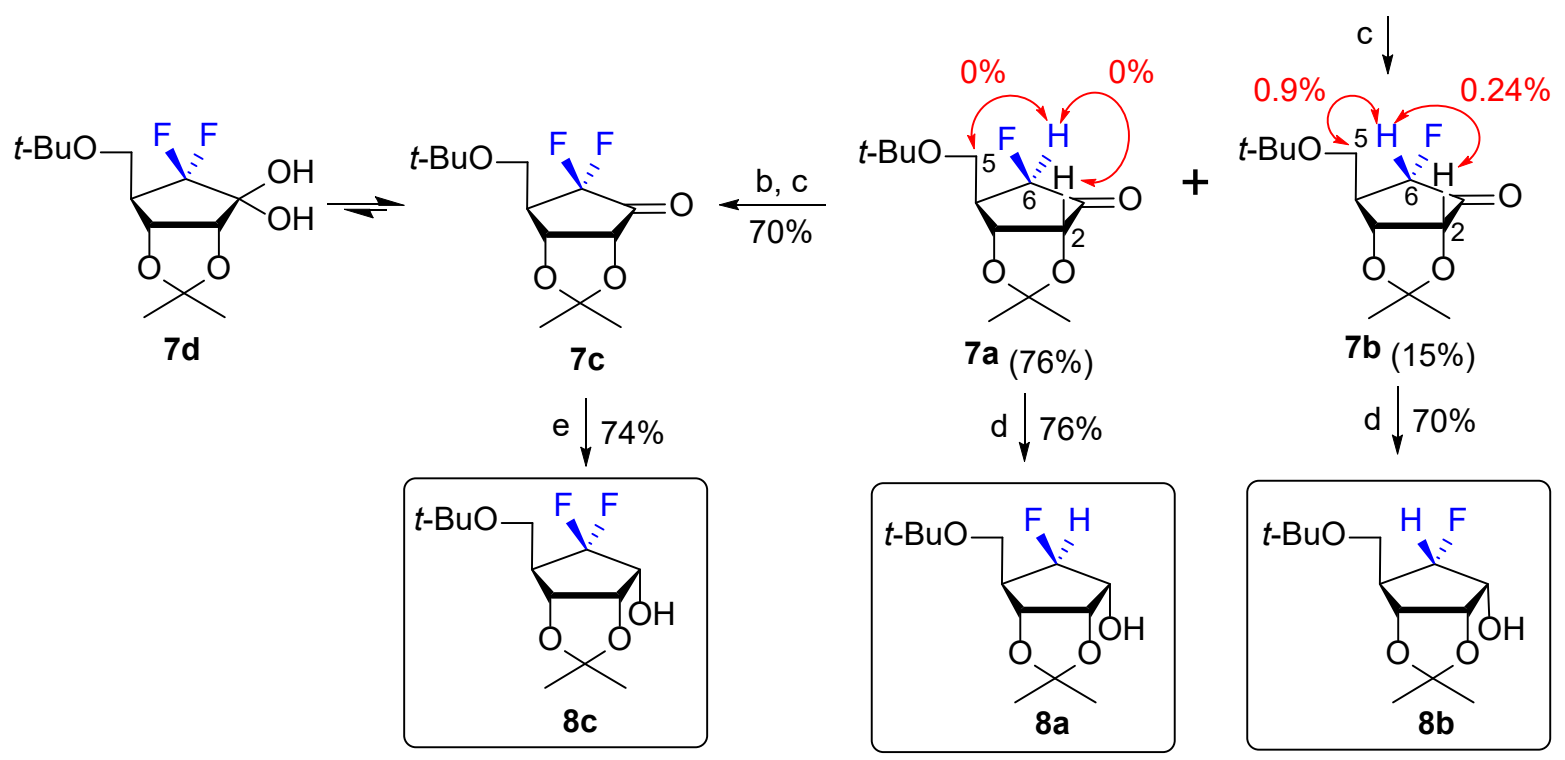

Reagents and conditions: a) $\mathrm{LiCu}\left(\mathrm{CH}_{2} \mathrm{Ot}-\mathrm{Bu}\right)_{2}$; b) TESCl, LiHMDS, THF, $-78^{\circ} \mathrm{C}, 10 \mathrm{~min}$; c) Selectfluor, DMF, $0{ }^{\circ} \mathrm{C}, 12 \mathrm{~h}$; d) $\mathrm{NaBH}_{4}, \mathrm{MeOH}, 0^{\circ} \mathrm{C}, 30 \mathrm{~min}$. e) $\mathrm{LiBH}_{4}, \mathrm{MeOH}, 0{ }^{\circ} \mathrm{C}, 30 \mathrm{~min}$.

D-Ribose was converted to D-cyclopentenone $\mathbf{4}$ according to our previously published procedure. $^{21}$ The 1,4-conjugated addition of $\mathbf{4}$ with Gilman reagent yielded the Dcyclopentanone derivative 5. ${ }^{22}$ Treatment of $\mathbf{5}$ with lithium hexamethyldisilazide (LiHMDS) 
followed by trapping with triethylsilyl chloride (TESCl) gave silylenol ether $\mathbf{6}$, which was treated with (1-chloromethyl-4-fluoro-1,4-diazoniabicyclo[2.2.2] octane bis(tetrafluoroborate): Selectfluor) in DMF at $0{ }^{\circ} \mathrm{C}$ to yield a $5: 1$ ratio of $6-\beta$-fluorosugar $7 \mathbf{a}$ to 6 - $\alpha$-fluorosugar $7 \mathbf{b} .^{20}$ The stereochemistry of the fluorine in $\mathbf{7 a}$ and $\mathbf{7 b}$ was confirmed by ${ }^{1} \mathrm{H}$ NOE experiments. Irradiation of $6-\mathrm{H}$ of $\mathbf{7 b}$ gave $\mathrm{NOE}$ effects on its $2-\mathrm{H}$ and $5-\mathrm{H}$, indicating the 6 - $\alpha$-fluoro configuration, but no NOE effects were observed on the same experiment in the case of $\mathbf{7 a}$, confirming the $6-\beta$-fluoro configuration. The configuration of the fluorine in $\mathbf{7 b}$ was further confirmed by the X-ray crystal structure obtained after it was converted to the final uracil derivative $2 \mathrm{~g}$ (Scheme 5). Further electrophilic fluorination of 6 - $\beta$-fluorosugar 7a or 6 - $\alpha$ fluorosugar $\mathbf{7 b}$ under the same conditions yielded the 6,6-difluorosugar $\mathbf{7 c}$, which was equilibrated to form a geminal diol due to the presence of electronegative fluorine atoms. Electrophilic fluorinations with other electrophilic fluorines such as $N$ fluorobenzenesulfonimide (NFSI) or $N$-fluoro- $O$-benzenedisulfonimide (NFOBS) were problematic, resulting in low yields with many side spots. The reduction of 7a-c with sodium borohydride $\left(\mathrm{NaBH}_{4}\right)$ or lithium borohydride $\left(\mathrm{LiBH}_{4}\right)$ in $\mathrm{MeOH}$ resulted in the production of the 1-hydroxyl derivatives 8a-c.

As the $\alpha$-fluoro derivative $\mathbf{8 b}$ was obtained as the minor isomer, as shown in Scheme 1, we wanted to improve the stereoselective synthesis of $\mathbf{8 b}$, by using Rubottom ${ }^{23}$ oxidation as the key step, as illustrated in Scheme 2. Rubottom oxidation of silylenol ether 6 with osmium tetroxide $\left(\mathrm{OsO}_{4}\right)$ and $N$-methylmorpholine- $N$-oxide (NMO) followed by trapping with $t$ butyldimethylsilyl chloride (TBSCl) produced 6- $\beta$-alkoxyketone 9 as a single stereoisomer in $53 \%$ yield. The reduction of ketone 9 with $\mathrm{NaBH}_{4}$ gave alcohol $\mathbf{1 0}$, which was protected with a benzyl group to give 11. Removal of the TBS group in $\mathbf{1 1}$ with tetra- $n$-butylammonium fluoride (TBAF) yielded the 6- $\beta$-alcohol 12. To our disappointment, the treatment of 12 with 
$N, N$-diethylaminosulfur trifluoride (DAST) gave the desired product, 6 - $\alpha$-fluoride 13a, but also the undesired product $1-\beta$-fluoride $\mathbf{1 3 b}$ at a $1: 1$ ratio. The formation of $\mathbf{1 3 a}$ (route I) resulted from the direct $S_{N} 2$ reaction of $12 a$ with fluoride, while $12 a$ was readily converted into the oxonium ion 12b (route II) via its participation of the neighboring benzyl group, which was attacked exclusively by the fluoride at the less sterically hindered 1-position to yield the undesired product $\mathbf{1 3 b}$ (route III). However, the product via route IV was not formed because of the steric effect of $t$-butyloxymethyl substituent. 


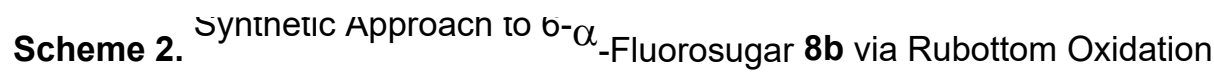

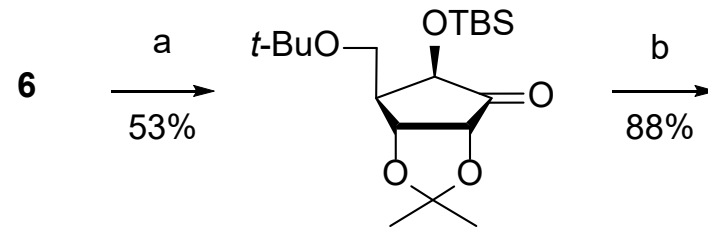

9<smiles>[R]C1C(O)C2OC(C)(C)OC1C2CO[R15](C)(C)C</smiles>

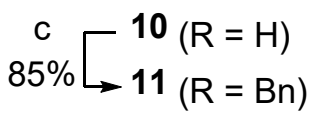<smiles>CC(C)(C)OCC1C2OC(C)(C)OC1C(O)C(Br)C2O</smiles>

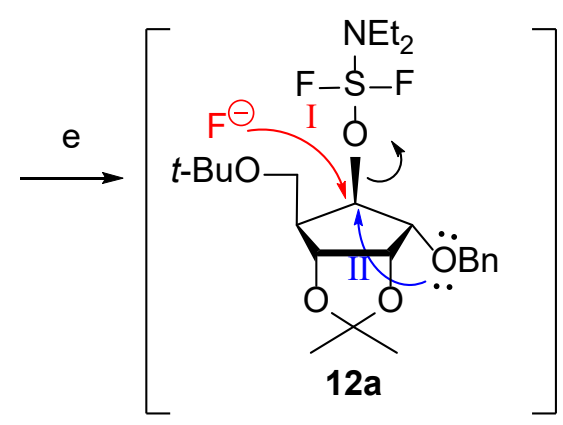
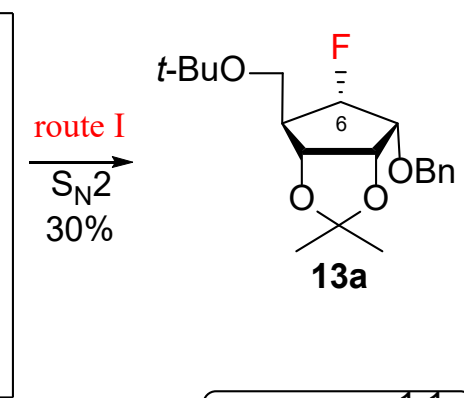

$13 a$

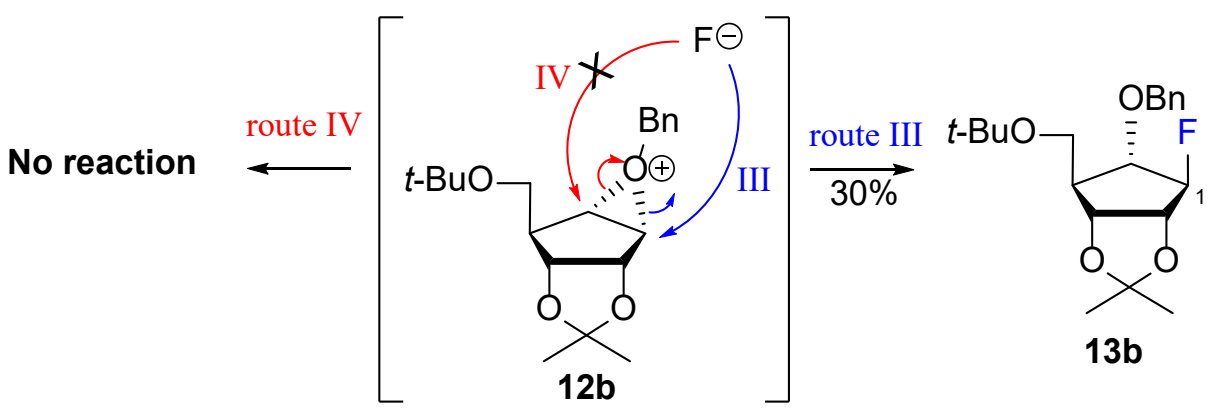

Reagents and conditions: a) i. OsO ${ }_{4}, \mathrm{NMO} \cdot \mathrm{H}_{2} \mathrm{O}, \mathrm{THF}, \mathrm{rt}, 1 \mathrm{~h}$, then $\mathrm{NaHCO}_{3}, \mathrm{MeOH}$, rt, 3 h; ii. TBSCl, imidazole, DMF, rt, 3 h; b) $\mathrm{NaBH}_{4}, \mathrm{MeOH}$, rt, 1 h; c) $\mathrm{BnBr}, \mathrm{NaH}$, DMF, $0{ }^{\circ} \mathrm{C}$ to rt, $12 \mathrm{~h}$; d) TBAF, THF, rt, $12 \mathrm{~h}$; e) DAST, toluene, $0{ }^{\circ} \mathrm{C}$ to rt, $2 \mathrm{~h}$.

To avoid the participation of the neighboring group, we considered using a cyclic sulfate substrate with electron-withdrawing property and conformational restraint to be the best choice. Furthermore, cyclic sulfate has the advantage that it can be utilized as a surrogate for epoxide during nucleobase condensation, as shown in Scheme 3. The regioselective cleavage of the 2,3acetonide in $\mathbf{1 0}$ with trimethylaluminum $\left(\mathrm{AlMe}_{3}\right)$ followed by treatment of the resulting diol with thionyl chloride $\left(\mathrm{SOCl}_{2}\right)$ yielded the 6- $\beta$-hydroxyl cyclic sulfite 14 after the removal of 
the TBS group. The treatment of $\mathbf{1 4}$ with DAST yielded the desired 6- $\alpha$-fluoro cyclic sulfite $\mathbf{1 5}$ as a single stereoisomer. The cyclic sulfite $\mathbf{1 5}$ was oxidized to form cyclic sulfate 16, which was subsequently condensed with 6-chloropurine anion; however, this resulted in decomposition..$^{20}$ Thus, we decided to synthesize the 6 - $\alpha$-fluoro derivative $\mathbf{8 b}$ according to Scheme 1.

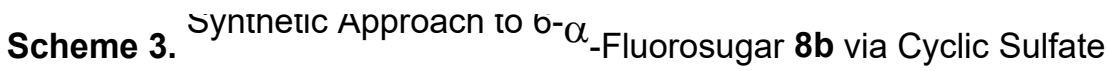

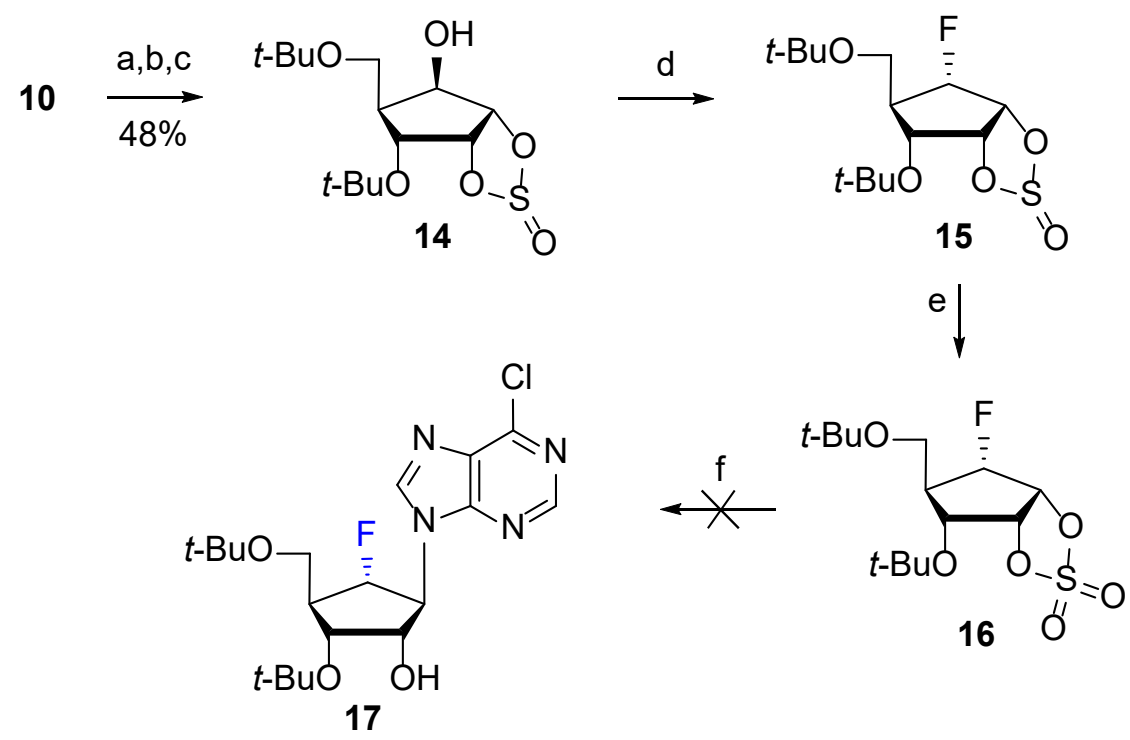

Reagents and conditions: a) AlMe $3, \mathrm{CH}_{2} \mathrm{Cl}_{2},-78{ }^{\circ} \mathrm{C}$ to rt, $12 \mathrm{~h}$; b) $\mathrm{SOCl}_{2},{ }_{3} \mathrm{~N}, \mathrm{CH}_{2} \mathrm{Cl}_{2},{ }^{\circ} \mathrm{C}, 10 \mathrm{~min}$; c) TBAF, AcOH, THF, rt, $12 \mathrm{~h}$; d) DAST, $\mathrm{CH}_{2} \mathrm{Cl}_{2},{ }^{\circ} \mathrm{C}$ to rt, $4 \mathrm{~h}$; e) $\mathrm{RuCl}_{3}, \mathrm{NaIO}_{4}, \mathrm{CCl}_{4}: \mathrm{CH}_{3} \mathrm{CN}: \mathrm{H}_{2} \mathrm{O}$ (1/1/1.5), rt, $20 \mathrm{~min}$; f) i. 6-chloropurine, 18-crown-6, NaH, THF, $65{ }^{\circ} \mathrm{C}$, 15 h; ii. $20 \% \mathrm{H}_{2} \mathrm{SO}_{4}$, rt, 1 h.

Scheme 4 depicts the synthesis of the aristeromycin analogues $\mathbf{2 a - e}$ from the 6 - $\beta$-fluoro-, $6-\alpha-$ fluoro-, and 6,6-difluorosugars 8a-c. ${ }^{20}$ Compounds 8a-c were treated with triflic anhydride $\left(\mathrm{Tf}_{2} \mathrm{O}\right)$ followed by treatment with sodium azide to give azido derivatives $\mathbf{1 8 a - c}$. The catalytic hydrogenation of 18a-c yielded the amino derivatives 19a-c, respectively, which are starting compounds for the base-building process. The treatment of 19a-c with 5-amino-4,6dichloropyrimidine ${ }^{18 \mathrm{a}-\mathrm{c}, 24}$ in the presence of $N, N$-diisopropylethylamine (DIPEA) under 
microwave radiation conditions yielded 20a-c, which were cyclized with diethoxymethyl acetate $^{18 \mathrm{a}-\mathrm{c}, 24}$ in the presence of microwave radiation to produce the 6-chloropurine derivatives 21a-c. The treatment of 21a-c with $t$-butanolic ammonia followed by the removal of protective groups under acidic conditions yielded the $6^{\prime}-\beta$-fluoro-, $6^{\prime}-\alpha$-fluoro-, and $6^{\prime}, 6^{\prime}-$ difluoroaristeromycins $\mathbf{2 a - c}$, respectively. The treatment of $\mathbf{2 1 a}$ and $21 \mathbf{c}$ with $40 \%$ aqueous methylamine followed by aqueous trifluoroacetic acid (TFA) resulted in $N^{6}$-methylaristeromycin analogues $\mathbf{2 d}$ and $\mathbf{2 e}$, respectively. 
Scheme 4. ${ }^{\text {syntnesis or }} \beta{ }^{-}$Fluoro-, ${ }^{-}{ }_{\text {Fluoro-' and Difluoro-aristeromycin Analogues } 2 a-e}$
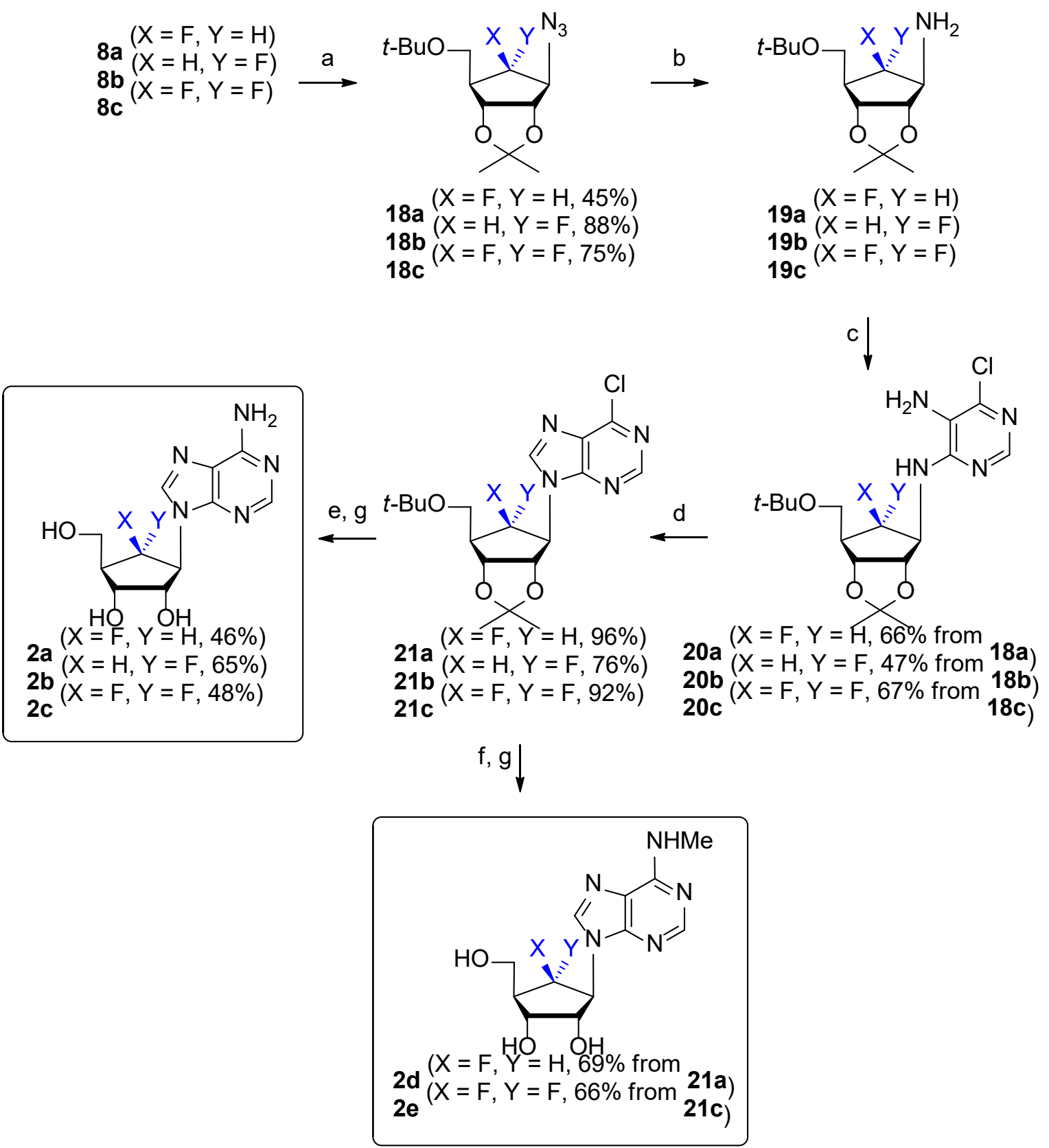

Reagents and conditions: a) i) $\mathrm{Tf}_{2} \mathrm{O}$, pyridine, $0{ }^{\circ} \mathrm{C}, 30 \mathrm{~min}$; ii) $\mathrm{NaN}_{3}$, DMF, $60-100{ }^{\circ} \mathrm{C}, 4-15 \mathrm{~h}$; b) $\mathrm{Pd} / \mathrm{C}, \mathrm{H}_{2}$, MeOH, rt, $18 \mathrm{~h}$; c) 5-amino-4,6-dichloropyrimidine, DIPEA, $n$-BuOH, $170-200{ }^{\circ} \mathrm{C}, 4-7 \mathrm{~h}$, MW; d) $\mathrm{CH}_{3} \mathrm{C}(\mathrm{O}) \mathrm{OCH}(\mathrm{OEt}){ }_{2}, 140{ }^{\circ} \mathrm{C}, 3 \mathrm{~h}, \mathrm{MW}$; e) $\mathrm{NH}_{3} / t-\mathrm{BuOH}, 120{ }^{\circ} \mathrm{C}, 15 \mathrm{~h}$; f) $\mathrm{NH}_{2} \mathrm{Me} / \mathrm{H}_{2} \mathrm{O}$, (40 wt \%), EtOH, $\left.30{ }^{\circ} \mathrm{C}, 2 \mathrm{~h} ; \mathrm{g}\right) 67 \%$ aq TFA, $50{ }^{\circ} \mathrm{C}, 15 \mathrm{~h}$. 


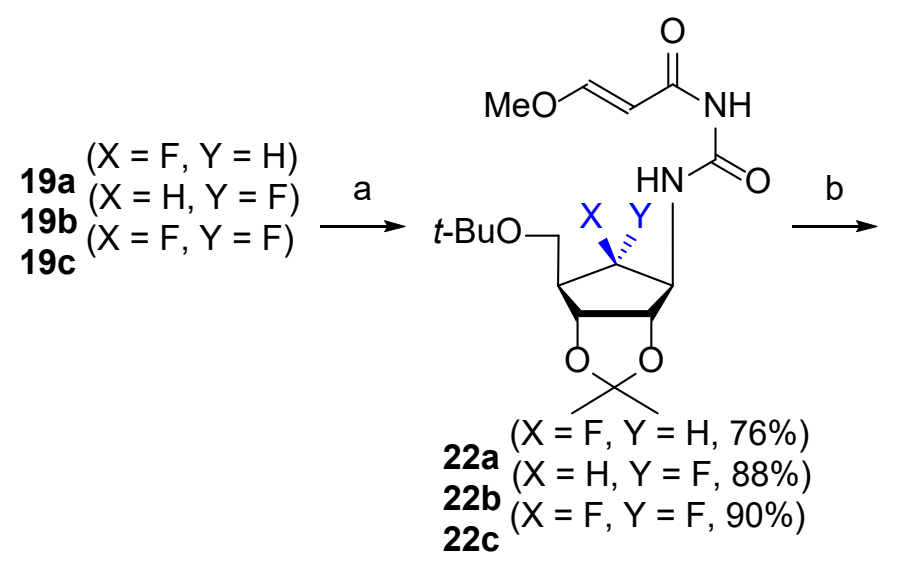

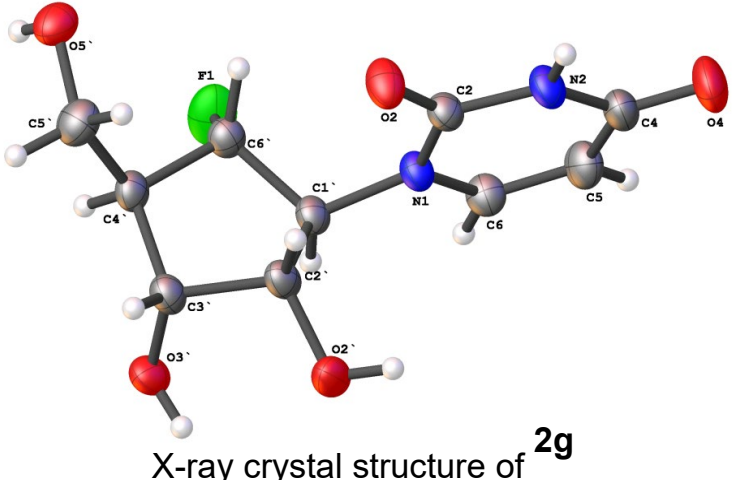

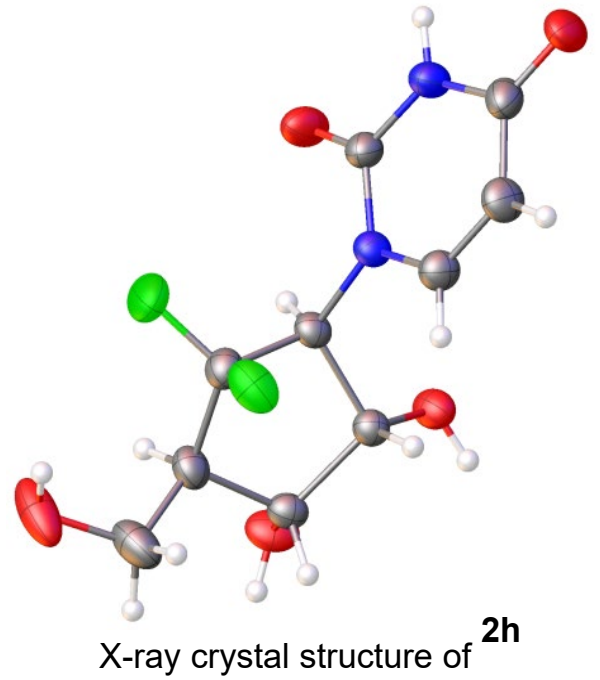

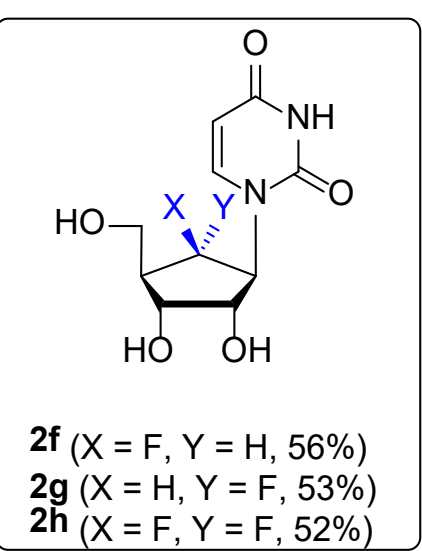

c

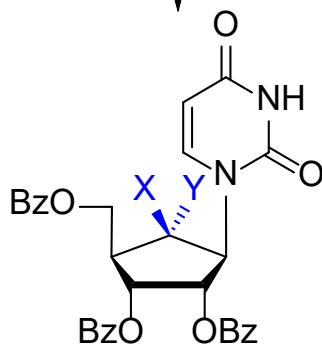
23a
23b $\left(\begin{array}{l}(X=F, Y=H, 75 \% \text { from } \\ (X)\end{array}\right.$

d

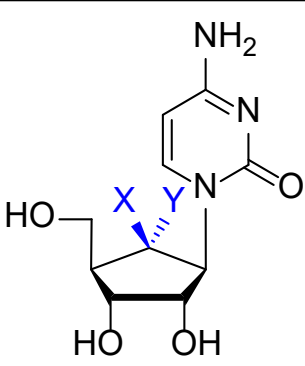

$2 \mathbf{i}(X=F, Y=H, 24 \%)$

$2 \mathrm{j}(X=F, Y=F, 33 \%)$

Reagents and conditions: a) (E)-3-methoxy-2-propenoyl isocyanate, benzene, $4 \AA-M S$, DMF, $-20^{\circ} \mathrm{C}$ to rt, $15 \mathrm{~h}$; b) $2 \mathrm{M} \mathrm{H}_{2} \mathrm{SO}_{4}$, dioxane, reflux, $1.5 \mathrm{~h}$; c) BzCl, pyridine, $\mathrm{CH}_{2} \mathrm{Cl}_{2}$, rt, $15 \mathrm{~h}$; d) i) 1,2,4-triazole, $\mathrm{POCl}_{3}, \mathrm{Et}_{3} \mathrm{~N}, \mathrm{CH}_{3} \mathrm{CN}$, rt, $15 \mathrm{~h}$. ii) $\mathrm{NH}_{4} \mathrm{OH}$, dioxane, rt, $15 \mathrm{~h}$. iii) $\mathrm{NH}_{3} / \mathrm{MeOH}, \mathrm{rt}, 15 \mathrm{~h}$

The amino derivatives 19a-c were also converted into the pyrimidine nucleoside derivatives 
$\mathbf{2 f}-\mathbf{j}$, as shown in Scheme 5. Treatment of 19a-c with (E)-3-methoxy-2-propenoyl isocyanate, which was prepared by reacting 3-methoxyacryloyl chloride with silver isocyanate, in benzene produced 22a-c, respectively, which were cyclized with $2 \mathrm{M} \mathrm{H}_{2} \mathrm{SO}_{4}$ to yield the uridine derivatives $\mathbf{2 f - h}$, respectively. ${ }^{25}$ The structures of $\mathbf{2 g}$ and $\mathbf{2 h}$ were confirmed by the X-ray crystallography(Scheme 5). ${ }^{26}$ To synthesize the cytidine derivatives $\mathbf{2 i}$ and $\mathbf{2 j}$, compounds $\mathbf{2 f}$ and $\mathbf{2 h}$ were benzoylated to give $\mathbf{2 3} \mathbf{a}$ and $\mathbf{2 3 b}$, respectively, which were converted to the cytidine derivatives $\mathbf{2} \mathbf{i}$ and $\mathbf{2} \mathbf{j}$ using a conventional three step procedures. ${ }^{27}$ 

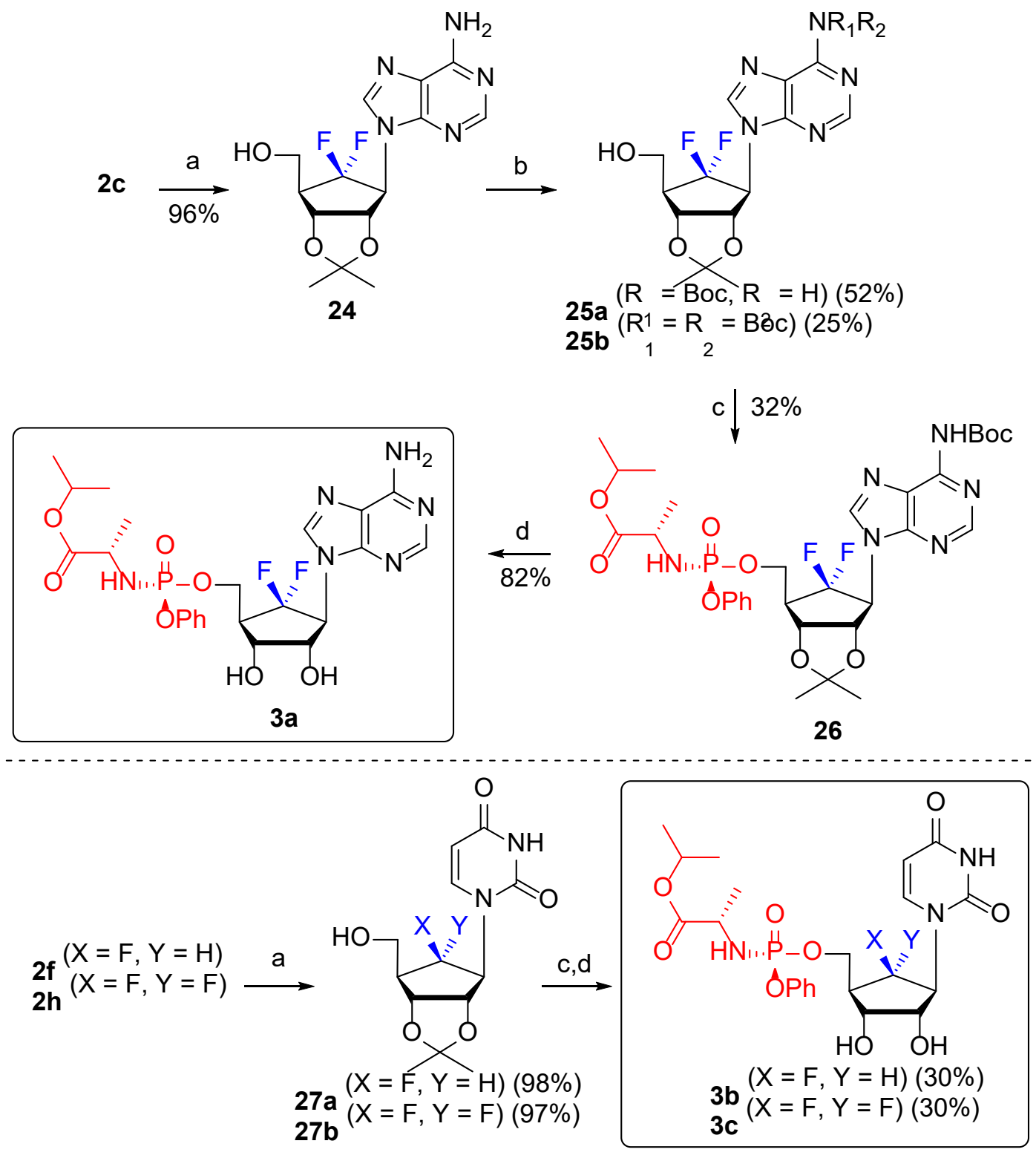

Reagents and Conditions: a) $\mathrm{cH}_{2} \mathrm{SO}_{4}$, acetone, rt, $4 \mathrm{~h}$; b) i. TMSOTf, DMAP, HMDS, $75^{\circ} \mathrm{C}, 2 \mathrm{~h}$; ii. $\mathrm{Boc}_{2} \mathrm{O}$, THF, rt, ${ }_{4}$ h $^{2}-\mathrm{Mij}^{\mathrm{MeOH}} \mathrm{Et}_{3} \mathrm{~N}(5: 1), 55^{\circ} \mathrm{C}, 16 \mathrm{~h}$; c) A' $\mathbf{A}^{-}$ BuMgCl, ${ }^{2}$, THF, $0{ }^{\circ} \mathrm{C}$ to rt, $36 \mathrm{~h}$; d) $50 \% \mathrm{HCOOH}$, $\mathrm{rt}, 8 \mathrm{~h}$.

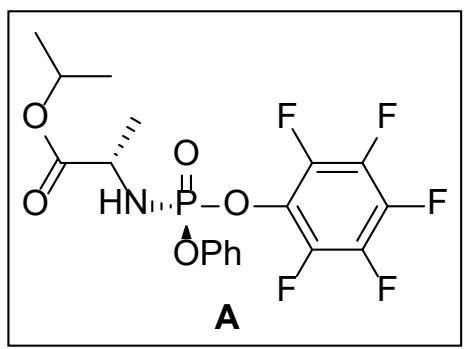

The uracil phosphoramidate analogue Sofosbuvir ${ }^{20}$ is used in the clinic as a powerful anti- 
hepatitis $\mathrm{C}$ virus (HCV) agent. Therefore, we have also synthesized the uracil phosphoramidate prodrugs $\mathbf{3 b}$-c and the adenine phosphoramidate prodrug 3a derived from the purine and pyrimidine nucleoside analogues 2a-j by using McGuigan's ProTide prodrug methodology, ${ }^{20}$ as shown in Scheme 6. 6', $6^{\prime}$-Difluoro-aristeromycin (2c) was treated with acetone under acidic conditions to give 2,3-acetonide $\mathbf{2 4}$. The treatment of $\mathbf{2 4}$ with di-tert-butyl dicarbonate $\left(\mathrm{Boc}_{2} \mathrm{O}\right)$ yielded a mixture of $\mathbf{2 5 a}$ and $\mathbf{2 5} \mathbf{b}$ in a 2:1 ratio, which was converted to the phosphoramidate prodrug 26 by treating with phosphoramiditing reagent (A) in the presence of $t$ butylmagnesium chloride. ${ }^{28}$ The treatment of $\mathbf{2 6}$ with $50 \%$ formic acid produced the final product, prodrug 3a. The monofluoro- and difluoropyrimidine derivatives $\mathbf{2 f}$ and $\mathbf{2 h}$ were similarly converted to the final prodrugs $\mathbf{3 b}$ and $\mathbf{3 c}$. 
Table 1. Inhibition of SAH hydrolase and the replication of several +RNA viruses by all final nucleoside analogues $\mathbf{2 a - j}$ and $\mathbf{3 a - c}$

\begin{tabular}{|c|c|c|c|c|c|c|c|c|c|c|c|c|c|}
\hline \multirow{2}{*}{$\begin{array}{c}\text { Compound } \\
\text { No. }\end{array}$} & \multirow{2}{*}{$\begin{array}{c}\text { SAH } \\
\text { hydrolase } \\
\text { IC }_{50} \\
(\mu \mathrm{M})\end{array}$} & \multicolumn{3}{|c|}{ MERS-CoV } & \multicolumn{3}{|c|}{ SARS-CoV } & \multicolumn{3}{|c|}{ ZIKV } & \multicolumn{3}{|c|}{ CHIKV } \\
\hline & & $\begin{array}{l}E_{50} \\
(\mu \mathrm{M})\end{array}$ & $\begin{array}{l}\mathbf{C C}_{50} \\
(\mu \mathrm{M})\end{array}$ & SI & $\begin{array}{l}\mathbf{E C}_{50} \\
(\mu \mathrm{M})\end{array}$ & $\begin{array}{l}\mathbf{C C}_{50} \\
(\mu \mathrm{M})\end{array}$ & SI & $\begin{array}{l}E_{50} \\
(\mu \mathrm{M})\end{array}$ & $\begin{array}{l}\mathbf{C C}_{50} \\
(\mu \mathrm{M})\end{array}$ & SI & $\begin{array}{l}\mathbf{E C}_{50} \\
(\mu \mathrm{M})\end{array}$ & $\begin{array}{l}\mathrm{CC}_{50} \\
(\mu \mathrm{M})\end{array}$ & SI \\
\hline 1 & 1.32 & $>50$ & 2 & & $>50$ & $>5$ & & 0.64 & 2.4 & 3.8 & 0.8 & 6.3 & 7.9 \\
\hline $2 a$ & 0.37 & 0.20 & 0.60 & 3 & ND & ND & & ND & ND & & $>100$ & $>100$ & \\
\hline $2 \mathrm{~b}$ & 9.70 & $\mathrm{ND}$ & ND & & $\mathrm{ND}$ & ND & & 2.54 & 3.97 & 1.56 & 0.53 & 1.32 & 2.49 \\
\hline $2 c$ & 1.06 & 0.2 & 3.2 & 16 & 0.5 & 5.9 & 11.8 & 0.26 & $>2.5$ & $>9.6$ & 0.13 & $>1.25$ & $>9.6$ \\
\hline 2d & 4.39 & $>50$ & $>50$ & & $>100$ & $>100$ & & $>100$ & $>100$ & & $>100$ & $>100$ & \\
\hline $2 e$ & 0.76 & $>50$ & 12.5 & & $>100$ & $>100$ & & $>100$ & $>100$ & & $>100$ & $>100$ & \\
\hline $2 f$ & $>100$ & $>100$ & $>100$ & & $>100$ & $>100$ & & $>100$ & $>100$ & & $>100$ & $>100$ & \\
\hline $2 \mathrm{~g}$ & $>100$ & $>100$ & $>100$ & & $>100$ & $>100$ & & $>100$ & $>100$ & & $>100$ & $>100$ & \\
\hline $2 \mathrm{~h}$ & $>100$ & $>50$ & $>50$ & & $>100$ & $>100$ & & $>100$ & $>100$ & & $>100$ & $>100$ & \\
\hline $2 \mathrm{i}$ & $>100$ & $>100$ & $>100$ & & $>100$ & $>100$ & & $>100$ & $>100$ & & $>100$ & $>100$ & \\
\hline $2 \mathrm{j}$ & $>100$ & $>50$ & $>50$ & & $>100$ & $>100$ & & $>100$ & $>100$ & & $>100$ & $>100$ & \\
\hline $3 \mathbf{a}$ & $>100$ & 9.3 & $>50$ & $\begin{array}{l}> \\
5 . \\
4\end{array}$ & 6.8 & $>25$ & $>3.7$ & 1.75 & $>25$ & $>14.3$ & 1.95 & $>12.5$ & $>6.4$ \\
\hline $\mathbf{3 b}$ & $>100$ & $>50$ & $>50$ & & $>100$ & $>100$ & & $>100$ & $>100$ & & $>100$ & $>100$ & \\
\hline $3 c$ & $>100$ & $>50$ & $>50$ & & $>100$ & $>100$ & & $>100$ & $>100$ & & $>100$ & $>100$ & \\
\hline
\end{tabular}

ND: Not Determined; Selectivity Index $(\mathrm{SI})=\mathrm{CC}_{50} / \mathrm{EC}_{50}$

$\mathrm{EC}_{50}$ : Effective concentration to inhibit the replication of the virus by $50 \%$

$\mathrm{CC}_{50}$ : Cytotoxic concentration to inhibit the replication of normal cells by $50 \%$

$\mathrm{EC}_{50}>100$ indicates that no antiviral activity was observed at the highest concentration tested, either because there was no protection or the compound was toxic. 
Inhibition of SAH hydrolase. All compounds $\mathbf{1}, \mathbf{2 a}-\mathbf{j}$ and $\mathbf{3 a}-\mathbf{c}$, were assayed for their ability to inhibit recombinant human SAH hydrolase protein, expressed in E. coli JM109, using a 5,5'-dithiobis-2-nitrobenzoate (DTNB) coupled assay as described by Lozada-Ramirez et al. ${ }^{29}$ As expected, all adenosine derivatives 2a-e potently inhibited SAH hydrolase, but none of the pyrimidine analogues $\mathbf{2} \mathbf{f}-\mathbf{j}$ showed any inhibitory activity at concentrations up to 100 $\mu \mathrm{M}$. None of the prodrugs 3a-c exhibited inhibitory activity at concentrations up to $100 \mu \mathrm{M}$. This result is not surprising because adenosine is the substrate for SAH hydrolase. Among the adenosine analogues, 6'- $\beta$-fluoroaristeromycin (2a) exhibited the most potent inhibitory activity $\left(\mathrm{IC}_{50}=0.37 \mu \mathrm{M}\right)$, which was 3.6-fold more potent than the control $\mathbf{1}\left(\mathrm{IC}_{50}=1.32 \mu \mathrm{M}\right)$. However, $6^{\prime}$ - $\alpha$-fluoroaristeromycin $\left(\mathbf{2 b}, \mathrm{IC}_{50}=9.70 \mu \mathrm{M}\right)$ was 26 -fold less potent than the corresponding $66^{\prime}-\beta$-fluoro analogue $\mathbf{2 a}$ and 7.4 -fold less active than the $6^{\prime}$-unsubstituted compound 1. This indicates that the stereochemistry at the $6^{\prime}$-position is important for inhibitory activity. Interestingly, the introduction of two fluorines at the 6 -position, resulted in $\mathbf{2 c}\left(\mathrm{IC}_{50}=1.06 \mu \mathrm{M}\right)$, which was slightly more potent than the control $\mathbf{1}$. The inhibitory activity of the $6^{\prime}$-fluoro-aristeromycin series can be ranked in the following order: $6^{\prime}-\beta-\mathrm{F}>6^{\prime}, 6^{\prime}-\mathrm{F}, \mathrm{F}>$ $6^{\prime}-\mathrm{H}>6^{\prime}-\alpha-\mathrm{F}$. The introduction of a methyl group at the $N^{6}$-amino group of $\mathbf{2 a}$, resulting in $\mathbf{2 d}$, decreased the inhibitory activity $\left(\mathrm{IC}_{50}=4.39 \mu \mathrm{M}\right)$ by 11.9 -fold, while the addition of a methyl group to the $N^{6}$-amino group of $\mathbf{2 c}$, resulting in $\mathbf{2 e}$, increased the inhibitory activity $\left(\mathrm{IC}_{50}=0.76\right.$ $\mu \mathrm{M})$ by 1.7 -fold. These results demonstrate that the $N^{6}$-mehyladenine and the adenine moieties do not lead to a decrease in inhibitory activity.

Antiviral activity. The novel 6 -fluoro-aristeromycin analogues $\mathbf{2 a - j}$ and $\mathbf{3 a - c}$ were screened for antiviral activity against a variety of + RNA viruses. The compounds were tested for antiviral activity in cytopathic effect (CPE) reduction assays at 4 concentrations, i.e. 150, 50, 
16.7, and 5.6 $\mu \mathrm{M}$ by preaparing 3-fold serial dilutions. Compounds that demonstrated antiviral activity in this primary screen were further tested more extensively in dose response experiments at up to 8 different concentrations to determine the $\mathrm{EC}_{50}$. Cytotoxicity $\left(\mathrm{CC}_{50}\right)$ was determined in parallel in uninfected cells (Table 1).

As shown in Table 1, only the adenosine derivatives 2a-c exhibited potent antiviral activities against + RNA viruses, while the other purine $N^{6}$-methyladenine derivatives $\mathbf{2 d}$ and 2e and pyrimidine derivatives $\mathbf{2} \mathbf{f}-\mathbf{j}$ did not show significant antiviral activities, not even at 100 $\mu \mathrm{M}$. This result suggests that the antiviral activity might be due to an (indirect) effect on viral MTase activity through the inhibition of host SAH hydrolase. Inhibition of the viral RdRp appears not to be important. The mechanism of action of these compounds has been studied in more detail and results will be published elsewhere (Kovacikova, K. et al. \& Ogando, N. S. et al., manuscripts in preparation).

Compound 2a inhibited MERS-CoV replication with an $\mathrm{EC}_{50}$ of $0.20 \mu \mathrm{M}$; however, it was also rather cytotoxic, resulting in a selectivity index (SI) of 3. Replacement of the remaining $6^{\prime}-\mathrm{H}$ in $\mathbf{2 a}$ with $\mathrm{F}$, resulted in compound $\mathbf{2 c}$, which exhibited a $>5$-fold reduction in cytotoxicity, while its antiviral activity remained unchanged, with an $\mathrm{EC}_{50}$ of $\sim 0.20 \mu \mathrm{M}$ and a SI of 15 for MERS-CoV. This compound was also active against SARS-CoV with a SI of 12.5, suggesting that it may be a broad-spectrum coronavirus inhibitor. In addition, it also inhibited ZIKV replication with an $\mathrm{EC}_{50}$ of $0.26 \mu \mathrm{M}(\mathrm{SI}>10)$, and was active against $\mathrm{CHIKV}$ with an $\mathrm{EC}_{50}$ of $0.13 \mu \mathrm{M}$. Compound $\mathbf{2 b}$ showed some inhibitory effects on CHIKV and ZIKV replication, but this was likely due to pleiotropic cytotoxic effects, as the SI was $<3$. Among the phosphoramidate prodrugs 3a-c, only the adenosine prodrug $\mathbf{3 a}$ exhibited significant broadspectrum antiviral activities, demonstrating that it may inhibit the RdRp of RNA viruses after 
conversion into the triphosphate form, although it remains to be determined in biochemical assays whether the triphosphate form affects RdRp activity. ${ }^{20}$ Compound 3a had an EC50 of 9.3 $\mu \mathrm{M}$ for MERS-CoV and $6.8 \mu \mathrm{M}$ for SARS-CoV, but it also had a $\mathrm{SI}<10$, and it was therefore not considered a potent inhibitor of coronavirus replication. However, for CHIKV and ZIKV, 3a had $\mathrm{EC}_{50}$ values of $1.95 \mu \mathrm{M}$ and $1.75 \mu \mathrm{M}$, respectively with good selectivity indices. Interestingly, the prodrug 3a was less potent, but also much less cytotoxic than the parent compound $\mathbf{2 c}$, which is unusual as regularly the phosphoamidate is more potent than the parent drug. ${ }^{20}$ The phosphoamidate 3 a might be slowly hydrolyzed to the $5^{\prime}$-monophosphate by metabolic enzymes, or to the parent drug $\mathbf{2 c}$ by a phosphatase, which could inhibit SAH hydrolase, explaining the observed antiviral effect. Viral load reduction assays were performed with compound $2 \mathrm{c}$ by infecting cells with CHIKV, ZIKV, SARS-CoV and MERS-CoV, followed by treatment with different concentrations of 2c. At 30 hpi (CHIKV) or 48 hpi (ZIKV, SARS- and MERS-CoV) infectious progeny titers in the medium were determined by plaque assay (Figure 2). Treatment with concentrations higher than $1 \mu \mathrm{M}$ of $2 \mathrm{c}$ reduced infectious CHIKV titers by more than $2 \log$. The effect on ZIKV infectious progeny titers was limited and showed a $\sim 1 \log$ reduction. For SARS-CoV the reduction in infectious progeny titer was $\sim 1.5$ $\log$ at $2 \mathrm{c}$ concentrations above $0.3 \mu \mathrm{M}$. The strongest antiviral effect was observed for MERS$\mathrm{CoV}$, with a $\sim 2.5 \log$ reduction in infectious progeny titers when infected cells were treated with $2 \mathrm{c}$ concentrations above $0.3 \mu \mathrm{M}$. Follow-up studies to gain more insight into the mode of action of $\mathbf{2 c}$ and $\mathbf{3 a}$ and related compounds are currently ongoing and results will be published elsewhere (Kovacikova, K. et al. \& Ogando, N. S. et al., manuscripts in preparation). 


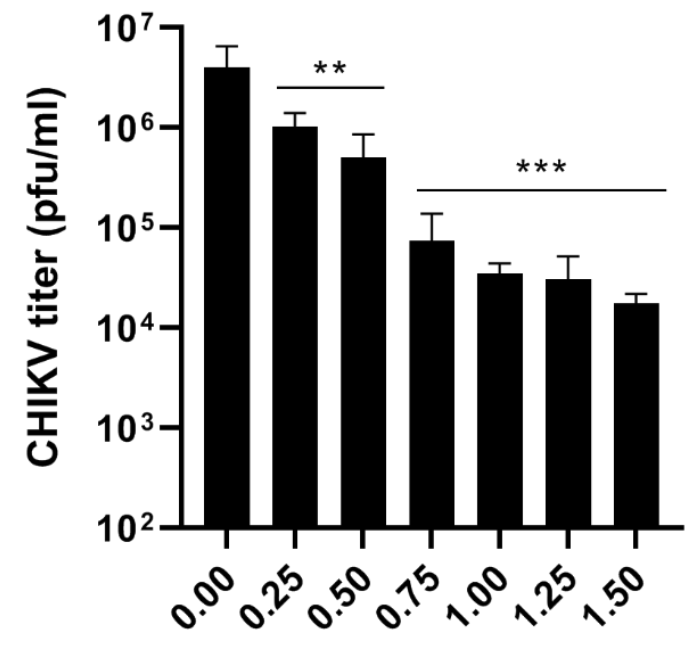

2c concentration $(\mu \mathrm{M})$

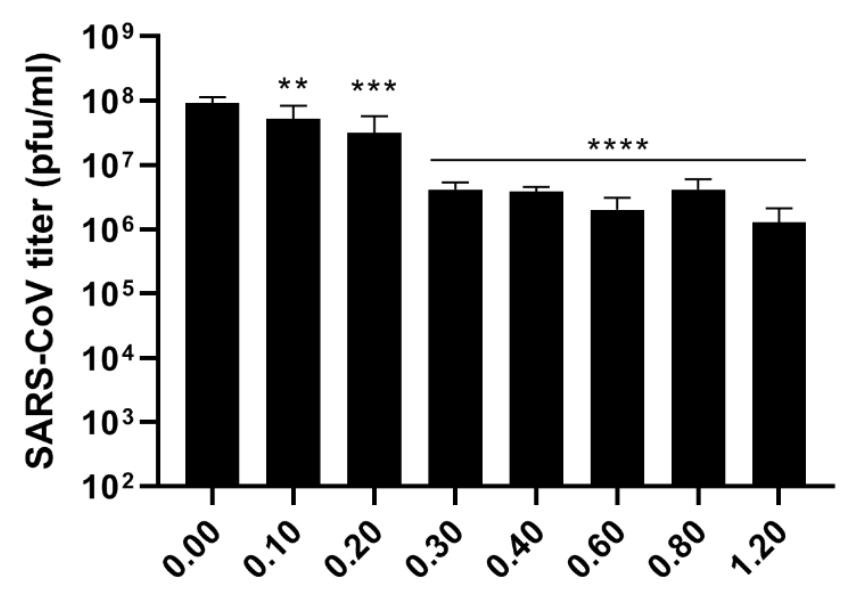

2c concentration $(\mu \mathrm{M})$

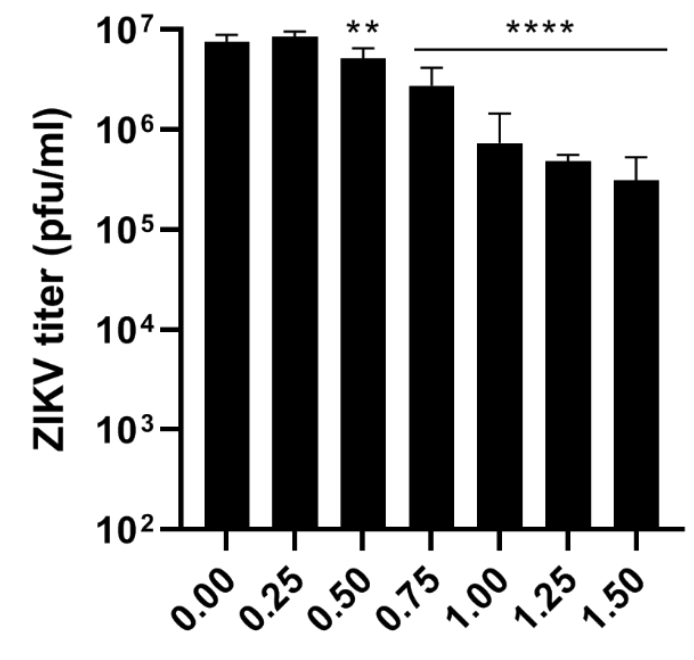

2c concentration $(\mu \mathrm{M})$

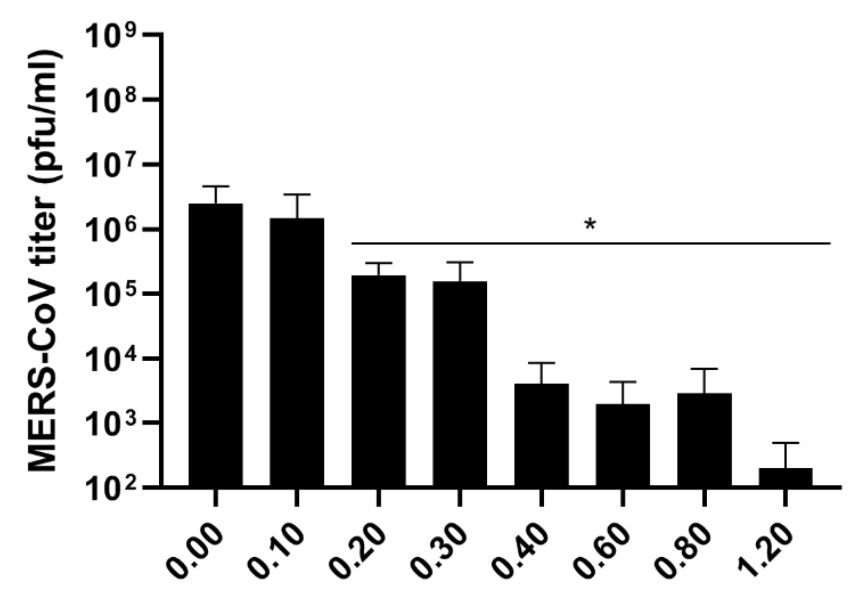

2c concentration $(\mu \mathrm{M})$ 
Figure 2: Effect of 2c on the infectious progeny of CHIKV, ZIKV, SARS-CoV and MERS-CoV. Cells were infected with the virus indicated on the $y$-axis of the graph in medium with various concentrations of 2 c. Infectious progeny titers were determined by plaque assay $(n=4)$ and viability of non-infected cells was monitored using the CellTiter 96®AQueous Non-Radioactive Cell Proliferation Assay (Promega). Significant differences are indicated by ${ }^{*}:{ }^{*}, p<0.05 ;{ }^{* *}, p<0.01 ;{ }^{* * *}, p<0.001 ;{ }^{* * * *}, p<0.0001$.

Finally, we measured the $\log P$ of the most active compound $2 \mathrm{c}$ by $\mathrm{pH}$-metric method, using a T3 Sirius instrument, because the lipophilicity is a major determinant for compound absorption, distribution in the body, penetration across biological barriers, metabolism and excretion. The measured $\log P$ was 0.02 , indicating that it is almost equally partitioned between the lipid and aqueous phases. The relatively low $\log P$ of $2 \mathbf{c}$ is expected to be overcome by converting it to the phosphoamidate $\mathbf{3 a}$.

\section{SAH Hydrolase Inhibitory Activity}

1. 6 '-fluorine $(X, Y)$ : $\beta$-fluorine $>$ difluorine $>\mathrm{H}, \mathrm{H}>\alpha_{\text {-fluorine }}$

2. Base $(\mathrm{B})$ : adenine $>N^{6}$-methyladenine $>>$ pyrimidine

3. $R: H>P$<smiles>Nc1ncnc2c1ncn2C1CC(O)C(O)C1O</smiles>

$$
\text { ( )-Aristeromycin (1) }
$$
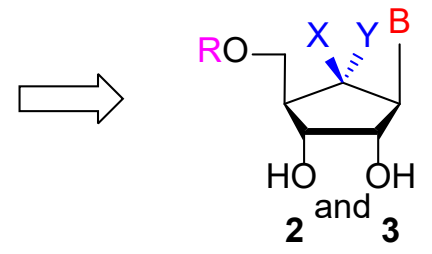

\section{Anti-RNA Virus Activity}

1. MERS-CoV $(X, Y / B / R): F, H / A / H=F, F / A / H>F, F / A / P>>(-$

1. MERS-CoV (X,Y/B/R): F,F/A/H > F,F/A/P >> (- )-aristeromycin

2. SARS $\left(\mathcal{C}, Y Y_{B / R): F, F / A / H>(-} \quad\right.$ )-aristeromycin

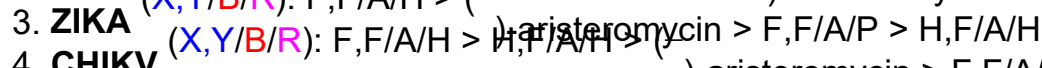

4. CHIKV (X,Y/B/R): F,F/A/H> H,F/A/F, )-aristeromycin > F,F/A/P

$P=$ phosphoramidate

Figure 2.

Summarized SAR of 6'-fluorinated aristeromycin analogues 2 and 3 . 


\section{- CONCLUSION}

We have synthesized the 6 -fluorinated aristeromycin analogues $\mathbf{2} \mathbf{a}-\mathbf{j}$, which were designed as dual-target antiviral compounds aimed at inhibiting both the viral RdRp and the host SAH hydrolase. The electrophilic fluorination of silyl enol ether with Selectfluor was the key step in the synthesis. We have also synthesized the phosphoramidate prodrugs 3a-c to determine whether these would inhibit virus replication through an effect on the viral RNA polymerase. Figure 3 depicts the summarized SAR of the synthesized $6^{\prime}$-fluorinated final nucleoside analogues, 2a-j and 3a-c concerning the inhibition of human SAH hydrolase and the inhibition of the replication of various +RNA viruses with capped genomes. It was discovered that the introduction of fluorine at the $6^{\prime}$-position increases the inhibitory activity on SAH hydrolase and the replication of selected + RNA viruses. Compared to the $6^{\prime}$-unsubstituted compound $\mathbf{1}$, the $6^{\prime}$-fluorinated aristeromycin analogues $\mathbf{2 a}$ and $\mathbf{2 c}$ more potently inhibited SAH hydrolase activity and the replication of MERS-CoV, SARS-CoV, ZIKV, and CHIKV. Among these compounds, $6^{\prime}-\beta$-fluoroaristeromycin (2a) was the most potent with an $\mathrm{IC}_{50}$ of $0.37 \mu \mathrm{M}$ for SAH hydrolase activity and an $\mathrm{EC}_{50}$ of $0.20 \mu \mathrm{M}$ for MERS-CoV replication. There was a correlation between the inhibition of SAH hydrolase and the antiviral activity of the compounds, suggesting the latter was mainly due to indirect targeting of viral methylation reactions. The SAR studies and lack of antiviral effect of several purine and pyrimidine analogues suggests 
that the antiviral effect of $\mathbf{1}, \mathbf{2 a}$, and $\mathbf{2 c}$ is unlikely due to targeting of the viral RdRp. Compound 2c appears to be an interesting compound for further development and evaluation as a broadspectrum antiviral agent, as it inhibited several coronaviruses, CHIKV, and ZIKV. More detailed biological studies on the efficacy of these compounds in virus-infected cells and into their mode of action are currently ongoing and will be published elsewhere.

\section{Experimental section}

Chemical Synthesis. General Methods. Proton $\left({ }^{1} \mathrm{H}\right)$ and carbon $\left({ }^{13} \mathrm{C}\right)$ NMR spectra were obtained on a Bruker AV 400 (400/100 MHz), Bruker AMX 500 (500/125 MHz), Jeol JNMECA600 (600/150 MHz), or Bruker AVANCE III 800 (800/200 MHz) spectrometer. Chemical shifts are reported as parts per million $(\delta)$ relative to the solvent peak. Coupling constants $(J)$ are reported in hertz $(\mathrm{Hz})$. Mass spectra were recorded on a Thermo LCQ XP instrument. Optical rotations were determined on Jasco III in appropriate solvent. UV spectra were recorded on U-3000 made by Hitachi in methanol or water. Infrared spectra were recorded on FT-IR (FTS-135) made by Bio-Rad. Melting points were determined on a Buchan B-540 instrument and are uncorrected. The crude compounds were purified by column chromatography on a silica gel (Kieselgel 60, 70-230 mesh, Merck). Elemental analyses (C, H, and $\mathrm{N}$ ) were used to determine the purity of all synthesized compounds, and the results were within $\pm 0.4 \%$ of the calculated values, confirming $\geq 95 \%$ purity.

\section{(((3aR,6R,6aR)-6-(tert-Butoxymethyl)-2,2-dimethyl-6,6a-dihydro-3aH-}

cyclopenta $[\boldsymbol{d}][1,3]$ dioxol-4-yl)oxy)triethylsilane (6). To a cooled $\left(-78{ }^{\circ} \mathrm{C}\right)$ solution of 5 (1568.0 mg, $6.470 \mathrm{mmol})$ in anhydrous THF $(32.0 \mathrm{~mL}, 0.2 \mathrm{M})$ was dropwise added chlorotriethylsilane $(5.4 \mathrm{~mL}, 32.355 \mathrm{mmol})$, followed by addition of LiHMDS (19.0 mL, 1.0 M solution in THF, $19.0 \mathrm{mmol}$ ) under $\mathrm{N}_{2}$. After being stirred at the same temperature for 10 
min, the reaction mixture was quenched with saturated aqueous $\mathrm{NH}_{4} \mathrm{Cl}(80 \mathrm{~mL})$. The layers were separated, and the aqueous layer was extracted with EtOAc $(150 \mathrm{~mL})$. The combined organic layers were washed successively with $\mathrm{H}_{2} \mathrm{O}$ and saturated brine, dried over anhydrous $\mathrm{MgSO}_{4}$, filtered, and evaporated. The residue was purified by column chromatography (silica gel, hexanes/EtOAc, $100 / 1$ to $30 / 1)$ to give $6(2267.0 \mathrm{mg}, 98 \%)$ as colorless oil: $[\alpha]_{\mathrm{D}}{ }^{20}=+36.48$ $\left(c 1.23, \mathrm{CHCl}_{3}\right) ;{ }^{1} \mathrm{H}$ NMR $\left(400 \mathrm{MHz}, \mathrm{CDCl}_{3}\right) \delta 4.73(\mathrm{dd}, J=1.1,6.0 \mathrm{~Hz}, 1 \mathrm{H}), 4.58(\mathrm{~d}, J=2.1$ $\mathrm{Hz}, 1 \mathrm{H}), 4.36(\mathrm{~d}, J=6.1 \mathrm{~Hz}, 1 \mathrm{H}), 3.27(\mathrm{dd}, J=5.6,8.6 \mathrm{~Hz}, 1 \mathrm{H}), 3.15(\mathrm{dd}, J=6.6,8.6 \mathrm{~Hz}, 1$ H), $2.72(\mathrm{dd}, J=5.9,5.9 \mathrm{~Hz}, 1 \mathrm{H}), 1.42(\mathrm{~s}, 3 \mathrm{H}), 1.32(\mathrm{~s}, 3 \mathrm{H}), 1.12(\mathrm{~s}, 9 \mathrm{H}), 0.96(\mathrm{t}, J=8.0$ $\mathrm{Hz}, 9 \mathrm{H}), 0.66-0.72(\mathrm{~m}, 6 \mathrm{H}) ;{ }^{13} \mathrm{C} \mathrm{NMR}\left(100 \mathrm{MHz}, \mathrm{CDCl}_{3}\right) \delta$ 154.1, 110.3, 104.4, 82.8, 79.7, 72.5, 63.9, 47.9, $27.4\left(3 \times \mathrm{CH}_{3}\right.$-tert-butyl $), 27.3,25.8,6.5(3 \times$ triethylsilyl $), 4.6(3 \times$ triethylsilyl); IR (neat) 2973, 1648, 1363, 1262, 1204, 1056, 851, 748 cm-1; HRMS (FAB) found 356.2388 [calcd for $\mathrm{C}_{19} \mathrm{H}_{36} \mathrm{O} 4 \mathrm{Si}+(\mathrm{M}+\mathrm{H})+356.2383$ ]

(3aR,5R,6R,6aR)-6-(tert-Butoxymethyl)-5-fluoro-2,2-dimethyldihydro-3aHcyclopenta $[d][1,3]$ dioxol-4(5H)-one (7a) and $(3 \mathrm{a} R, 5 S, 6 R, 6 \mathrm{a} R)-6-($ tert-butoxymethyl)-5fluoro-2,2-dimethyldihydro-3aH-cyclopenta[ $[d][1,3]$ dioxol-4(5H)-one (7b). To a cooled $(0$ $\left.{ }^{\circ} \mathrm{C}\right)$ solution of silyl enol ether $6(8.75 \mathrm{~g}, 24.548 \mathrm{mmol})$ in anhydrous DMF $(123.0 \mathrm{~mL}, 0.20$ M) was added 1-chloromethyl-4-fluoro-1,4-diazoniabicyclo[2.2.2]octane bis(tetrafluoroborate) (13.04 g, $36.824 \mathrm{mmol}$, Selectfluor) in one portion under $\mathrm{N}_{2}$. After being stirred at the same temperature for $12 \mathrm{~h}$, the reaction mixture was quenched with saturated aqueous $\mathrm{NH}_{4} \mathrm{Cl}(130 \mathrm{~mL})$, diluted with EtOAc $(130 \mathrm{~mL})$. The layers were separated and the aqueous layer was extracted with EtOAc $(2 \times 100 \mathrm{~mL})$. The combined organic layers were washed successively with $\mathrm{H}_{2} \mathrm{O}$ and saturated brine, dried over anhydrous $\mathrm{MgSO}_{4}$, filtered, and evaporated. The residue was purified by column chromatography (silica gel, hexanes/EtOAc, 
40/1 to $20 / 1)$ to give $7 \mathbf{a}$ and $7 \mathbf{b}\left(5.80 \mathrm{~g}, 91 \%\right.$, total yield, $7 \mathbf{a}: 7 \mathbf{b}=5.2: 1$ by ${ }^{1} \mathrm{H}$ NMR analysis $)$. Compound 7a: white solid; $[\alpha]_{\mathrm{D}}{ }^{25}=-156.69\left(c 0.735, \mathrm{CHCl}_{3}\right) ;{ }^{1} \mathrm{H} \mathrm{NMR}\left(400 \mathrm{MHz}, \mathrm{CDCl}_{3}\right)$ $\delta 5.29(\mathrm{dd}, J=8.2,49.5 \mathrm{~Hz}, 1 \mathrm{H}), 4.70(\mathrm{t}, J=5.7 \mathrm{~Hz}, 1 \mathrm{H}), 4.20(\mathrm{dd}, J=2.4,6.1 \mathrm{~Hz}, 1 \mathrm{H}), 3.61$ $(\mathrm{dd}, J=1.6,8.6 \mathrm{~Hz}, 1 \mathrm{H}) 3.38-3.41(\mathrm{~m}, 1 \mathrm{H}), 2.75(\mathrm{~d}, J=8.2 \mathrm{~Hz}, 1 \mathrm{H}), 1.41(\mathrm{~s}, 3 \mathrm{H}), 1.30(\mathrm{~s}$, $3 \mathrm{H}), 1.06(\mathrm{~s}, 9 \mathrm{H}) ;{ }^{13} \mathrm{C} \mathrm{NMR}\left(100 \mathrm{MHz}, \mathrm{CDCl}_{3}\right) \delta 203.0(\mathrm{~d}, J=12.9 \mathrm{~Hz}), 111.4,88.5(\mathrm{~d}, J=$ $201.5 \mathrm{~Hz}), 78.2(\mathrm{~d}, J=6.9 \mathrm{~Hz}), 75.0(\mathrm{~d}, J=3.1 \mathrm{~Hz}), 74.3,56.6(\mathrm{~d}, J=6.6 \mathrm{~Hz}), 40.5(\mathrm{~d}, J=$ 15.5 Hz), $26.8\left(3 \times \mathrm{CH}_{3}\right.$-tert-butyl), 26.2, 23.6; ${ }^{19} \mathrm{~F} \mathrm{NMR}\left(376 \mathrm{MHz}, \mathrm{CDCl}_{3}\right) \delta-220.60 \sim 221.14$ (m); LRMS (ESI+) found 283.13 [calcd for $\mathrm{C}_{13} \mathrm{H}_{21} \mathrm{FO}_{4} \mathrm{Na}^{+}(\mathrm{M}+\mathrm{Na})^{+} 283.1322$ ]; Anal. Calcd for $\mathrm{C}_{13} \mathrm{H}_{21} \mathrm{FO}_{4}$ : C, 59.98; H, 8.13. Found: C, 59.99; H, 8.53.

Compound 7b: white solid; $[\alpha]_{\mathrm{D}}{ }^{25}=-83.72\left(c 0.495, \mathrm{CHCl}_{3}\right) ;{ }^{1} \mathrm{H} \mathrm{NMR}\left(600 \mathrm{MHz}, \mathrm{CDCl}_{3}\right) \delta$ 5.21-5.36 (ddd, $J=1.3,4.5,50.8 \mathrm{~Hz}, 1 \mathrm{H}), 4.55(\mathrm{~d}, J=5.9 \mathrm{~Hz}, 1 \mathrm{H}), 4.50(\mathrm{~d}, J=5.9 \mathrm{~Hz}, 1 \mathrm{H})$, $3.63(\mathrm{~d}, J=2.2 \mathrm{~Hz}, 2 \mathrm{H}), 2.52-2.58(\mathrm{~m}, 1 \mathrm{H}), 1.41(\mathrm{~s}, 3 \mathrm{H}), 1.33(\mathrm{~s}, 3 \mathrm{H}), 1.13(\mathrm{~s}, 9 \mathrm{H}) ;{ }^{13} \mathrm{C}$ NMR $\left(150 \mathrm{MHz}, \mathrm{CDCl}_{3}\right) \delta 207.8(\mathrm{~d}, J=12.9 \mathrm{~Hz}), 112.2,91.9(\mathrm{~d}, J=192.4 \mathrm{~Hz}), 78.78(\mathrm{~d}, J=$ 3.5 Hz), 78.74, 73.6, 60.5 (d, $J=4.3 \mathrm{~Hz}), 45.0$ (d, $J=17.9 \mathrm{~Hz}), 27.2\left(3 \times \mathrm{CH}_{3}\right.$-tert-butyl), 26.8, 25.2; ${ }^{19} \mathrm{~F}$ NMR (376 MHz, $\left.\mathrm{CDCl}_{3}\right) \delta-196.0 \sim 196.2$ (m); HRMS (FAB) found 262.1679 [calcd for $\left.\mathrm{C}_{13} \mathrm{H}_{22} \mathrm{FO}_{4}{ }^{+}(\mathrm{M}+\mathrm{H})^{+} 261.1505\right]$; Anal. Calcd for $\mathrm{C}_{13} \mathrm{H}_{21} \mathrm{FO}_{4}$ : C, 59.98; H, 8.13. Found: $\mathrm{C}$, $59.77 ; \mathrm{H}, 8.45$.

(3aR,6R,6aR)-6-(tert-Butoxymethyl)-5,5-difluoro-2,2-dimethyldihydro-3a $H$ cyclopenta $[\boldsymbol{d}][\mathbf{1 , 3}]$ dioxol-4(5H)-one $(7 \mathbf{c})$. Yield $=70 \%$ (mixture of $7 \mathbf{c}$ and $7 \mathbf{d}$ ); white solid; $[\alpha]_{\mathrm{D}}{ }^{25}=-4.34(c 0.21, \mathrm{MeOH}) ;{ }^{1} \mathrm{H} \mathrm{NMR}\left(\mathbf{7 c}\right.$ and $\mathbf{7 d}$ mixture, $400 \mathrm{MHz}, \mathrm{CDCl}_{3} ; \mathbf{7 c}$ and $\mathbf{7 d}$ mixture) $\delta 4.82(\mathrm{~s}, 1 \mathrm{H}), 4.72(\mathrm{t}, J=6.1 \mathrm{~Hz}, 1 \mathrm{H}), 4.52-4.57(\mathrm{~m}, 1 \mathrm{H}), 4.35-4.41(\mathrm{~m}, 1 \mathrm{H}), 4.25$ (dd, $J=8.0,4.0 \mathrm{~Hz}, 1 \mathrm{H}), 3.74(\mathrm{~s}, 1 \mathrm{H}), 3.69$ (d, $J=8.0 \mathrm{~Hz}, 1 \mathrm{H}), 3.67-3.60$ (m, $1 \mathrm{H}), 3.54-$ 
$3.59(\mathrm{~m}, 1 \mathrm{H}), 3.46(\mathrm{~d}, J=8.3 \mathrm{~Hz}, 1 \mathrm{H}), 2.68(\mathrm{~d}, J=17.4 \mathrm{~Hz}, 1 \mathrm{H}), 2.53-2.62(\mathrm{~m}, 1 \mathrm{H}), 1.48(\mathrm{~s}$, $3 \mathrm{H}), 1.44$ (s, $3 \mathrm{H}), 1.34$ (s, $3 \mathrm{H}), 1.32$ (s, $3 \mathrm{H}), 1.21$ (s, $9 \mathrm{H}), 1.06$ (s, $9 \mathrm{H})$.

General procedure for the synthesis of 8a-c. To a cooled $\left(0^{\circ} \mathrm{C}\right)$ solution of $7 \mathbf{a}-\mathbf{c}$ ( 1 equiv) in $\mathrm{MeOH}(0.18 \mathrm{M})$ sodium borohydride or lithium borohydride was added in a single portion in a $\mathrm{N}_{2}$ atmosphere. After stirring for $30 \mathrm{~min}$ at the same temperature, the reaction mixture was neutralized with acetic acid $(2 \mathrm{~mL})$ and evaporated. The residue was diluted with saturated aqueous $\mathrm{NH}_{4} \mathrm{Cl}$, and the aqueous layer was extracted with EtOAc $(2 \times 100 \mathrm{~mL})$. The combined organic layers were dried over anhydrous $\mathrm{MgSO}_{4}$, filtered, and evaporated. The residue was purified by column chromatography (silica gel, hexanes/EtOAc, 20/1) to give 8a-c.

(3aS,4R,5R,6R,6aR)-6-(tert-Butoxymethyl)-5-fluoro-2,2-dimethyltetrahydro-3aHcyclopenta $[\boldsymbol{d}][1,3]$ dioxol-4-ol $(\mathbf{8 a})$. Yield $=71 \%$; colorless syrup; $[\alpha]_{\mathrm{D}}{ }^{25}=-47.46(c 0.395$, $\left.\mathrm{CHCl}_{3}\right) ;{ }^{1} \mathrm{H}$ NMR $\left(400 \mathrm{MHz}, \mathrm{CDCl}_{3}\right) \delta 4.91(\mathrm{td}, J=6.6,52.5 \mathrm{~Hz}, 1 \mathrm{H}), 4.51-4.52(\mathrm{~m}, 1 \mathrm{H})$, 4.47 (ddd, $J=1.6,6.3,7.8 \mathrm{~Hz}, 1 \mathrm{H}), 4.26-4.34(\mathrm{~m}, 1 \mathrm{H}), 3.52(\mathrm{dd}, J=3.3,8.8 \mathrm{~Hz}, 1 \mathrm{H}), 3.36-$ 3.39 (m, $1 \mathrm{H}), 2.67$ (d, J= 7.9 Hz, $1 \mathrm{H}), 2.46$ (bs, $1 \mathrm{H}), 1.45$ (s, $3 \mathrm{H}), 1.32$ (s, $3 \mathrm{H}), 1.14$ (s, 9 $\mathrm{H}) ;{ }^{13} \mathrm{C}$ NMR $\left(100 \mathrm{MHz}, \mathrm{CDCl}_{3}\right) \delta 111.1,99.5(\mathrm{~d}, J=185.9 \mathrm{~Hz}), 81.2(\mathrm{~d}, J=4.4 \mathrm{~Hz}), 76.3(\mathrm{~d}$, $J=9.0 \mathrm{~Hz}), 74.0(\mathrm{~d}, J=23.4 \mathrm{~Hz}), 73.0,56.8(\mathrm{~d}, J=8.2 \mathrm{~Hz}), 44.6(\mathrm{~d}, J=18.1 \mathrm{~Hz}),), 27.3(3 \times$ $\mathrm{CH}_{3}$-tert-butyl), 26.1, 24.1; ${ }^{19} \mathrm{~F}$ NMR (376 MHz, $\left.\mathrm{CDCl}_{3}\right)$-211.0 211.21 (m); HRMS (FAB) found 263.1662 [calcd for $\mathrm{C}_{13} \mathrm{H}_{24} \mathrm{FO}_{4}{ }^{+}(\mathrm{M}+\mathrm{H})+263.1659$ ]; Anal. Calcd for $\mathrm{C}_{13} \mathrm{H}_{23} \mathrm{FO}_{4}$ : $\mathrm{C}$, 59.52; H, 8.84. Found: C, 59.32; H, 9.15.

(3aS,4R,5S,6R,6aR)-6-(tert-Butoxymethyl)-5-fluoro-2,2-dimethyltetrahydro-3a $H$ cyclopenta $[d][1,3]$ dioxol-4-ol $(\mathbf{8 b})$. Yield $=67 \%$; colorless syrup ; $[\alpha]_{\mathrm{D}}{ }^{25}=-40.42(c 0.22$, $\mathrm{MeOH}) ;{ }^{1} \mathrm{H}$ NMR $\left(500 \mathrm{MHz}, \mathrm{CDCl}_{3}\right) \delta 4.68(\mathrm{dd}, J=4.1,52.4 \mathrm{~Hz}, 1 \mathrm{H}), 4.46-4.53(\mathrm{~m}, 2 \mathrm{H})$, 4.13-4.24 (m, $1 \mathrm{H}), 3.33-3.40(\mathrm{~m}, 1 \mathrm{H}), 2.81(\mathrm{~d}, J=11.4 \mathrm{~Hz}, 1 \mathrm{H}), 2.50(\mathrm{dt}, J=2.9,22.9 \mathrm{~Hz}, 1$ 
$\mathrm{H}), 1.46(\mathrm{~s}, 3 \mathrm{H}), 1.30(\mathrm{~s}, 3 \mathrm{H}), 1.08(\mathrm{~s}, 9 \mathrm{H}) ;{ }^{13} \mathrm{C} \mathrm{NMR}\left(125 \mathrm{MHz}, \mathrm{CDCl}_{3}\right) \delta 111.4,98.4(\mathrm{~d}, J$ $=181.5 \mathrm{~Hz},), 82.8,79.3,73.8(\mathrm{~d}, J=16.3 \mathrm{~Hz}), 73.0,60.6(\mathrm{~d}, J=12.1 \mathrm{~Hz}), 49.2(\mathrm{~d}, J=18.3 \mathrm{~Hz})$, $27.1\left(3 \times \mathrm{CH}_{3}\right.$-tert-butyl), 26.2, 24.2; $\mathrm{HRMS}\left(\mathrm{ESI}^{+}\right)$found 285.1480 [calcd for $\mathrm{C}_{13} \mathrm{H}_{23} \mathrm{FNaO}_{4}{ }^{+}$ $\left.(\mathrm{M}+\mathrm{Na})^{+} 285.1478\right]$; Anal. Calcd for $\mathrm{C}_{13} \mathrm{H}_{23} \mathrm{FO}_{4}$ : C, 55.70; H, 7.91. Found: C, 55.40; H, 7.75. (3aS,4R,6R,6aR)-6-(tert-Butoxymethyl)-5,5-difluoro-2,2-dimethyltetrahydro-3aHcyclopenta $[\boldsymbol{d}][\mathbf{1 , 3}]$ dioxol-4-ol $\mathbf{( 8 c )}$. Yield $=74 \%$; colorless syrup; $[\alpha]_{\mathrm{D}}^{25}=22.37($ c 0.28 , $\mathrm{MeOH}) ;{ }^{1} \mathrm{H}$ NMR $\left(500 \mathrm{MHz}, \mathrm{CDCl}_{3}\right) \delta 4.53(\mathrm{t}, J=5.7 \mathrm{~Hz}, 1 \mathrm{H}), 4.44(\mathrm{ddd}, J=2.6,6.4,8.9$ $\mathrm{Hz}, 1 \mathrm{H}), 4.20-4.29(\mathrm{~m}, 1 \mathrm{H}), 3.55(\mathrm{~d}, J=8.7 \mathrm{~Hz}, 1 \mathrm{H}), 3.39(\mathrm{~d}, J=8.8 \mathrm{~Hz}, 1 \mathrm{H}), 2.76(\mathrm{~d}, J=$ 11.5 Hz, $1 \mathrm{H}), 2.43$ (d, $J=17.2 \mathrm{~Hz}, 1 \mathrm{H}), 1.46(\mathrm{~s}, 3 \mathrm{H}), 1.31$ (s, $3 \mathrm{H}), 1.12(\mathrm{~s}, 9 \mathrm{H}) ;{ }^{13} \mathrm{C} \mathrm{NMR}$ $\left(125 \mathrm{MHz}^{\left.\mathrm{CDCl}_{3}\right)} \delta 126.9(\mathrm{dd}, J=252.3,260.3 \mathrm{~Hz}), 110.9,79.6(\mathrm{~d}, J=5.9 \mathrm{~Hz}), 75.5(\mathrm{~d}, J=\right.$ $11.3 \mathrm{~Hz}), 73.7(\mathrm{dd}, J=18.5,25.8 \mathrm{~Hz}), 73.4,57.6(\mathrm{dd}, J=4.6,8.5 \mathrm{~Hz}), 48.7(\mathrm{t}, J=20.8 \mathrm{~Hz})$,

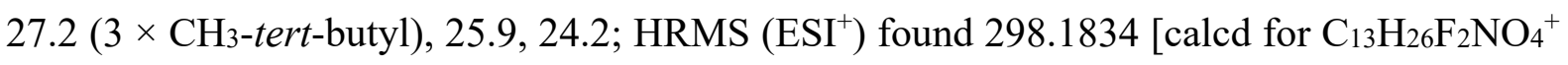
$\left(\mathrm{M}+\mathrm{NH}_{4}\right)^{+} 298.1830$ ]; Anal. Calcd for $\mathrm{C}_{13} \mathrm{H}_{22} \mathrm{~F}_{2} \mathrm{O}_{4}: \mathrm{C}$, 55.70; H, 7.91. Found: C, 55.45; H, 7.56.

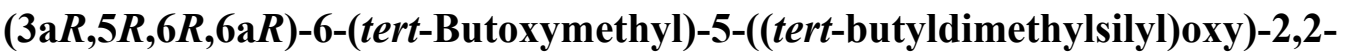

dimethyldihydro-3a $H$-cyclopenta $[\boldsymbol{d}][1,3]$ dioxol-4(5H)-one (9). To a cooled $\left(0^{\circ} \mathrm{C}\right)$ solution of 6 (1275 mg, $3.57 \mathrm{mmol})$ in anhydrous THF (12 mL, $0.3 \mathrm{M})$ was added 4-methylmorpholine $\mathrm{N}$-oxide monohydrate (967 mg, $7.15 \mathrm{mmol}, 2$ equiv) and osmium tetroxide (1000 mg, 3.93 mmol, 1.1 equiv) under $\mathrm{N}_{2}$ atmosphere. After stirring for $30 \mathrm{~min}$, the reaction mixture was added sodium thiosulfate pentahydrate $(300 \mathrm{mg})$, sodium sulfite $(300 \mathrm{mg})$ and acetone $(30 \mathrm{~mL})$ and stirred additional $1 \mathrm{~h}$ at the same temperature. The layers were separated, and the aqueous layer was extracted with EtOAc $(100 \mathrm{~mL})$. The combined organic layers were washed with $\mathrm{H}_{2} \mathrm{O}$ followed by saturated brine, dried over anhydrous $\mathrm{MgSO}_{4}$, filtered, and evaporated. The 
residue was used for the next step without further purification. To a solution of above generated intermediate in anhydrous DMF $(18 \mathrm{~mL}, 0.19 \mathrm{M})$ was added tert-butyldimethylsilyl chloride (1614 mg, $10.71 \mathrm{mmol})$ and imidazole $(729 \mathrm{mg}, 10.71 \mathrm{mmol})$ under $\mathrm{N}_{2}$ atmosphere. After stirring for $3 \mathrm{~h}$ at room temperature, the reaction mixture was quenched with saturated aqueous $\mathrm{NH}_{4} \mathrm{Cl}(50 \mathrm{~mL})$ and diluted with EtOAc $(50 \mathrm{~mL})$. The layers were separated, and the aqueous layer was extracted with EtOAc $(2 \times 50 \mathrm{~mL})$. The combined organic layers were washed successively with $\mathrm{H}_{2} \mathrm{O}$ and saturated brine, dried over anhydrous $\mathrm{MgSO}_{4}$, filtered, and evaporated. The residue was purified by column chromatography (silica gel, hexanes/EtOAc, $40 / 1$ to $20 / 1)$ to give $9(705 \mathrm{mg}, 53 \%)$ as a colorless syrup: $[\alpha]_{\mathrm{D}}^{25}=-103.19(c 0.30, \mathrm{MeOH})$; ${ }^{1} \mathrm{H}$ NMR $\left(400 \mathrm{MHz}, \mathrm{CDCl}_{3}\right) \delta 4.65(\mathrm{~d}, J=6.4 \mathrm{~Hz}, 1 \mathrm{H}), 4.53(\mathrm{~d}, J=8.0 \mathrm{~Hz}, 1 \mathrm{H}), 4.11(\mathrm{~d}, J=$ $6.3 \mathrm{~Hz}, 1 \mathrm{H}), 3.61(\mathrm{dd}, J=1.6,8.0 \mathrm{~Hz}, 1 \mathrm{H}), 3.30(\mathrm{dd}, J=2.4,8.1 \mathrm{~Hz}, 1 \mathrm{H}), 2.41-2.46(\mathrm{~m}, 1$ $\mathrm{H}), 1.42(\mathrm{~s}, 3 \mathrm{H}), 1.30(\mathrm{~s}, 3 \mathrm{H}), 1.03(\mathrm{~s}, 9 \mathrm{H}), 0.88(\mathrm{~s}, 9 \mathrm{H}), 0.13(\mathrm{~s}, 3 \mathrm{H}), 0.05(\mathrm{~s}, 3 \mathrm{H}) ;{ }^{13} \mathrm{C}$ NMR $\left(100 \mathrm{MHz}, \mathrm{CDCl}_{3}\right) \delta 207.2,110.9,78.1,75.8,73.7,71.3,56.9,42.3,27.0\left(3 \times \mathrm{CH}_{3}\right.$-tertbutyl), 26.4, $25.7\left(3 \times \mathrm{CH}_{3}\right.$-tert-butyl), 23.8, 18.3, -4.4, -5.6; HRMS $\left(\mathrm{FAB}^{+}\right)(\mathrm{m} / \mathrm{z})$ found 373.2398, [calcd for $\mathrm{C}_{19} \mathrm{H}_{37} \mathrm{O}_{5} \mathrm{Si}^{+}(\mathrm{M}+\mathrm{H})^{+}$373.2410]; Anal. Calcd for $\mathrm{C}_{19} \mathrm{H}_{36} \mathrm{O}$ S Si: C, 61.25; $\mathrm{H}$, 9.74. Found: C, 61.26; H, 9.75.

(3aS,4R,5R,6R,6aR)-6-(tert-Butoxymethyl)-5-((tert-butyldimethylsilyl)oxy)-2,2dimethyltetrahydro-3aH-cyclopenta $[\boldsymbol{d}][\mathbf{1 , 3}]$ dioxol-4-ol $(\mathbf{1 0})$. To a cooled $\left(0^{\circ} \mathrm{C}\right)$ solution of 9 (471 $\mathrm{mg}, 1.26 \mathrm{mmol})$ in methanol $(6.3 \mathrm{~mL}, 0.2 \mathrm{M})$ was added sodium borohydride $(144 \mathrm{mg}$, 3.79 mmol, 3 equiv) under $\mathrm{N}_{2}$ atmosphere. After being stirred at the same temperature for $1 \mathrm{~h}$, the reaction mixture was diluted with $\mathrm{H}_{2} \mathrm{O}(20 \mathrm{~mL})$ and EtOAc $(20 \mathrm{~mL})$. The layers were separated, and the aqueous layer was extracted with EtOAc $(3 \times 50 \mathrm{~mL})$. The combined organic layers were washed successively with $\mathrm{H}_{2} \mathrm{O}$ and saturated brine, dried over anhydrous $\mathrm{MgSO}_{4}$, filtered, and evaporated. The residue was purified by column chromatography (silica gel, 
hexanes/EtOAc, $30 / 1$ to $20 / 1)$ to give $\mathbf{1 0}(415 \mathrm{mg}, 88 \%)$ as a colorless syrup: $[\alpha]_{\mathrm{D}}{ }^{25}=-40.39$ (c $0.32, \mathrm{MeOH}) ;{ }^{1} \mathrm{H}$ NMR $\left(500 \mathrm{MHz}, \mathrm{CDCl}_{3}\right) \delta 4.49(\mathrm{~d}, J=6.1 \mathrm{~Hz}, 1 \mathrm{H}), 4.41(\mathrm{t}, J=6.2 \mathrm{~Hz}$, $1 \mathrm{H}), 4.07(\mathrm{t}, J=6.9 \mathrm{~Hz}, 1 \mathrm{H}), 3.95(\mathrm{dd}, J=6.8,14.7 \mathrm{~Hz}, 1 \mathrm{H}), 3.48(\mathrm{dd}, J=3.9,8.5 \mathrm{~Hz}, 1 \mathrm{H})$, $3.32(\mathrm{dd}, J=4.6,8.5 \mathrm{~Hz}, 1 \mathrm{H}), 2.43(\mathrm{~d}, J=8.4 \mathrm{~Hz}, 1 \mathrm{H}), 2.12-2.18(\mathrm{~m}, 1 \mathrm{H}), 1.45(\mathrm{~s}, 3 \mathrm{H}), 1.32$ (s, $3 \mathrm{H}), 1.12$ (s, $9 \mathrm{H}), 0.87$ (s, $9 \mathrm{H}), 0.09$ (s. $3 \mathrm{H}), 0.05$ (s, $3 \mathrm{H}) ;{ }^{13} \mathrm{C} \mathrm{NMR}\left(125 \mathrm{MHz}, \mathrm{CDCl}_{3}\right)$ $\delta 110.4,81.0,78.8,77.0,76.1,72.6,57.3,46.0,27.4\left(3 \times \mathrm{CH}_{3}\right.$-tert-butyl $), 26.2,25.8\left(3 \times \mathrm{CH}_{3}-\right.$ tert-butyl), 24.0, 18.1, -4.5, -5.1; HRMS $\left(\mathrm{FAB}^{+}\right)(\mathrm{m} / \mathrm{z})$ found 375.2584 , [calcd for $\mathrm{C}_{19} \mathrm{H}_{39} \mathrm{O}_{5} \mathrm{Si}^{+}$ $(\mathrm{M}+\mathrm{H})^{+}$375.2567]; Anal. Calcd for $\mathrm{C}_{19} \mathrm{H}_{38} \mathrm{O}$ S Si: C, 60.92; H, 10.23. Found: C, 60.91; H, 10.25. (((3aR,4R,5R,6R,6aR)-4-(Benzyloxy)-6-(tert-butoxymethyl)-2,2-dimethyltetrahydro-3aHcyclopenta $[d][1,3]$ dioxol-5-yl)oxy)(tert-butyl)dimethylsilane (11). To a cooled $\left(0{ }^{\circ} \mathrm{C}\right)$ solution of 10 (193 mg, $0.515 \mathrm{mmol})$ in DMF (5.2 mL, 0.1 M) was added benzyl chloride $(0.12$ $\mathrm{mL}, 1.030 \mathrm{mmol}, 2.0$ equiv) and sodium hydride (41 mg, $1.030 \mathrm{mmol}, 2.0$ equiv) under $\mathrm{N}_{2}$ atmosphere. After being stirred at room temperature for $12 \mathrm{~h}$, the reaction mixture was diluted with $\mathrm{H}_{2} \mathrm{O}(20 \mathrm{~mL})$ and EtOAc $(20 \mathrm{~mL})$. The layers were separated, and the aqueous layer was extracted with EtOAc $(3 \times 50 \mathrm{~mL})$. The combined organic layers were washed successively with $\mathrm{H}_{2} \mathrm{O}$ and saturated brine, dried over anhydrous $\mathrm{MgSO}_{4}$, filtered, and evaporated. The residue was purified by column chromatography (silica gel, hexanes/EtOAc, 50/1) to give 11 $(204 \mathrm{mg}, 85 \%)$ as a colorless syrup: $[\alpha]_{\mathrm{D}}{ }^{25}=-46.64(c$ 0.66, MeOH$) ;{ }^{1} \mathrm{H}$ NMR $(400 \mathrm{MHz}$, $\left.\mathrm{CDCl}_{3}\right) \delta 7.22-7.39(\mathrm{~m}, 5 \mathrm{H}), 4.76(\mathrm{~d}, J=12.4 \mathrm{~Hz}, 1 \mathrm{H}), 4.59(\mathrm{~d}, J=12.4 \mathrm{~Hz}, 1 \mathrm{H}), 4.45(\mathrm{~d}, J$ $=6.0 \mathrm{~Hz}, 1 \mathrm{H}), 4.33-4.37(\mathrm{~m}, 2 \mathrm{H}), 3.83(\mathrm{dd}, J=5.6,8.8 \mathrm{~Hz}, 1 \mathrm{H}), 3.39(\mathrm{dd}, J=4.4,8.8 \mathrm{~Hz}, 1$ H), $3.32(\mathrm{dd}, J=4.0,8.4 \mathrm{~Hz}, 1 \mathrm{H}), 2.05-2.11(\mathrm{~m}, 1 \mathrm{H}), 1.48(\mathrm{~s}, 3 \mathrm{H}), 1.29$ (s, $3 \mathrm{H}), 1.03$ (s, 9 H), 0.88 (s, $9 \mathrm{H}), 0.09$ (s, $3 \mathrm{H}), 0.05$ (s, $3 \mathrm{H}) ;{ }^{13} \mathrm{C} \mathrm{NMR}\left(200 \mathrm{MHz}, \mathrm{CDCl}_{3}\right) \delta$ 138.9, 128.4, $128.1,127.9,127.7,127.2,110.0,82.1,80.2,76.0,75.6,72.4,71.7,57.5,45.7,27.3\left(3 \times \mathrm{CH}_{3}-\right.$ 
tert-butyl), 26.4, $25.8\left(3 \times \mathrm{CH}_{3}\right.$-tert-butyl $), 24.2,-4.7,-4.9 ; \mathrm{HRMS}\left(\mathrm{FAB}^{+}\right)(\mathrm{m} / \mathrm{z})$ found 465.3001, [calcd for $\mathrm{C}_{26} \mathrm{H}_{45} \mathrm{O}_{5} \mathrm{Si}^{+}(\mathrm{M}+\mathrm{H})^{+}$465.3029]; Anal. Calcd for $\mathrm{C}_{26} \mathrm{H}_{44} \mathrm{O} 5 \mathrm{Si}: \mathrm{C}, 67.20 ; \mathrm{H}$, 9.54. Found: C, 67.22; H, 9.55.

(3a $R, 4 S, 5 R, 6 S, 6 a R)-4-(B e n z y l o x y)-6-(t e r t-b u t o x y m e t h y l)-2,2-d i m e t h y l t e t r a h y d r o-3 a H-$ cyclopenta[d][1,3]dioxol-5-ol (12). To a cooled $\left(0^{\circ} \mathrm{C}\right)$ solution of $11(179 \mathrm{mg}, 0.385 \mathrm{mmol})$ in anhydrous THF $(3.8 \mathrm{~mL}, 0.1 \mathrm{M})$ was added tetra- $n$-butylammonium fluoride solution $(1.2$ $\mathrm{mL}, 1.0 \mathrm{M}$ solution in THF, $1.2 \mathrm{mmol}, 3.0$ equiv) under $\mathrm{N}_{2}$ atmosphere. After being stirred at room temperature for $12 \mathrm{~h}$, the reaction mixture was diluted with $\mathrm{H}_{2} \mathrm{O}(30 \mathrm{~mL})$ and EtOAc (30 $\mathrm{mL})$. The layers were separated, and the aqueous layer was extracted with EtOAc $(3 \times 50 \mathrm{~mL})$. The combined organic layers were washed successively with $\mathrm{H}_{2} \mathrm{O}$ and saturated brine, dried over anhydrous $\mathrm{MgSO}_{4}$, filtered, and evaporated. The residue was purified by column chromatography (silica gel, hexanes/EtOAc, 8/1) to give 12 (129 mg, 88\%) as a colorless syrup: $[\alpha] \mathrm{D}^{25}=-49.04(c 0.28, \mathrm{MeOH}) ;{ }^{1} \mathrm{H} \mathrm{NMR}\left(400 \mathrm{MHz}, \mathrm{CDCl}_{3}\right) \delta 7.39(\mathrm{~d}, J=7.2 \mathrm{~Hz}, 2 \mathrm{H}), 7.29-$ $7.35(\mathrm{~m}, 2 \mathrm{H}), 7.23-7.28(\mathrm{~m}, 1 \mathrm{H}), 4.85(\mathrm{~d}, J=12.4 \mathrm{~Hz}, 1 \mathrm{H}), 4.62(\mathrm{~d}, J=12.4 \mathrm{~Hz}, 1 \mathrm{H}), 4.51$ $(\mathrm{t}, J=6.0 \mathrm{~Hz}, 1 \mathrm{H}), 4.40-4.45(\mathrm{~m}, 2 \mathrm{H}), 3.81(\mathrm{dd}, J=4.8,7.2 \mathrm{~Hz}, 1 \mathrm{H}), 3.58(\mathrm{dd}, J=3.6,8.8$ Hz, $1 \mathrm{H}), 3.44$ (dd, $J=4.4,8.8 \mathrm{~Hz}, 1 \mathrm{H}), 2.70$ (bs, $1 \mathrm{H}), 2.26-2.32$ (m, $1 \mathrm{H}), 1.48(\mathrm{~s}, 3 \mathrm{H}), 1.31$ (s, $3 \mathrm{H}), 1.08(\mathrm{~s}, 9 \mathrm{H}) ;{ }^{13} \mathrm{C} \mathrm{NMR}\left(200 \mathrm{MHz}, \mathrm{CDCl}_{3}\right) \delta 138.5,128.3(2 \times \mathrm{CH}$-benzene $), 128.0$ ( $2 \times$ CH-benzene $), 127.5,111.1,82.7,80.6,77.2,76.7,73.4,71.9,59.3,45.4,27.2\left(3 \times \mathrm{CH}_{3}-\right.$ tert-butyl), 26.5, 24.6; Anal. Calcd for $\mathrm{C}_{20} \mathrm{H}_{30} \mathrm{O}_{5}$ : C, 68.54; H, 8.63. Found: C, 68.52; H, 8.64. $(3 \mathrm{a} R, 4 R, 5 S, 6 R, 6 \mathrm{a} R)-4-($ benzyloxy)-6-(tert-butoxymethyl)-5-fluoro-2,2-

dimethyltetrahydro-3aH-cyclopenta $[d][1,3]$ dioxole (13a). To a cooled $\left(0^{\circ} \mathrm{C}\right)$ solution of 12 (20 $\mathrm{mg}, 0.052 \mathrm{mmol})$ in anhydrous toluene $(2.0 \mathrm{~mL}, 0.026 \mathrm{M})$ was dropwise added diethylaminosulfur trifluoride $\left(30 \mu \mathrm{L}, 0.210 \mathrm{mmol}, 4.0\right.$ equiv) under $\mathrm{N}_{2}$ atmosphere. After 
being stirred at room temperature for $2 \mathrm{~h}$, the reaction mixture was quenched with saturated aqueous $\mathrm{NH}_{4} \mathrm{Cl}(30 \mathrm{~mL})$ and EtOAc $(30 \mathrm{~mL})$. The layers were separated, and the aqueous layer was extracted with EtOAc $(3 \times 50 \mathrm{~mL})$. The combined organic layers were washed successively with $\mathrm{H}_{2} \mathrm{O}$ and saturated brine, dried over anhydrous $\mathrm{MgSO}_{4}$, filtered, and evaporated. The residue was purified by column chromatography (silica gel, hexanes/EtOAc, 30/1) to give 13a (5.6 $\mathrm{mg}, 30 \%)$ and $\mathbf{1 3 b}(5.6 \mathrm{mg}, 30 \%)$ as a colorless syrup.

Compound 13a. $[\alpha]_{\mathrm{D}}{ }^{25}=-26.59(c 0.22, \mathrm{MeOH}) ;{ }^{1} \mathrm{H}$ NMR $\left(500 \mathrm{MHz}, \mathrm{CDCl}_{3}\right) \delta$ 7.25-7.34 $(\mathrm{m}, 5 \mathrm{H}), 4.96(\mathrm{ddd}, J=2.6,6.8,52.7 \mathrm{~Hz}, 1 \mathrm{H}), 4.72(\mathrm{dd}, J=0.8,11.6 \mathrm{~Hz}, 1 \mathrm{H}), 4.54(\mathrm{~d}, J=$ 11.6 Hz, $1 \mathrm{H}), 4.44-4.52(\mathrm{~m}, 2 \mathrm{H}), 4.02-4.09$ (m, $1 \mathrm{H}), 3.41-3.47$ (m, $2 \mathrm{H}), 2.15-2.18(\mathrm{~m}, 1 \mathrm{H})$, 1.47 (s, $3 \mathrm{H}), 1.28(\mathrm{~s}, 3 \mathrm{H}), 1.12(\mathrm{~s}, 9 \mathrm{H}) ;{ }^{13} \mathrm{C} \mathrm{NMR}\left(200 \mathrm{MHz}, \mathrm{CDCl}_{3}\right) \delta 137.8,128.3(2 \times \mathrm{CH}-$ benzyl), $128.1(2 \times \mathrm{CH}$-benzyl), 127.8, 111.8, $96.0(\mathrm{~d}, J=187.1 \mathrm{~Hz}), 81.6,79.3,78.2(\mathrm{~d}, J=$ 15.7 Hz), 72.6, 71.8, $60.6(\mathrm{~d}, J=11.0 \mathrm{~Hz}), 50.2(\mathrm{~d}, J=18.7 \mathrm{~Hz}), 27.0\left(3 \times \mathrm{CH}_{3}\right.$-tert-butyl), 26.6, 24.4; HRMS $\left(\mathrm{FAB}^{+}\right)(\mathrm{m} / \mathrm{z})$ found 353.2121, [calcd for $\mathrm{C}_{20} \mathrm{H}_{30} \mathrm{FO}_{4}{ }^{+}(\mathrm{M}+\mathrm{H})^{+}$353.2128]; Anal. Calcd for $\mathrm{C}_{20} \mathrm{H}_{29} \mathrm{FO}_{4}$ : C, 68.16; H, 8.29. Found: C, 68.13; H, 8.27.

Compound 13b. $[\alpha]_{\mathrm{D}}{ }^{25}=-61.72(c 0.42, \mathrm{MeOH}) ;{ }^{1} \mathrm{H} \mathrm{NMR}\left(500 \mathrm{MHz}, \mathrm{CDCl}_{3}\right) \delta 7.38(\mathrm{t}, J=$ $7.3 \mathrm{~Hz}, 2 \mathrm{H}), 7.31$ (t, $J=7.2 \mathrm{~Hz}, 2 \mathrm{H}), 7.25(\mathrm{~d}, J=7.2 \mathrm{~Hz}, 1 \mathrm{H}), 5.18$ (dt, $J=7.8,53.7 \mathrm{~Hz}, 1$ H), $4.76(\mathrm{~d}, J=12.2 \mathrm{~Hz}, 1 \mathrm{H}), 4.66(\mathrm{~d}, J=12.2 \mathrm{~Hz}, 1 \mathrm{H}), 4.45-4.49(\mathrm{~m}, 1 \mathrm{H}), 4.41-4.44(\mathrm{~m}, 1$ H), $4.19(\mathrm{ddd}, J=5.9,7.7,16.5 \mathrm{~Hz}, 1 \mathrm{H}), 3.45(\mathrm{dd}, J=3.0,8.8 \mathrm{~Hz}, 1 \mathrm{H}), 3.31-3.34(\mathrm{~m}, 1 \mathrm{H})$, 2.37-2.43 (m, $1 \mathrm{H}), 1.47$ (s, $3 \mathrm{H}), 1.28(\mathrm{~s}, 3 \mathrm{H}), 1.01(\mathrm{~s}, 9 \mathrm{H}) ;{ }^{13} \mathrm{C} \mathrm{NMR}\left(125 \mathrm{MHz}, \mathrm{CDCl}_{3}\right)$ $\delta$ 138.0, 128.3, $127.9(2 \times$ CH-benzyl $), 127.7(2 \times$ CH-benzyl $), 112.2,103.5,102.1,81.5(\mathrm{~d}, \mathrm{~J}$ $=27.5 \mathrm{~Hz}), 81.1(\mathrm{~d}, J=20.0 \mathrm{~Hz}), 72.6,72.4,57.6,48.8(\mathrm{~d}, J=6.2 \mathrm{~Hz}), 27.4\left(3 \times \mathrm{CH}_{3}\right.$-tertbutyl), 27.1, 25.0; HRMS $\left(\mathrm{FAB}^{+}\right)(\mathrm{m} / \mathrm{z})$ found 353.2131, [calcd for $\mathrm{C}_{20} \mathrm{H}_{30} \mathrm{FO}_{4}{ }^{+}(\mathrm{M}+\mathrm{H})^{+}$ 353.2128]; Anal. Calcd for $\mathrm{C}_{20} \mathrm{H}_{29} \mathrm{FO}_{4}$ : C, 68.16; H, 8.29. Found: C, 68.13; H, 8.27. 
$(3 \mathrm{a} R, 4 R, 5 S, 6 R, 6 \mathrm{aS})-4-($ tert-Butoxy)-5-(tert-butoxymethyl)-6-hydroxytetrahydro-3aHcyclopenta $[\boldsymbol{d}][1,3,2]$ dioxathiole 2 -oxide (14). Regioselective cleavage. To a cooled $\left(-78^{\circ} \mathrm{C}\right)$ solution of $10(420 \mathrm{mg}, 1.121 \mathrm{mmol})$ in anhydrous $\mathrm{CH}_{2} \mathrm{Cl}_{2}(5.6 \mathrm{~mL}, 0.2 \mathrm{M})$ was dropwise added trimethylaluminum (3.4 mL, 2.0 M solution in haxane, $6.727 \mathrm{mmol}, 6.0$ equiv) under $\mathrm{N}_{2}$ atmosphere. After being stirred at room temperature for $12 \mathrm{~h}$, the reaction mixture was quenched with saturated aqueous $\mathrm{NH}_{4} \mathrm{Cl}(30 \mathrm{~mL})$ and EtOAc $(30 \mathrm{~mL})$. The layers were separated, and the aqueous layer was extracted with EtOAc $(3 \times 50 \mathrm{~mL})$. The combined organic layers were washed successively with $\mathrm{H}_{2} \mathrm{O}$ and saturated brine, dried over anhydrous $\mathrm{MgSO}_{4}$, filtered, and evaporated. The residue was purified by column chromatography (silica gel, hexanes/EtOAc, 10/1) to give diol intermediate (245 $\mathrm{mg}, 56 \%)$ 10a as a colorless syrup. Introduction of cyclic sulfite. To a cooled $\left(0^{\circ} \mathrm{C}\right)$ solution of diol intermediate 10a $(250 \mathrm{mg}$, $0.639 \mathrm{mmol})$ in anhydrous $\mathrm{CH}_{2} \mathrm{Cl}_{2}(6.4 \mathrm{~mL}, 0.1 \mathrm{M})$ was dropwise added triethylamine $(0.3 \mathrm{~mL}$, 2.239 mmol, 3.5 equiv) followed by thionyl chloride $(70 \mu \mathrm{L}, 0.959 \mathrm{mmol})$ under $\mathrm{N}_{2}$ atmosphere. After being stirred at room temperature for $30 \mathrm{~min}$, the reaction mixture was quenched with saturated aqueous $\mathrm{NH}_{4} \mathrm{Cl}(30 \mathrm{~mL})$ and diluted with EtOAc $(30 \mathrm{~mL})$. The layers were separated, and the aqueous layer was extracted with EtOAc $(3 \times 50 \mathrm{~mL})$. The combined organic layers were washed successively with $\mathrm{H}_{2} \mathrm{O}$ and saturated brine, dried over anhydrous $\mathrm{MgSO}_{4}$, filtered, and evaporated. The residue was purified by flash column chromatography (silica gel, hexanes/EtOAc, 10/1) to give cyclic sulfite intermediate $\mathbf{1 0 b}(249 \mathrm{mg}, 89 \%)$ as a colorless syrup. TBS deprotection. To a cooled $\left(0^{\circ} \mathrm{C}\right)$ solution of $\mathbf{1 0 b}(286 \mathrm{mg}, 0.654 \mathrm{mmol})$ in anhydrous THF $(6.5 \mathrm{~mL}, 0.1 \mathrm{M})$ was added acetic acid $(0.13 \mathrm{~mL}, 0.131 \mathrm{mmol}, 0.2$ equiv) followed by tetra- $n$-butylammonium fluoride solution $(2.6 \mathrm{~mL}, 1.0 \mathrm{M}$ solution in THF, 2.6 mmol, 4.0 equiv) under $\mathrm{N}_{2}$ atmosphere. After being stirred at room temperature for $12 \mathrm{~h}$, the reaction mixture was quenched with $\mathrm{H}_{2} \mathrm{O}(30 \mathrm{~mL})$ and diluted with EtOAc $(30 \mathrm{~mL})$. The layers 
were separated, and the aqueous layer was extracted with EtOAc $(3 \times 50 \mathrm{~mL})$. The combined organic layers were washed successively with $\mathrm{H}_{2} \mathrm{O}$ and saturated brine, dried over anhydrous $\mathrm{MgSO}_{4}$, filtered, and evaporated. The residue was purified by column chromatography (silica gel, hexanes/EtOAc, 6/1) to give $\mathbf{1 4}$ (202 mg, 96\%, Two diastereomers A and $\mathbf{B}$ were generated from sulfoxide stereogenic center) as a colorless syrup: For $\mathbf{A}:{ }^{1} \mathrm{H}$ NMR (400 $\left.\mathrm{MHz}, \mathrm{CDCl}_{3}\right)$ $\delta 5.27(\mathrm{t}, J=5.4 \mathrm{~Hz}, 1 \mathrm{H}), 5.02(\mathrm{~d}, J=5.9 \mathrm{~Hz}, 1 \mathrm{H}), 4.79(\mathrm{~s}, 1 \mathrm{H}), 4.44(\mathrm{dd}, J=4.8,11.4 \mathrm{~Hz}$, $1 \mathrm{H}), 4.19(\mathrm{~d}, J=3.9 \mathrm{~Hz}, 1 \mathrm{H}), 3.80(\mathrm{dd}, J=2.6,9.3 \mathrm{~Hz}, 1 \mathrm{H}), 1.90-1.94(\mathrm{~m}, 1 \mathrm{H}), 1.27$ (s, 9 $\mathrm{H}), 1.21(\mathrm{~s}, 9 \mathrm{H}) ;{ }^{13} \mathrm{C} \mathrm{NMR}\left(125 \mathrm{MHz}, \mathrm{CDCl}_{3}\right) \delta 86.9,82.6,74.9,74.5,74.1,69.4,58.2,43.6$, $28.3\left(3 \times \mathrm{CH}_{3}\right.$-tert-butyl), $27.2\left(3 \times \mathrm{CH}_{3}\right.$-tert-butyl $)$; HRMS $\left(\mathrm{FAB}^{+}\right)(\mathrm{m} / \mathrm{z})$ found 323.1530 , [calcd for $\mathrm{C}_{14} \mathrm{H}_{27} \mathrm{O}_{6} \mathrm{~S}^{+}(\mathrm{M}+\mathrm{H})^{+}$323.1528]; For $\mathbf{B}:{ }^{1} \mathrm{H}$ NMR $\left(500 \mathrm{MHz}, \mathrm{CDCl}_{3}\right) \delta$ 4.98-5.07 (m, $2 \mathrm{H}), 4.79(\mathrm{~d}, J=6.4 \mathrm{~Hz}, 1 \mathrm{H}), 4.36(\mathrm{dd}, J=4.6,11.5 \mathrm{~Hz}, 1 \mathrm{H}), 4.31(\mathrm{~d}, J=4.1 \mathrm{~Hz}, 1 \mathrm{H}), 3.84$ (d, $J=9.2 \mathrm{~Hz}, 1 \mathrm{H}), 3.77(\mathrm{~d}, J=9.3 \mathrm{~Hz}, 1 \mathrm{H}), 2.65(\mathrm{~d}, J=10.1 \mathrm{~Hz}, 1 \mathrm{H}), 1.25(\mathrm{~s}, 9 \mathrm{H}), 1.21(\mathrm{~s}$, $9 \mathrm{H})$.

$(3 a R, 4 R, 5 R, 6 S, 6 a R)-4-($ tert-butoxy)-5-(tert-butoxymethyl)-6-fluorotetrahydro-3a $H$ cyclopenta $[d][1,3,2]$ dioxathiole 2 -oxide (15). To a cooled $\left(0^{\circ} \mathrm{C}\right)$ solution of $14(33 \mathrm{mg}, 0.102$ mmol) in anhydrous $\mathrm{CH}_{2} \mathrm{Cl}_{2}(1.5 \mathrm{~mL}, 0.068 \mathrm{M})$ was dropwise added diethylaminosulfur trifluoride ( $60 \mu \mathrm{L}, 0.434 \mathrm{mmol}, 4.0$ equiv) under $\mathrm{N}_{2}$ atmosphere. After being stirred at room temperature for $4 \mathrm{~h}$, the reaction mixture was quenched with saturated aqueous $\mathrm{NH}_{4} \mathrm{Cl}(30 \mathrm{~mL})$ and diluted with EtOAc $(30 \mathrm{~mL})$. The layers were separated, and the aqueous layer was extracted with EtOAc $(3 \times 50 \mathrm{~mL})$. The combined organic layers were washed successively with $\mathrm{H}_{2} \mathrm{O}$ and saturated brine, dried over anhydrous $\mathrm{MgSO}_{4}$, filtered, and evaporated. The residue was purified by flash column chromatography (silica gel, hexanes/EtOAc, 15/1) to give $15(12 \mathrm{mg}, 37 \%)$ as a colorless syrup: ${ }^{1} \mathrm{H} \mathrm{NMR}\left(600 \mathrm{MHz}, \mathrm{CDCl}_{3}\right) \delta 5.17(\mathrm{ddd}, J=4.6,7.8$, 
$52.7 \mathrm{~Hz}, 1 \mathrm{H}), 5.03(\mathrm{t}, J=8.2 \mathrm{~Hz}, 1 \mathrm{H}), 4.92(\mathrm{ddd}, J=5.0,8.7,17.8 \mathrm{~Hz}, 1 \mathrm{H}), 4.06(\mathrm{ddd}, J=$ 7.8, 11.0, 16.5 Hz, $1 \mathrm{H}), 3.53(\mathrm{ddd}, J=2.7,2.7,6.8 \mathrm{~Hz}, 1 \mathrm{H}), 3.44(\mathrm{dd}, J=2.2,9.1 \mathrm{~Hz}, 1 \mathrm{H})$, 2.54-2.58 (m, $1 \mathrm{H}), 1.17(\mathrm{~s}, 18 \mathrm{H}) ;{ }^{13} \mathrm{C} \mathrm{NMR}\left(125 \mathrm{MHz}, \mathrm{CDCl}_{3}\right) \delta 102.1(\mathrm{~d}, J=191.2 \mathrm{~Hz})$ $87.2(\mathrm{~d}, J=28.2 \mathrm{~Hz}), 81.9(\mathrm{~d}, J=5.8 \mathrm{~Hz}), 74.5,72.8,72.4(\mathrm{~d}, J=19.2 \mathrm{~Hz}), 55.5,50.4(\mathrm{~d}, J=$ $6.5 \mathrm{~Hz}), 28.6\left(3 \times \mathrm{CH}_{3}\right.$-tert-butyl $), 27.5\left(3 \times \mathrm{CH}_{3}\right.$-tert-butyl $)$.

$(3 \mathrm{a} R, 4 R, 5 R, 6 S, 6 \mathrm{a} R)-4-($ tert-butoxy)-5-(tert-butoxymethyl)-6-fluorotetrahydro-3a $H$ cyclopenta $[d][1,3,2]$ dioxathiole 2,2-dioxide (16). To a solution of cyclic sulfite 15 (13 mg, $0.040 \mathrm{mmol})$ in $\mathrm{CCl}_{4} / \mathrm{CH}_{3} \mathrm{CN} / \mathrm{H}_{2} \mathrm{O}(1: 1: 1.5$, total $1.75 \mathrm{~mL}, 0.14 \mathrm{M})$ was added in one portion sodium periodate $(26 \mathrm{mg}, 0.120 \mathrm{mmol})$, followed by ruthenium (III) chloride trihydrate $(2 \mathrm{mg}$, $0.008 \mathrm{mmol}$ ) at room temperature under $\mathrm{N}_{2}$ atmosphere. After being stirred at the same temperature for $20 \mathrm{~min}$, the reaction mixture was quenched with $\mathrm{H}_{2} \mathrm{O}(20 \mathrm{~mL})$, and diluted with $\mathrm{CH}_{2} \mathrm{Cl}_{2}(20 \mathrm{~mL})$. The layers were separated, and the aqueous layer was extracted with $\mathrm{CH}_{2} \mathrm{Cl}_{2}$ $(2 \times 50 \mathrm{~mL})$. The combined organic layers were washed successively with $\mathrm{H}_{2} \mathrm{O}$ and saturated brine, dried over anhydrous $\mathrm{MgSO}_{4}$, filtered, and evaporated. The crude product $\mathbf{1 6}$ was used for the next step without further purification.

General procedure for the synthesis of 18a-c. Triflation. To a cooled $\left(0{ }^{\circ} \mathrm{C}\right)$ solution of $\mathbf{8 a - c}$ (1 equiv) in anhydrous pyridine $(0.32 \mathrm{M})$, trifluoromethanesulfonic anhydride (2 equiv) was added dropwise in a $\mathrm{N}_{2}$ atmosphere. After stirring at the same temperature for $30 \mathrm{~min}$, the reaction mixture was quenched with $\mathrm{H}_{2} \mathrm{O}(50 \mathrm{~mL})$ and diluted with EtOAc $(30 \mathrm{~mL})$. The layers were separated, and the aqueous layer was extracted with EtOAc $(2 \times 30 \mathrm{~mL})$. The combined organic layers were washed with saturated aqueous $\mathrm{CuSO}_{4}$ followed by water, dried over anhydrous $\mathrm{MgSO}_{4}$, filtered and evaporated. The residue was used for the next step without further purification.

Azidation. To a solution of triflate intermediate (1 equiv) in anhydrous DMF (0.19 M), sodium 
azide ( 3 equiv) was added in a single portion at room temperature. After being heated to 60$100{ }^{\circ} \mathrm{C}$ and stirred for $4-15 \mathrm{~h}$, the reaction mixture was cooled to room temperature, quenched with $\mathrm{H}_{2} \mathrm{O}(50 \mathrm{~mL})$, and diluted with EtOAc $(50 \mathrm{~mL})$. The layers were separated, and the aqueous layer was extracted with EtOAc $(2 \times 50 \mathrm{~mL})$. The combined organic layers were washed with $\mathrm{H}_{2} \mathrm{O}$ followed by saturated brine, dried over anhydrous $\mathrm{MgSO}_{4}$, filtered, and evaporated. The residue was purified by column chromatography (silica gel, hexanes /EtOAc, 10/1) to give 18a-c.

(3aS,4S,5R,6R,6aR)-4-Azido-6-(tert-butoxymethyl)-5-fluoro-2,2-dimethyltetrahydro3a $H$-cyclopenta $[\boldsymbol{d}][\mathbf{1 , 3}]$ dioxole $\mathbf{( 1 8 a )}$. Yield $=45 \%$; colorless syrup; $[\alpha]_{\mathrm{D}}{ }^{25}=-24.42(c 0.016$, $\left.\mathrm{CH}_{2} \mathrm{Cl}_{2}\right) ;{ }^{1} \mathrm{H} \mathrm{NMR}\left(500 \mathrm{MHz}, \mathrm{CDCl}_{3}\right) \delta 5.16(\mathrm{td}, J=52.4,3.1 \mathrm{~Hz}, 1 \mathrm{H}), 4.66(\mathrm{t}, J=6.0 \mathrm{~Hz}, 1$ $\mathrm{H}), 4.41(\mathrm{t}, J=6.5 \mathrm{~Hz}, 1 \mathrm{H}), 3.62-3.69(\mathrm{~m}, 1 \mathrm{H}), 3.54(\mathrm{~s}, 1 \mathrm{H}), 3.50(\mathrm{~s}, 1 \mathrm{H}), 2.27-2.36(\mathrm{~m}, 1$ $\mathrm{H}), 1.47(\mathrm{~s}, 3 \mathrm{H}), 1.29(\mathrm{~s}, 3 \mathrm{H}), 1.16(\mathrm{~s}, 9 \mathrm{H}) ;{ }^{13} \mathrm{C} \mathrm{NMR}\left(125 \mathrm{MHz}, \mathrm{CDCl}_{3}\right) \delta 114.1,96.9(\mathrm{~d}, J$ $=182.6 \mathrm{~Hz}), 82.0,80.2,73.1,67.9(\mathrm{~d}, J=15.7 \mathrm{~Hz}), 57.8(\mathrm{~d}, J=7.2 \mathrm{~Hz}), 49.4(\mathrm{~d}, J=17.6 \mathrm{~Hz})$, $27.3\left(3 \times \mathrm{CH}_{3}\right.$-tert-butyl), 27.1, 24.6; ${ }^{19} \mathrm{~F} \mathrm{NMR}\left(376 \mathrm{MHz}, \mathrm{CDCl}_{3}\right)-206.9 \sim 207.2$ (m); IR (neat) $2108 \mathrm{~cm}^{-1}$; LR-MS $\left(\mathrm{ESI}^{+}\right) 310.15$ [calcd for $\mathrm{C}_{13} \mathrm{H}_{22} \mathrm{FN}_{2} \mathrm{NaO}_{3}{ }^{+}(\mathrm{M}+\mathrm{Na})^{+} 310.1543$ ]; Anal. Calcd for $\mathrm{C}_{13} \mathrm{H}_{22} \mathrm{FN}_{3} \mathrm{O}_{3}$ : C, 54.34; H, 7.72; N, 14.62. Found: C, 54.35; H, 7.45; N, 14.23.

(3aS,4S,5S,6R,6aR)-4-Azido-6-(tert-butoxymethyl)-5-fluoro-2,2-dimethyltetrahydro3a $H$-cyclopenta $[d][\mathbf{1 , 3}]$ dioxole $(\mathbf{1 8 b})$. Yield $=88 \%$; colorless syrup; $[\alpha]_{\mathrm{D}}^{25}=9.66(c 0.51$, $\mathrm{MeOH}) ;{ }^{1} \mathrm{H}$ NMR $\left(500 \mathrm{MHz}, \mathrm{CDCl}_{3}\right) \delta 4.75(\mathrm{dt}, J=7.7,53.0 \mathrm{~Hz}, 1 \mathrm{H}), 4.41(\mathrm{dd}, J=4.5,6.7$ $\mathrm{Hz}, 1 \mathrm{H}), 4.22(\mathrm{t}, J=5.7 \mathrm{~Hz}, 1 \mathrm{H}), 4.00(\mathrm{ddd}, J=5.5,7.4,16.6 \mathrm{~Hz}, 1 \mathrm{H}), 3.43-3.50(\mathrm{~m}, 2 \mathrm{H})$, 2.33-2.44 (m, $1 \mathrm{H}), 1.50(\mathrm{~s}, 3 \mathrm{H}), 1.27$ (s, $3 \mathrm{H}), 1.15(\mathrm{~s}, 9 \mathrm{H}) ;{ }^{13} \mathrm{C} \mathrm{NMR}\left(150 \mathrm{MHz}, \mathrm{CDCl}_{3}\right)$ $\delta 112.7,95.8(\mathrm{~d}, J=188.9 \mathrm{~Hz}), 81.0(\mathrm{~d}, J=8.6 \mathrm{~Hz}), 77.8(\mathrm{~d}, J=7.2 \mathrm{~Hz}), 73.0,70.9(\mathrm{~d}, J=$ 20.1 Hz), 57.9, 49.1 (d, $J=18.7 \mathrm{~Hz}), 27.3$ (3 × $\mathrm{CH}_{3}$-tert-butyl), 27.2, 25.0; IR (neat) $2111 \mathrm{~cm}^{-}$ 
1. Anal. Calcd for $\mathrm{C}_{13} \mathrm{H}_{22} \mathrm{FN}_{3} \mathrm{O}_{3}$ : C, 54.34; H, 7.72; N, 14.62. Found: C, 54.12; H, 7.94; N, 14.33.

(3aS,4S,6R,6aR)-4-Azido-6-(tert-butoxymethyl)-5,5-difluoro-2,2-dimethyltetrahydro3a $H$-cyclopenta $[\boldsymbol{d}][\mathbf{1 , 3}]$ dioxole $\mathbf{( 1 8 c )}$. Yield $=75 \%$; colorless syrup; $[\alpha]_{\mathrm{D}}{ }^{25}=-43.39(c 0.36$, $\mathrm{MeOH}) ;{ }^{1} \mathrm{H}$ NMR $\left(500 \mathrm{MHz}, \mathrm{CDCl}_{3}\right) \delta$ 4.40-4.44 (m, $\left.1 \mathrm{H}\right), 4.34-4.39(\mathrm{~m}, 1 \mathrm{H})$, 3.87-3.95 (m, $1 \mathrm{H}), 3.61(\mathrm{dd}, J=6.5,9.3 \mathrm{~Hz}, 1 \mathrm{H}), 3.48(\mathrm{t}, J=7.6 \mathrm{~Hz}, 1 \mathrm{H}), 2.54-2.66(\mathrm{~m}, 1 \mathrm{H}), 1.49$ (s, 3 $\mathrm{H}), 1.28(\mathrm{~s}, 3 \mathrm{H}), 1.17(\mathrm{~s}, 9 \mathrm{H}) ;{ }^{13} \mathrm{C} \mathrm{NMR}\left(125 \mathrm{MHz}, \mathrm{CDCl}_{3}\right) \delta 127.1(\mathrm{dd}, J=255.9,260.9 \mathrm{~Hz})$, 113.0, $80.0(\mathrm{~d}, J=5.9 \mathrm{~Hz}), 78.4(\mathrm{~d}, J=5.6 \mathrm{~Hz}), 73.4,69.1(\mathrm{dd}, J=18.8,25.1 \mathrm{~Hz}), 57.2(\mathrm{~d}, J=$ $6.4 \mathrm{~Hz}), 50.8(\mathrm{t}, J=20.0 \mathrm{~Hz}), 27.3\left(3 \times \mathrm{CH}_{3}\right.$-tert-butyl), 26.9, 24.7; IR (neat) $2116 \mathrm{~cm}^{-1}$; Anal. Calcd for $\mathrm{C}_{13} \mathrm{H}_{21} \mathrm{~F}_{2} \mathrm{~N}_{3} \mathrm{O}_{3}$ : C, 51.14; H, 6.93; N, 13.76. Found: C, 51.45; H, 7.21; N, 14.10.

General procedure for the synthesis of 19a-c. To a suspension of 18a-c (1 equiv) in methanol $(0.2 \mathrm{M}), 10 \%$ palladium on activated carbon ( 0.03 equiv) was added and stirred overnight at room temperature in $\mathrm{H}_{2}$ atmosphere. After filtration, the solvent was removed, and the residue was used for the next step without further purification.

General procedure for the synthesis of 20a-c. To a solution of 19a-c ( 1 equiv) in $n$-butanol (0.38 M), 5-amino-4,6-dichloro pyrimidine (3-10 equiv) and diisopropylamine (10 equiv) were added. The reaction mixture was placed under microwave irradiation at $170-200{ }^{\circ} \mathrm{C}$ for $4-7 \mathrm{~h}$. The solvent was co-evaporated with $\mathrm{MeOH}$, and the residue was purified with column chromatography (silica gel, hexane/EtOAc, 4/1) to give 20a-c, respectively.

$N^{4}$-((3aS,4S,5R,6R,6aR)-6-(tert-Butoxymethyl)-5-fluoro-2,2-dimethyltetrahydro-4Hcyclopenta $[d][1,3]$ dioxol-4-yl)-6-chloropyrimidine-4,5-diamine (20a). Yield $=66 \%$ from 18a; yellow foam; $[\alpha]_{\mathrm{D}}{ }^{25}=-53.8\left(c 0.10, \mathrm{CH}_{2} \mathrm{Cl}_{2}\right) ;{ }^{1} \mathrm{H}$ NMR $\left(500 \mathrm{MHz}, \mathrm{CDCl}_{3}\right) \delta 8.08(\mathrm{~s}, 1$ H), 5.27-5.33 (bs, $1 \mathrm{H},), 5.24(\mathrm{td}, J=3.5,52.9 \mathrm{~Hz}, 1 \mathrm{H}), 4.71-4.81(\mathrm{~m}, 1 \mathrm{H}), 4.57(\mathrm{t}, J=6.1$ 
Hz, $1 \mathrm{H}), 4.44(\mathrm{t}, J=6.3 \mathrm{~Hz}, 1 \mathrm{H}), 3.58-3.63(\mathrm{~m}, 1 \mathrm{H}), 3.53$ (t, $J=9.2 \mathrm{~Hz}, 1 \mathrm{H}), 3.39(\mathrm{bs}, 2 \mathrm{H})$, 2.42-2.55 (m, $1 \mathrm{H}), 1.52(\mathrm{~s}, 3 \mathrm{H}), 1.30(\mathrm{~s}, 3 \mathrm{H}), 1.18(\mathrm{~s}, 9 \mathrm{H}) ;{ }^{13} \mathrm{C} \mathrm{NMR}\left(200 \mathrm{MHz}, \mathrm{CDCl}_{3}\right) \delta$ 154.4, 149.0, 122.4, 113.8, $95.9(\mathrm{~d}, J=178.7 \mathrm{~Hz}), 84.2,80.1,77.1,73.3,59.8(\mathrm{~d}, J=15.9 \mathrm{~Hz})$, $58.0(\mathrm{~d}, J=7.0 \mathrm{~Hz}), 49.4(\mathrm{~d}, J=17.6 \mathrm{~Hz}), 27.4\left(3 \times \mathrm{CH}_{3}\right.$-tert-butyl $), 27.2,24.8 ;{ }^{19} \mathrm{~F} \mathrm{NMR}(376$ $\left.\mathrm{MHz}, \mathrm{CDCl}_{3}\right)-212.8 \sim 213.1(\mathrm{~m}) ; \mathrm{UV}\left(\mathrm{CH}_{2} \mathrm{Cl}_{2}\right) \lambda_{\max } 287 \mathrm{~nm}$; LRMS (ESI ${ }^{+}$) found 388.17 [calcd for $\left.\mathrm{C}_{17} \mathrm{H}_{27} \mathrm{ClFN}_{4} \mathrm{O}_{3}{ }^{+}(\mathrm{M}+\mathrm{H})^{+} 389.1756\right]$; Anal. Calcd for $\mathrm{C}_{17} \mathrm{H}_{26} \mathrm{ClFN}_{4} \mathrm{O}_{3}$ : C, 52.51; H, 6.50; N, 14.45. Found: C, 52.45; H, 6.13; N, 14.15.

$N^{4}$-((3aS,4S,5S,6R,6aR)-6-(tert-Butoxymethyl)-5-fluoro-2,2-dimethyltetrahydro-4Hcyclopenta $[d][1,3]$ dioxol-4-yl)-6-chloropyrimidine-4,5-diamine (20b). Yield $=47 \%$ from 18b; yellow foam; $[\alpha]_{\mathrm{D}}{ }^{25}=-11.79(c 0.36, \mathrm{MeOH}) ;{ }^{1} \mathrm{H}$ NMR $\left(500 \mathrm{MHz}, \mathrm{CDCl}_{3}\right) \delta 8.10(\mathrm{~s}, 1$ H), $5.56(\mathrm{~d}, J=9.2 \mathrm{~Hz}, 1 \mathrm{H}), 4.89(\mathrm{dt}, J=3.1,51.0 \mathrm{~Hz}, 1 \mathrm{H}), 4.77(\mathrm{dd}, J=9.1,21.2 \mathrm{~Hz}, 1 \mathrm{H})$, $4.61(\mathrm{dd}, J=2.5,5.0 \mathrm{~Hz}, 1 \mathrm{H}), 4.51(\mathrm{dd}, J=2.4,6.0 \mathrm{~Hz}, 1 \mathrm{H}), 3.60(\mathrm{dd}, J=2.6,9.2 \mathrm{~Hz}, 1 \mathrm{H})$, 3.55 (dd, $J=2.5,9.3 \mathrm{~Hz}, 1 \mathrm{H}), 3.39$ (bs, $2 \mathrm{H}), 2.60$ (d, J = 23.5 Hz, $1 \mathrm{H}), 1.54$ (s, $3 \mathrm{H}), 1.29$ (s, $3 \mathrm{H}), 1.21(\mathrm{~s}, 9 \mathrm{H}) ;{ }^{13} \mathrm{C} \mathrm{NMR}\left(125 \mathrm{MHz}, \mathrm{CDCl}_{3}\right) \delta 154.2,149.6,143.4,122.4,111.7,101.3(\mathrm{~d}$, $J=185.1 \mathrm{~Hz}), 85.5(\mathrm{~d}, J=3.3 \mathrm{~Hz}), 82.0(\mathrm{~d}, J=2.6 \mathrm{~Hz}), 74.0,63.7(\mathrm{~d}, J=26.6 \mathrm{~Hz}), 60.6(\mathrm{~d}, J$ $=7.1 \mathrm{~Hz}), 51.3(\mathrm{~d}, J=20.5 \mathrm{~Hz}), 27.5\left(3 \times \mathrm{CH}_{3}\right.$-tert-butyl), 27.1, 24.9; $\mathrm{UV}(\mathrm{MeOH}) \lambda_{\max } 297.60$, $265.07 \mathrm{~nm} ; \mathrm{HRMS}\left(\mathrm{ESI}^{+}\right)$found 389.1762 [calcd for $\mathrm{C}_{17} \mathrm{H}_{27} \mathrm{ClFN}_{4} \mathrm{O}_{3}{ }^{+}(\mathrm{M}+\mathrm{H})^{+}$389.1756]; Anal. Calcd for $\mathrm{C}_{17} \mathrm{H}_{26} 1 \mathrm{FN} 4 \mathrm{O}_{3}:$ C, 52.51; H, 6.50; N, 14.45. Found: C, 52.56; H, 6.51; N, 14.43. $N^{4}$-((3aS,4S,6R,6aR)-6-(tert-Butoxymethyl)-5,5-difluoro-2,2-dimethyltetrahydro-4Hcyclopenta $[d][1,3]$ dioxol-4-yl)-6-chloropyrimidine-4,5-diamine (20c). Yield $=67 \%$ from 18c; yellow foam; $[\alpha]_{\mathrm{D}}{ }^{25}=-61.76(c 0.23, \mathrm{MeOH}) ;{ }^{1} \mathrm{H} \mathrm{NMR}\left(500 \mathrm{MHz}, \mathrm{CDCl}_{3}\right) \delta 8.11(\mathrm{~s}, 1$ H), $5.71(\mathrm{~d}, J=10.1 \mathrm{~Hz}, 1 \mathrm{H}), 5.03(\mathrm{t}, J=12.7 \mathrm{~Hz}, 1 \mathrm{H}), 4.56(\mathrm{t}, J=4.6 \mathrm{~Hz}, 1 \mathrm{H}), 4.40-4.45$ (m, $1 \mathrm{H}), 3.69(\mathrm{dd}, J=2.6,9.5 \mathrm{~Hz}, 1 \mathrm{H}), 3.57(\mathrm{dd}, \mathrm{J}=4.4,9.4 \mathrm{~Hz}, 1 \mathrm{H}), 3.38(\mathrm{bs}, 2 \mathrm{H}), 2.72(\mathrm{~d}$, 
$J=14.7 \mathrm{~Hz}, 1 \mathrm{H}), 1.53(\mathrm{~s}, 3 \mathrm{H}), 1,44(\mathrm{~s}, 3 \mathrm{H}), 1.25(\mathrm{~s}, 9 \mathrm{H}) ;{ }^{13} \mathrm{C} \mathrm{NMR}\left(125 \mathrm{MHz}, \mathrm{CDCl}_{3}\right) \delta$ $154.5,149.6,143.9,128.0(\mathrm{dd}, J=257.3,260.0 \mathrm{~Hz}), 122.3,111.7,84.5,79.7(\mathrm{~d}, J=4.1 \mathrm{~Hz})$, 74.5, $61.7(\mathrm{dd}, J=18.1,31.9 \mathrm{~Hz}), 58.3(\mathrm{t}, J=5.8 \mathrm{~Hz}), 51.6(\mathrm{t}, J=22.6 \mathrm{~Hz}), 27.5\left(3 \times \mathrm{CH}_{3}-\right.$ tert-butyl), 26.7, 24.6; UV (MeOH) $\lambda_{\max } 297.39,263.29 \mathrm{~nm}$; HRMS $\left(\mathrm{ESI}^{+}\right)$found 407.1658 [calcd for $\mathrm{C}_{17} \mathrm{H}_{26} \mathrm{ClF}_{2} \mathrm{~N}_{4} \mathrm{O}_{3}{ }^{+}(\mathrm{M}+\mathrm{H})^{+} 407.1661$ ]; Anal. Calcd for $\mathrm{C}_{17} \mathrm{H}_{25} \mathrm{ClF}_{2} \mathrm{~N}_{4} \mathrm{O}_{3}$ : C, 50.19; $\mathrm{H}$, 6.19; N, 13.77. Found: C, 50.11; H, 6.23; N, 13.65.

General procedure for the synthesis of 21a-c. A solution of 20a-c in diethoxymethyl acetate $(0.15 \mathrm{M})$ was placed under microwave irradiation at $140{ }^{\circ} \mathrm{C}$ for $3 \mathrm{~h}$. The mixture was then coevaporated with $\mathrm{MeOH}$ three times and the resulting residue was purified with column chromatography (silica gel, hexane/EtOAc, 7/1) to give 21a-c.

9-((3aS,4S,5R,6R,6aR)-6-(tert-Butoxymethyl)-5-fluoro-2,2-dimethyltetrahydro-4Hcyclopenta $[\boldsymbol{d}][1,3]$ dioxol-4-yl)-6-chloro-9H-purine (21a). Yield =96\%; yellow foam; $[\alpha]_{\mathrm{D}}{ }^{25}$ $=-29.2\left(c\right.$ 0.17, $\left.\mathrm{CH}_{2} \mathrm{Cl}_{2}\right) ;{ }^{1} \mathrm{H} \mathrm{NMR}\left(400 \mathrm{MHz}, \mathrm{CDCl}_{3}\right) \delta 8.74(\mathrm{~s}, 1 \mathrm{H}), 8.34(\mathrm{~d}, J=2.4 \mathrm{~Hz}, 1$ $\mathrm{H}), 5.28-5.43(\mathrm{td}, J=2.8,52.8 \mathrm{~Hz}, 1 \mathrm{H}), 5.12-5.23(\mathrm{~m}, 2 \mathrm{H}), 4.61(\mathrm{t}, J=5.0 \mathrm{~Hz}, 1 \mathrm{H}), 3.65-$ $3.69(\mathrm{~m}, 1 \mathrm{H}), 3.61(\mathrm{t}, J=9.2 \mathrm{~Hz}, 1 \mathrm{H}), 2.56-2.71(\mathrm{~m}, 1 \mathrm{H}), 1.56(\mathrm{~s}, 3 \mathrm{H}), 1.32(\mathrm{~s}, 3 \mathrm{H}), 1.17$ $(\mathrm{s}, 9 \mathrm{H}) ;{ }^{13} \mathrm{C} \mathrm{NMR}\left(100 \mathrm{MHz}, \mathrm{CDCl}_{3}\right) \delta 152.3,151.4,144.2,144.1,131.4,115.4,97.7-95.9(\mathrm{~d}$, $J=181.2 \mathrm{~Hz}), 82.9,80.1,73.5,63.1(\mathrm{~d}, J=16.1 \mathrm{~Hz}), 58.0(\mathrm{~d}, J=7.4 \mathrm{~Hz}), 50.0(\mathrm{~d}, J=17.5$ $\mathrm{Hz}), 27.6\left(3 \times \mathrm{CH}_{3}\right.$-tert-butyl), 27.5, 25.1; $\left.{ }^{19} \mathrm{~F} \mathrm{NMR} \mathrm{(376} \mathrm{MHz,} \mathrm{CDCl}_{3}\right)-202.6 \sim 202.9$ (m); UV $\left(\mathrm{CH}_{2} \mathrm{Cl}_{2}\right) \lambda_{\max } 271 \mathrm{~nm}$; LRMS $\left(\mathrm{ESI}^{+}\right)$found 399.16 [calcd for $\mathrm{C}_{18} \mathrm{H}_{25} \mathrm{ClFN}_{4} \mathrm{O}_{3}{ }^{+}(\mathrm{M}+\mathrm{H})^{+}$ 399.1599]; Anal. Calcd for $\mathrm{C}_{18} \mathrm{H}_{24} \mathrm{ClFN}_{4} \mathrm{O}_{3}$ : C, 54.20; H, 6.06; $\mathrm{N}, 14.05$. Found: $\mathrm{C}, 54.12 ; \mathrm{H}$, $6.34 ; \mathrm{N}, 14.23$.

9-((3aS,4S,5S,6R,6aR)-6-(tert-Butoxymethyl)-5-fluoro-2,2-dimethyltetrahydro-4Hcyclopenta $[d][1,3]$ dioxol-4-yl)-6-chloro-9H-purine (21b). Yield = 76\%; yellow foam; $[\alpha]_{\mathrm{D}}{ }^{25}$ 
$=-31.54\left(c\right.$ 0.54, MeOH); ${ }^{1} \mathrm{H}$ NMR $\left(500 \mathrm{MHz}, \mathrm{CDCl}_{3}\right) \delta 8.67(\mathrm{~s}, 1 \mathrm{H}), 8.15(\mathrm{~s}, 1 \mathrm{H}), 5.55(\mathrm{dt}$, $J=8.4,53.6 \mathrm{~Hz}, 1 \mathrm{H}), 5.02(\mathrm{t}, J=6.4 \mathrm{~Hz}, 1 \mathrm{H}), 4.84-4.94(\mathrm{~m}, 1 \mathrm{H}), 4.65(\mathrm{t}, J=5.1 \mathrm{~Hz}, 1 \mathrm{H})$, 3.53-3.63 (m, $2 \mathrm{H}), 2.47-2.57$ (m, $1 \mathrm{H}), 1.54$ (s, $3 \mathrm{H}), 1.25$ (s, $3 \mathrm{H}), 1.17$ (s, $9 \mathrm{H}) ;{ }^{13} \mathrm{C}$ NMR $\left(150 \mathrm{MHz}, \mathrm{CDCl}_{3}\right) \delta 151.7,151.5,151.3,144.8,132.3,113.1,93.9(\mathrm{~d}, J=191.0 \mathrm{~Hz}), 79.1(\mathrm{~d}$, $J=7.9 \mathrm{~Hz}), 77.6(\mathrm{~d}, J=7.9 \mathrm{~Hz}), 73.1,67.8(\mathrm{~d}, J=20.8 \mathrm{~Hz}), 58.1,48.7(\mathrm{~d}, J=18.7 \mathrm{~Hz}) 27.5$ (3 $\times \mathrm{CH}_{3}$-tert-butyl), 27.3, 25.0; UV (MeOH) $\lambda_{\max } 264.36 \mathrm{~nm} ; \mathrm{HRMS}\left(\mathrm{ESI}^{+}\right)$found 399.1589 [calcd for $\mathrm{C}_{18} \mathrm{H}_{25} \mathrm{ClFN}_{4} \mathrm{O}_{3}{ }^{+}(\mathrm{M}+\mathrm{H})^{+}$399.1599]; Anal. Calcd for $\mathrm{C}_{18} \mathrm{H}_{24} \mathrm{ClFN}_{4} \mathrm{O}_{3}$ : C, 54.20; $\mathrm{H}$, 6.06; N, 14.05. Found: C, 54.34; H, 6.46; N, 13.99.

9-((3aS,4S,6R,6aR)-6-(tert-Butoxymethyl)-5,5-difluoro-2,2-dimethyltetrahydro-4Hcyclopenta $[\boldsymbol{d}][1,3]$ dioxol-4-yl)-6-chloro-9H-purine $(21 \mathrm{c})$. Yield $=92 \%$; yellow foam; $[\alpha] \mathrm{D}^{25}$ $=-46.05(c 0.43, \mathrm{MeOH}) ;{ }^{1} \mathrm{H} \mathrm{NMR}\left(500 \mathrm{MHz}, \mathrm{CDCl}_{3}\right) \delta 8.73(\mathrm{~s}, 1 \mathrm{H}), 8.28(\mathrm{~d}, J=2.1 \mathrm{~Hz}, 1$ H), $5.30(\mathrm{dt}, J=6.9,20.1 \mathrm{~Hz}, 1 \mathrm{H}), 5.10(\mathrm{t}, J=6.7 \mathrm{~Hz}, 1 \mathrm{H}), 4.57-4.62(\mathrm{~m}, 1 \mathrm{H}), 3.63-3.73(\mathrm{~m}$, $2 \mathrm{H}), 2.81-2.93(\mathrm{~m}, 1 \mathrm{H}), 1.56(\mathrm{~s}, 3 \mathrm{H}), 1.30(\mathrm{~s}, 3 \mathrm{H}), 1.18(\mathrm{~s}, 9 \mathrm{H}) ;{ }^{13} \mathrm{C} \mathrm{NMR}\left(125 \mathrm{MHz}, \mathrm{CDCl}_{3}\right)$ $\delta 152.4,152.4,151.3,143.9(\mathrm{~d}, J=4.0 \mathrm{H}), 131.2,125.6(\mathrm{dd}, J=253.4,264.6 \mathrm{~Hz}), 114.0,79.5$ (d, $J=7.7 \mathrm{~Hz}), 77.9$ (d, $J=7.5 \mathrm{~Hz}), 73.7,64.6(\mathrm{dd}, J=19.3,24.3 \mathrm{~Hz}), 57.1(\mathrm{~d}, J=7.1 \mathrm{~Hz})$, $50.3(\mathrm{t}, J=19.8 \mathrm{~Hz}), 27.3\left(3 \times \mathrm{CH}_{3}\right.$-tert-butyl), 27.2, 25.0; UV $(\mathrm{MeOH}) \lambda_{\max } 263.74 \mathrm{~nm}$; HRMS $\left(\mathrm{ESI}^{+}\right.$) found 417.1500 [calcd for $\mathrm{C}_{18} \mathrm{H}_{24} \mathrm{ClF}_{2} \mathrm{~N}_{4} \mathrm{O}_{3}{ }^{+}(\mathrm{M}+\mathrm{H})^{+} 417.1505$ ]; Anal. Calcd for $\mathrm{C}_{18} \mathrm{H}_{23} \mathrm{ClF}_{2} \mathrm{~N}_{4} \mathrm{O}_{3}: \mathrm{C}, 51.86 ; \mathrm{H}, 5.56 ; \mathrm{N}, 13.44$. Found: $\mathrm{C}, 51.56 ; \mathrm{H}, 5.96 ; \mathrm{N}, 13.13$.

General procedure for the synthesis of 2 a-c. To a solution of 21 a-c in tert-butanol $(2 \mathrm{~mL}$, $0.27 \mathrm{M})$ contained in a stainless steel bomb reactor, saturated ammonia in tert-butanol $(15 \mathrm{~mL})$ was added and the reactor was locked. After being heated to $120{ }^{\circ} \mathrm{C}$ with stirring for $15 \mathrm{~h}$, the mixture was cooled to room temperature and co-evaporated with $\mathrm{MeOH}$. Without purification, the residue was added to a trifluoroacetic acid/ $\mathrm{H}_{2} \mathrm{O}$ solution $(2: 1, \mathrm{v} / \mathrm{v}$, total $15 \mathrm{~mL})$ and heated 
to $50{ }^{\circ} \mathrm{C}$ with stirring for $15 \mathrm{~h}$. After the reaction mixture was evaporated, the residue was purified by column chromatography ( silica gel, $\mathrm{CH}_{2} \mathrm{Cl}_{2} / \mathrm{MeOH}, 9 / 1$ ) to give 2a-c.

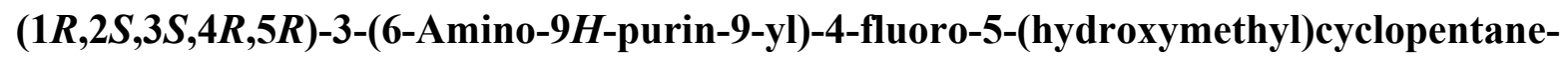
1,2-diol (2a). Yield $=43 \%$; white solid; mp 172-177 ${ }^{\circ} \mathrm{C} ;[\alpha]_{\mathrm{D}}{ }^{25}=-64.49(c 0.22, \mathrm{MeOH}) ;{ }^{1} \mathrm{H}$ NMR (800 MHz, CD $\left.{ }_{3} \mathrm{OD}-d_{6}\right) \delta 8.26(\mathrm{~d}, J=2.0 \mathrm{~Hz}, 1 \mathrm{H}), 8.21(\mathrm{~s}, 1 \mathrm{H}), 5.21$ (dt, $J=4.0,54.6$, $1 \mathrm{H}), 4.99(\mathrm{ddd}, J=3.4,10.8,29.5 \mathrm{~Hz}, 1 \mathrm{H}), 4.75(\mathrm{dd}, J=6.7,9.4 \mathrm{~Hz}, 1 \mathrm{H}), 4.02(\mathrm{dd}, J=4.8$, $6.4 \mathrm{~Hz}, 1 \mathrm{H}), 3.79-3.85(\mathrm{~m}, 2 \mathrm{H}), 2.42-2.51(\mathrm{~m}, 1 \mathrm{H}) ;{ }^{13} \mathrm{C} \mathrm{NMR}\left(200 \mathrm{MHz}, \mathrm{CD}_{3} \mathrm{OD}\right) \delta$ 158.1, 154.6, 152.2, $142.4(\mathrm{~d}, J=3.3 \mathrm{~Hz}), 120.5,92.8(\mathrm{~d}, J=180.7 \mathrm{~Hz}), 74.3,71.8,64.0(\mathrm{~d}, J=17.0$ $\mathrm{Hz}), 60.6(\mathrm{~d}, J=10.7 \mathrm{~Hz}), 54.3(\mathrm{~d}, J=17.9 \mathrm{~Hz}) ;{ }^{19} \mathrm{~F}$ NMR $\left(376 \mathrm{MHz}, \mathrm{CD}_{3} \mathrm{OD}\right) \delta-204.7 \sim$ 205.4 (m); UV (MeOH) $\lambda_{\max } 259.90 \mathrm{~nm}$; HRMS $\left(\mathrm{ESI}^{+}\right)$found 284.1161 [calcd for $\mathrm{C}_{11} \mathrm{H}_{15} \mathrm{FN}_{5} \mathrm{O}_{3}{ }^{+}(\mathrm{M}+\mathrm{H})^{+}$284.1159]; Anal. Calcd for $\mathrm{C}_{11} \mathrm{H}_{14} \mathrm{FN}_{5} \mathrm{O}_{3}$ : C, 46.64; H, 4.98; N, 24.72 . Found: C, 46.65; H, 5.38; N, 25.10.

$(1 R, 2 S, 3 S, 4 S, 5 R)-3-(6-A m i n o-9 H$-purin-9-yl)-4-fluoro-5-(hydroxymethyl)cyclopentane1,2-diol (2b). Yield = 71\%; white solid; mp 182-186 ${ }^{\circ} \mathrm{C} ;[\alpha]_{\mathrm{D}}{ }^{25}=-11.85(c 0.26, \mathrm{MeOH}) ;{ }^{1} \mathrm{H}$ NMR (500 MHz, CD $\left.{ }_{3} \mathrm{OD}\right) \delta 8.19(\mathrm{~s}, 1 \mathrm{H}), 8.18(\mathrm{~s}, 1 \mathrm{H}), 5.40$ (ddd, $\left.J=5.2,7.3,54.4 \mathrm{~Hz}, 1 \mathrm{H}\right)$, $5.03(\mathrm{ddd}, J=7.5,9.8,20.7 \mathrm{~Hz}, 1 \mathrm{H}), 4.60(\mathrm{dd}, J=5.1,9.9 \mathrm{~Hz}, 1 \mathrm{H}), 4.05-4.09$ (m, $1 \mathrm{H}), 3.80$ $(\mathrm{d}, J=5.8 \mathrm{~Hz}, 2 \mathrm{H}), 2.28-2.40(\mathrm{~m}, 1 \mathrm{H}) ;{ }^{13} \mathrm{C} \mathrm{NMR}\left(125 \mathrm{MHz}, \mathrm{CD}_{3} \mathrm{OD}\right) \delta 158.0,154.3,151.9$, 143.4, 121.6, 95.8 (d, $J=186.4 \mathrm{~Hz}), 74.2(\mathrm{~d}, J=7.4 \mathrm{~Hz}), 73.2(\mathrm{~d}, J=3.3 \mathrm{~Hz}), 68.6(\mathrm{~d}, J=21.1$ $\mathrm{Hz}), 62.6,54.6(\mathrm{~d}, J=19.0 \mathrm{~Hz}) ;{ }^{19} \mathrm{~F}$ NMR $\left(378 \mathrm{MHz}, \mathrm{CD}_{3} \mathrm{OD}\right) \delta-185.244(\mathrm{dt}, J=23.8,53.7$ $\mathrm{Hz}$ ); UV (MeOH) $\lambda_{\max } 260.88 \mathrm{~nm}$; HRMS $\left(\mathrm{ESI}^{+}\right.$) found 284.1155 [calcd for $\mathrm{C}_{11} \mathrm{H}_{15} \mathrm{FN}_{5} \mathrm{O}_{3}{ }^{+}$ $(\mathrm{M}+\mathrm{H})^{+} 284.1159$ ]; Anal. Calcd for $\mathrm{C}_{11} \mathrm{H}_{14} \mathrm{FN}_{5} \mathrm{O}_{3}: \mathrm{C}, 46.64 ; \mathrm{H}, 4.98 ; \mathrm{N}, 24.72$. Found: C, 46.38; H, 5.12; N, 24.33 . 


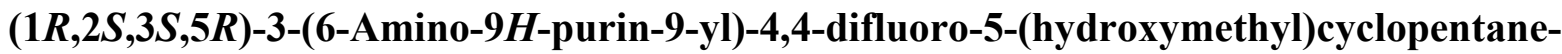
1,2-diol (2c). Yield = 61\%; white solid; mp 180-185 ${ }^{\circ} \mathrm{C} ;[\alpha]_{\mathrm{D}}{ }^{25}=-56.51(c 0.30, \mathrm{MeOH}) ;{ }^{1} \mathrm{H}$ NMR (500 MHz, CD 3 OD) $\delta 8.26(\mathrm{~d}, J=19.5 \mathrm{~Hz}, 1 \mathrm{H}), 8.20(\mathrm{~s}, 1 \mathrm{H}), 5.33(\mathrm{dt}, J=10.0,17.0$ $\mathrm{Hz}, 1 \mathrm{H}), 4.79$ (dd, $J=5.2,10.6 \mathrm{~Hz}, 1 \mathrm{H}$, merged with solvent peak), 4.13-4.17 (m, $1 \mathrm{H}), 3.79$ $3.91(\mathrm{~m}, 2 \mathrm{H}), 2.60-2.71(\mathrm{~m}, 1 \mathrm{H}) ;{ }^{13} \mathrm{C} \mathrm{NMR}\left(200 \mathrm{MHz}, \mathrm{CD}_{3} \mathrm{OD}\right) \delta 158.2,154.8,152.6,142.7$ $(\mathrm{d}, J=2.4 \mathrm{~Hz}), 125.9(\mathrm{dd}, \mathrm{J}=252.3,258.4 \mathrm{~Hz}), 120.6,73.7(\mathrm{~d}, J=7.3 \mathrm{~Hz}), 71.8(\mathrm{~d}, J=3.3$ $\mathrm{Hz}), 64.8(\mathrm{dd}, J=19.4,23.8 \mathrm{~Hz}), 59.6(\mathrm{~d}, J=10.8 \mathrm{~Hz}), 56.4(\mathrm{t}, J=19.9 \mathrm{~Hz}) ;{ }^{19} \mathrm{~F}$ NMR $(378$ $\left.\mathrm{MHz}, \mathrm{CD}_{3} \mathrm{OD}\right) \delta-97.5(\mathrm{~d}, J=238.5 \mathrm{~Hz}),-115.4(\mathrm{dt}, J=15.9,238.9 \mathrm{~Hz}) ; \mathrm{UV}(\mathrm{MeOH}) \lambda_{\max }$ $259.92 \mathrm{~nm}$; HRMS $\left(\mathrm{ESI}^{+}\right)$found 302.1066 [calcd for $\mathrm{C}_{11} \mathrm{H}_{14} \mathrm{~F}_{2} \mathrm{~N}_{5} \mathrm{O}_{3}{ }^{+}(\mathrm{M}+\mathrm{H})^{+}$302.1065]; Anal. Calcd for $\mathrm{C}_{11} \mathrm{H}_{13} \mathrm{~F}_{2} \mathrm{~N}_{5} \mathrm{O}_{3}$ : C, 43.86; H, 4.35; N, 23.25. Found: C, 44.17; H, 4.14; N, 23.05.

General procedure for the synthesis of $2 d$ and $2 \mathrm{e}$. To a solution of $21 \mathrm{a}$ and $21 \mathrm{c}(0.283 \mathrm{mmol})$ in $\operatorname{EtOH}(1.5 \mathrm{~mL}, 0.19 \mathrm{M})$ in a sealed glass tube, methylamine (40 wt. \% in $\mathrm{H}_{2} \mathrm{O}, 10 \mathrm{~mL}$ ) was added. After being stirred at room temperature for $2 \mathrm{~h}$, the mixture was concentrated and added to a trifluoroacetic acid/ $\mathrm{H}_{2} \mathrm{O}$ solution $(2: 1, \mathrm{v} / \mathrm{v}$, total $15 \mathrm{~mL})$ without purification. After being heated to $50{ }^{\circ} \mathrm{C}$ with stirring for $15 \mathrm{~h}$, the reaction mixture was evaporated. The residue was purified by column chromatography (silica gel, $\mathrm{CH}_{2} \mathrm{Cl}_{2} / \mathrm{MeOH}, 9 / 1$ ) to give $\mathbf{2 d}$ and $\mathbf{2 e}$ respectively.

(1S,2R,3R,4R,5S)-4-Fluoro-3-(hydroxymethyl)-5-(6-(methylamino)-9H-purin-9-

yl)cyclopentane-1,2-diol (2d). Yield $=67 \%$; white solid; mp 197-201 ${ }^{\circ} \mathrm{C} ;[\alpha]_{\mathrm{D}}{ }^{25}=-61.46(\mathrm{c}$ $0.40, \mathrm{MeOH}) ;{ }^{1} \mathrm{H} \mathrm{NMR}\left(800 \mathrm{MHz}, \mathrm{CD}_{3} \mathrm{OD}\right) \delta 8.27(\mathrm{~s}, 1 \mathrm{H}), 8.20(\mathrm{~d}, J=18.4 \mathrm{~Hz}, 1 \mathrm{H}), 5.21$ $(\mathrm{dt}, J=4.0,54.6 \mathrm{~Hz}, 1 \mathrm{H}), 4.98(\mathrm{ddd}, J=3.4,10.0,29.6 \mathrm{~Hz}, 1 \mathrm{H}), 4.74(\mathrm{dd}, J=6.7,9.4 \mathrm{~Hz}, 1$ $\mathrm{H}), 4.01(\mathrm{dd}, J=4.9,6.4 \mathrm{~Hz}, 1 \mathrm{H}), 3.79-3.85(\mathrm{~m}, 2 \mathrm{H}), 3.11(\mathrm{bs}, 3 \mathrm{H}), 2.42-2.51(\mathrm{~m}, 1 \mathrm{H}) ;{ }^{13} \mathrm{C}$ NMR (200 MHz, CD 3 OD) $\delta 157.5,154.6,151.1,141.8(\mathrm{~d}, J=3.7 \mathrm{~Hz}), 121.1,92.9(\mathrm{~d}, J=$ 
$180.8 \mathrm{~Hz}), 74.3,71.8,64.0(\mathrm{~d}, J=17.0 \mathrm{~Hz}), 60.6(\mathrm{~d}, J=10.5 \mathrm{~Hz}), 54.3(\mathrm{~d}, J=18.0 \mathrm{~Hz}), 28.5$; ${ }^{19} \mathrm{~F}$ NMR (376 MHz, CD $\left.3 \mathrm{OD}\right) \delta-206.3(\mathrm{dt}, J=29.7,53.4 \mathrm{~Hz})$; UV (MeOH) $\lambda_{\max } 266.89 \mathrm{~nm}$; HRMS $\left(\mathrm{ESI}^{+}\right.$) found 298.1317 [calcd for $\mathrm{C}_{12} \mathrm{H}_{17} \mathrm{FN}_{5} \mathrm{O}_{3}{ }^{+}(\mathrm{M}+\mathrm{H})^{+}$298.1315]; Anal. Calcd for $\mathrm{C}_{12} \mathrm{H}_{16} \mathrm{FN}_{5} \mathrm{O}_{3}: \mathrm{C}, 48.48 ; \mathrm{H}, 5.42 ; \mathrm{N}, 23.56$. Found: $\mathrm{C}, 48.50 ; \mathrm{H}, 5.22 ; \mathrm{N}, 23.93$.

(1S,2R,3R,5S)-4,4-Difluoro-3-(hydroxymethyl)-5-(6-(methylamino)-9H-purin-9-

yl)cyclopentane-1,2-diol (2e). Yield $=76 \%$; white solid; mp $125-129{ }^{\circ} \mathrm{C} ;[\alpha]_{\mathrm{D}}{ }^{25}=-48.62(\mathrm{c}$ 0.25, MeOH); ${ }^{1} \mathrm{H}$ NMR (500 MHz, $\left.\mathrm{CD}_{3} \mathrm{OD}\right) \delta 8.24$ (s, $\left.1 \mathrm{H}\right), 8.20$ (s, $\left.1 \mathrm{H}\right), 5.33$ (dt, $J=9.9$, $18.41 \mathrm{H}), 4.79$ (dd, $J=10.3,10.2 \mathrm{~Hz}, 1 \mathrm{H}), 4.17$ (s, $1 \mathrm{H}), 3.81-3.90$ (m, $2 \mathrm{H}), 3.10$ (bs, $3 \mathrm{H})$, $2.67(\mathrm{~m}, 1 \mathrm{H}) ;{ }^{13} \mathrm{C} \mathrm{NMR}\left(125 \mathrm{MHz}, \mathrm{CD}_{3} \mathrm{OD}\right) \delta 157.5,154.7,151.5,142.1,125.9(\mathrm{dd}, J=252.4$, 258.1 Hz), 121.1, 73.7 (d, $J=7.25 \mathrm{~Hz}), 71.9$ (d, $J=3.1 \mathrm{~Hz}), 64.7(\mathrm{dd}, J=20.0,24.3 \mathrm{~Hz}), 59.6$ $(\mathrm{d}, J=10.8 \mathrm{~Hz}), 56.4(\mathrm{t}, J=19.9 \mathrm{~Hz}), 28.6 ;{ }^{19} \mathrm{~F}$ NMR $\left(378 \mathrm{MHz}, \mathrm{CD}_{3} \mathrm{OD}\right) \delta-97.4(\mathrm{~d}, J=$ $238.5 \mathrm{~Hz}),-115.3(\mathrm{~d}, J=238.9 \mathrm{~Hz}) ; \mathrm{UV}(\mathrm{MeOH}) \lambda_{\max } 263.72 \mathrm{~nm}$; HRMS $\left(\mathrm{ESI}^{+}\right)$found 316.1227 [calcd for $\mathrm{C}_{12} \mathrm{H}_{16} \mathrm{~F}_{2} \mathrm{~N}_{5} \mathrm{O}_{3}{ }^{+}(\mathrm{M}+\mathrm{H})^{+}$316.1221]; Anal. Calcd for $\mathrm{C}_{12} \mathrm{H}_{15} \mathrm{~F}_{2} \mathrm{~N}_{5} \mathrm{O}_{3}$ : C, 45.71; H, 4.80; N, 22.21. Found: C, 45.99; H, 4.47; N, 22.02.

General procedure for the synthesis of $22 \mathrm{a}-\mathrm{c}$. To a cooled $\left(-20{ }^{\circ} \mathrm{C}\right)$ solution of $19 \mathrm{a}-\mathrm{c}(1$ equiv) in DMF (0.2 M), 3-methoxyacryloyl isocyanate (2 equiv) in benzene was added dropwise in a $\mathrm{N}_{2}$ atmosphere. After the reaction mixture was slowly warmed to room temperature for $15 \mathrm{~h}$ with stirring, the reaction mixture was filtered with $\mathrm{CH}_{2} \mathrm{Cl}_{2}$ and coevaporated with toluene and ethanol. The residue was purified by column chromatography (silica gel, hexane/EtOAc, 1.5/1) to give 22a-c.

(E)-N-(((3aS,4S,5R,6R,6aR)-6-(tert-Butoxymethyl)-5-fluoro-2,2-dimethyltetrahydro-4Hcyclopenta $[d][1,3]$ dioxol-4-yl)carbamoyl)-3-methoxyacrylamide $(22 a)$. Yield $=76 \%$; colorless syrup; $[\alpha]_{\mathrm{D}}{ }^{25}=-19.41(c 0.37, \mathrm{MeOH}) ;{ }^{1} \mathrm{H}$ NMR $\left(600 \mathrm{MHz}, \mathrm{CDCl}_{3}\right) \delta 10.24(\mathrm{~s}, 1 \mathrm{H})$, 
$9.16(\mathrm{~d}, J=8.2 \mathrm{~Hz}, 1 \mathrm{H}), 7.61(\mathrm{~d}, J=12.4 \mathrm{~Hz}, 1 \mathrm{H}), 5.35(\mathrm{~d}, J=12.4 \mathrm{~Hz}, 1 \mathrm{H}), 5.06$ (dt, $J=$ 3.2, 52.7 Hz, $1 \mathrm{H}), 4.51(\mathrm{t}, J=6.6 \mathrm{~Hz}, 1 \mathrm{H}), 4.29-4.38(\mathrm{~m}, 2 \mathrm{H}), 3.64(\mathrm{~s}, 3 \mathrm{H}), 3.45-3.52$ (m, 2 $\mathrm{H}), 2.21-2.31(\mathrm{~m}, 1 \mathrm{H}), 1.41(\mathrm{~s}, 3 \mathrm{H}), 1.21(\mathrm{~s}, 3 \mathrm{H}), 1.10(\mathrm{~s}, 9 \mathrm{H}) ;{ }^{13} \mathrm{C} \mathrm{NMR}\left(150 \mathrm{MHz}, \mathrm{CDCl}_{3}\right)$ $\delta 168.0,163.3,155.4,113.7,97.5,96.7(\mathrm{~d}, J=178.8 \mathrm{~Hz}), 84.4,80.1,72.9,58.6(\mathrm{~d}, J=15.8$ $\mathrm{Hz}), 57.8(\mathrm{~d}, J=6.5 \mathrm{~Hz}), 57.4,49.8(\mathrm{~d}, J=17.2 \mathrm{~Hz}), 27.2\left(3 \times \mathrm{CH}_{3}\right.$-tert-butyl), 27.1, 24.6; UV $(\mathrm{MeOH}) \lambda_{\max } 243.14 \mathrm{~nm}$; HRMS $\left(\mathrm{ESI}^{+}\right)$found 389.2088 [calcd for $\mathrm{C}_{18} \mathrm{H}_{30} \mathrm{FN}_{2} \mathrm{O}_{6}{ }^{+}(\mathrm{M}+\mathrm{H})^{+}$ 389.2088].

(E)-N-(((3aS,4S,5S,6R,6aR)-6-(tert-Butoxymethyl)-5-fluoro-2,2-dimethyltetrahydro-4Hcyclopenta $[d][1,3]$ dioxol-4-yl)carbamoyl)-3-methoxyacrylamide $(\mathbf{2 2 b})$. Yield $=88 \%$; colorless syrup; $[\alpha]_{\mathrm{D}}{ }^{25}=-20.47(c 0.34, \mathrm{MeOH}) ;{ }^{1} \mathrm{H}$ NMR $\left(500 \mathrm{MHz}, \mathrm{CDCl}_{3}\right) \delta 10.33(\mathrm{~s}, 1 \mathrm{H})$, $8.96(\mathrm{~d}, J=7.4 \mathrm{~Hz}, 1 \mathrm{H}), 7.63(\mathrm{~d}, J=12.3 \mathrm{~Hz}, 1 \mathrm{H}), 5.39$ (d, $J=12.3 \mathrm{~Hz}, 1 \mathrm{H}), 4.80(\mathrm{dt}, J=$ 6.4, $52.5 \mathrm{~Hz}, 1 \mathrm{H}), 4.44(\mathrm{t}, J=5.5 \mathrm{~Hz}, 1 \mathrm{H}), 4.33-4.41(\mathrm{~m}, 2 \mathrm{H}), 3.67(\mathrm{~s}, 3 \mathrm{H}), 3.46(\mathrm{~d}, J=32.5$ $\mathrm{Hz}, 2 \mathrm{H}), 2.33-2.42(\mathrm{~m}, 1 \mathrm{H}), 1.46(\mathrm{~s}, 3 \mathrm{H}), 1.24(\mathrm{~s}, 3 \mathrm{H}), 1.13(\mathrm{~s}, 9 \mathrm{H}) ;{ }^{13} \mathrm{C}$ NMR $(150 \mathrm{MHz}$, $\left.\mathrm{CDCl}_{3}\right) \delta 168.1,163.2,155.5,111.9,97.9(\mathrm{~d}, J=187.4 \mathrm{~Hz}), 97.5,83.3(\mathrm{~d}, J=7.2 \mathrm{~Hz}), 79.0(\mathrm{~d}$, $J=6.5 \mathrm{~Hz}), 73.1,61.9(\mathrm{~d}, J=23.7 \mathrm{~Hz}), 58.6(\mathrm{~d}, J=2.1 \mathrm{~Hz}), 57.4,49.9(\mathrm{~d}, J=19.4 \mathrm{~Hz}), 27.3$

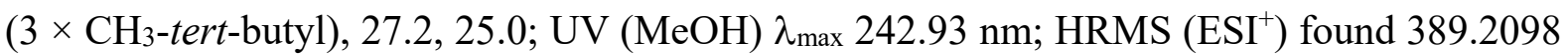
[calcd for $\mathrm{C}_{18} \mathrm{H}_{30} \mathrm{FN}_{2} \mathrm{O}_{6}{ }^{+}(\mathrm{M}+\mathrm{H})^{+} 389.2088$ ]

(E)-N-(((3aS,4S,6R,6aR)-6-(tert-Butoxymethyl)-5,5-difluoro-2,2-dimethyltetrahydro-4Hcyclopenta $[\boldsymbol{d}][\mathbf{1 , 3}]$ dioxol-4-yl)carbamoyl)-3-methoxyacrylamide $\quad(22 \mathrm{c})$. Yield $=90 \%$; colorless syrup; $[\alpha]_{\mathrm{D}}{ }^{25}=-40.41(c 0.52, \mathrm{MeOH}) ;{ }^{1} \mathrm{H}$ NMR $\left(500 \mathrm{MHz}, \mathrm{CDCl}_{3}\right) \delta 10.26(\mathrm{~s}$, $1 \mathrm{H}), 9.11(\mathrm{~d}, J=8.7 \mathrm{~Hz}, 1 \mathrm{H}), 7.65(\mathrm{~d}, J=12.3 \mathrm{~Hz}, 1 \mathrm{H}), 5.37(\mathrm{~d}, J=12.4 \mathrm{~Hz}, 1 \mathrm{H}), 4.52-4.62$ (m, $1 \mathrm{H}), 4.39$ (s, $2 \mathrm{H}), 3.67$ (s, $3 \mathrm{H}), 3.53-3.60(\mathrm{~m}, 2 \mathrm{H}), 2.57-2.68(\mathrm{~m}, 1 \mathrm{H}), 1.47$ (s, $3 \mathrm{H}), 1.27$ (s, $3 \mathrm{H}), 1.16(\mathrm{~s}, 9 \mathrm{H}) ;{ }^{13} \mathrm{C} \mathrm{NMR}\left(125 \mathrm{MHz}, \mathrm{CDCl}_{3}\right) \delta 167.9,163.4,155.7,126.9(\mathrm{dd}, J=252.9$, 
$261.3 \mathrm{~Hz}), 112.4,97.4,82.5(\mathrm{~d}, J=6.9 \mathrm{~Hz}), 78.6(\mathrm{~d}, J=4.9 \mathrm{~Hz}), 73.5,60.6(\mathrm{dd}, J=19.4,29.2$ Hz), $57.4(\mathrm{~d}, J=6.1 \mathrm{~Hz}), 57.3,50.8(\mathrm{t}, J=20.8 \mathrm{~Hz}), 27.1$ (3 $\times \mathrm{CH}_{3}$-tert-butyl), 27.0, 24.9; UV $(\mathrm{MeOH}) \lambda_{\max } 242.22 \mathrm{~nm} ; \quad$ HRMS (ESI+) found 407.1991 [calcd for $\mathrm{C}_{18} \mathrm{H}_{29} \mathrm{~F}_{2} \mathrm{~N}_{2} \mathrm{O}_{6}{ }^{+}(\mathrm{M}+\mathrm{H})^{+}$ 407.1994].

General procedure for the synthesis of $\mathbf{2 f - h}$. To a stirred solution of $\mathbf{2 2 a - c}$ in 1,4-dioxane (3 $\mathrm{mL}, 2.5 \mathrm{M}) 2 \mathrm{M}$ sulfuric acid $(0.3 \mathrm{~mL})$ was dropwise added. After refluxing with stirring for 1 $\mathrm{h}$, the reaction mixture was cooled to room temperature and neutralized with DOWEX 66 ionexchange resin. The mixture was filtered, and evaporated. The residue was purified by column chromatography (silica gel, $\mathrm{CH}_{2} \mathrm{Cl}_{2} / \mathrm{MeOH}, 9 / 1$ ) to give $\mathbf{2} \mathbf{f}-\mathbf{h}$, respectively.

1-((1S,2R,3R,4R,5S)-2-Fluoro-4,5-dihydroxy-3-(hydroxymethyl)cyclopentyl)pyrimidine2,4(1H,3H)-dione (2f). Yield = 56\%; white solid; mp $112-118{ }^{\circ} \mathrm{C} ;[\alpha]_{\mathrm{D}}{ }^{25}=-77.11(c$ 0.20, $\mathrm{MeOH}) ;{ }^{1} \mathrm{H}$ NMR $\left(500 \mathrm{MHz}, \mathrm{CD}_{3} \mathrm{OD}\right) \delta 7.70(\mathrm{dd}, J=1.1,8.1 \mathrm{~Hz}, 1 \mathrm{H}), 5.69(\mathrm{~d}, J=8.0 \mathrm{~Hz}, 1$ H), $5.10(\mathrm{dt}, J=4.1,55.3 \mathrm{~Hz}, 1 \mathrm{H}), 4.91$ (dd, $J=3.4,10.2 \mathrm{~Hz}, 1 \mathrm{H}$, merged with solvent peak), $4.46(\mathrm{dd}, J=6.6,10.1 \mathrm{~Hz}, 1 \mathrm{H}), 3.93$ (t, $J=4.8 \mathrm{~Hz}, 1 \mathrm{H}), 3.70-3.80$ (m, $2 \mathrm{H}), 3.69$ (s, $1 \mathrm{H})$, 2.29-2.41 (m, $1 \mathrm{H}) ;{ }^{13} \mathrm{C}$ NMR (125 MHz, CD $\left.3 \mathrm{OD}\right) \delta 166.9,154.2,145.5(\mathrm{~d}, J=3.8 \mathrm{~Hz}), 102.7$, $93.0(\mathrm{~d}, J=180.1 \mathrm{~Hz}), 72.4,71.7,64.4(\mathrm{~d}, J=16.6 \mathrm{~Hz}), 60.6(\mathrm{~d}, J=11.4 \mathrm{~Hz}), 53.8(\mathrm{~d}, J=17.9$ $\mathrm{Hz}) ;{ }^{19} \mathrm{~F}$ NMR $\left(378 \mathrm{MHz}, \mathrm{CD}_{3} \mathrm{OD}\right) \delta-208.9(\mathrm{dt}, J=29.9,59.7 \mathrm{~Hz}) ; \mathrm{UV}(\mathrm{MeOH}) \lambda_{\max } 264.11$ nm; HRMS (ESI+) found 261.0886 [calcd for $\mathrm{C}_{10} \mathrm{H}_{14} \mathrm{FN}_{2} \mathrm{O}_{5}{ }^{+}(\mathrm{M}+\mathrm{H})^{+}$261.0887]; Anal. Calcd for $\mathrm{C}_{10} \mathrm{H}_{13} \mathrm{FN}_{2} \mathrm{O}_{5}$ : C, 46.16; H, 5.04; N, 10.77. Found: C, 45.98; H, 5.44; N, 10.98 .

1-((1S,2S,3R,4R,5S)-2-Fluoro-4,5-dihydroxy-3-(hydroxymethyl)cyclopentyl)pyrimidine2,4(1H,3H)-dione (2g). Yield $=53 \%$; white solid; mp $195-200{ }^{\circ} \mathrm{C} ;[\alpha]_{\mathrm{D}}{ }^{25}=-16.89(c 0.35$, $\mathrm{MeOH}) ;{ }^{1} \mathrm{H}$ NMR $\left(500 \mathrm{MHz}, \mathrm{CD}_{3} \mathrm{OD}\right) \delta 7.60(\mathrm{~d}, J=7.9 \mathrm{~Hz}, 1 \mathrm{H}), 5.69(\mathrm{~d}, J=7.9 \theta \mathrm{Hz}, 1 \mathrm{H})$, 5.07-5.21 (ddd, $J=5.10,6.85,55.2 \mathrm{~Hz}, 1 \mathrm{H}), 4.61-4.69$ (ddd, $J=7.35,8.75,22.6 \mathrm{~Hz}, 1 \mathrm{H})$, 
$4.32(\mathrm{dd}, J=5.25,9.0 \theta \mathrm{Hz}, 1 \mathrm{H}), 3.98(\mathrm{t}, J=3.75 \mathrm{~Hz}, 1 \mathrm{H}), 3.70(\mathrm{~m}, 2 \mathrm{H}), 2.24(\mathrm{~m}, 1 \mathrm{H}) ;{ }^{13} \mathrm{C}$ NMR $\left(125 \mathrm{MHz}, \mathrm{CDCl}_{3}\right) \delta 167.1,153.6,147.4,103.5,94.8(\mathrm{~d}, J=183.9 \mathrm{~Hz}), 73.4(\mathrm{~d}, J=7.3$ $\mathrm{Hz}), 73.1(\mathrm{~d}, J=22.0 \mathrm{~Hz}), 72.7(\mathrm{~d}, J=3.5 \mathrm{~Hz}), 62.3(\mathrm{~d}, J=1.8 \mathrm{~Hz}), 54.1(\mathrm{~d}, J=18.9 \mathrm{~Hz}) ;{ }^{19} \mathrm{~F}$ NMR (378 MHz, CD $\left.{ }_{3} \mathrm{OD}\right) \delta-184.3(\mathrm{dt}, J=23.8,53.7 \mathrm{~Hz})$; UV (MeOH) $\lambda \max 265.33 \mathrm{~nm}$; HRMS (ESI+) found 261.0894 [calcd for $\mathrm{C}_{10} \mathrm{H}_{14} \mathrm{FN}_{2} \mathrm{O}_{5}{ }^{+}(\mathrm{M}+\mathrm{H})^{+}$261.0887]; Anal. Calcd for $\mathrm{C}_{10} \mathrm{H}_{13} \mathrm{FN}_{2} \mathrm{O}_{5}: \mathrm{C}, 46.16 ; \mathrm{H}, 5.04 ; \mathrm{N}, 10.77$. Found: $\mathrm{C}, 46.24 ; \mathrm{H}, 5.23 ; \mathrm{N}, 10.78$.

\section{1-((1S,3R,4R,5S)-2,2-Difluoro-4,5-dihydroxy-3-(hydroxymethyl)cyclopentyl)pyrimidine-}

2,4(1H,3H)-dione (2h). Yield $=52 \%$; white solid; mp 164-169 ${ }^{\circ} \mathrm{C} ;[\alpha]_{\mathrm{D}}^{25}=-31.06(c 0.30$, $\mathrm{MeOH}) ;{ }^{1} \mathrm{H}$ NMR $\left(500 \mathrm{MHz}, \mathrm{CD}_{3} \mathrm{OD}\right) \delta 7.67(\mathrm{dd}, J=2.35,8.15 \mathrm{~Hz}, 1 \mathrm{H}) 5.71(\mathrm{~d}, J=8.05 \mathrm{~Hz}$, $1 \mathrm{H}), 5.36,(\mathrm{dt}, J=10.3,17.7 \mathrm{~Hz}, 1 \mathrm{H}), 4.41(\mathrm{dd}, J=5.15,10.7 \mathrm{~Hz}, 1 \mathrm{H}), 4.07(\mathrm{~m}, 1 \mathrm{H}), 3.73-$ $3.82(\mathrm{~m}, 2 \mathrm{H}), 2.53(\mathrm{~m}, 1 \mathrm{H}) ;{ }^{13} \mathrm{C}$ NMR $\left(150 \mathrm{MHz}, \mathrm{CD}_{3} \mathrm{OD}\right) \delta 166.6,154.1,145.3(\mathrm{~d}, J=4.3$ $\mathrm{Hz}), 126.8(\mathrm{dd}, J=252.8,258.5 \mathrm{~Hz}), 103.4,72.5(\mathrm{~d}, J=7.9 \mathrm{~Hz}), 71.8(\mathrm{~d}, J=2.9 \mathrm{~Hz}), 64.4(\mathrm{dd}$, $J=18.7,25.1 \mathrm{~Hz}), 59.5(\mathrm{~d}, J=11.5 \mathrm{~Hz}), 56.3(\mathrm{t}, J=20.1 \mathrm{~Hz}) ;{ }^{19} \mathrm{~F} \mathrm{NMR}\left(378 \mathrm{MHz}, \mathrm{CD}_{3} \mathrm{OD}\right)$ $\delta-96.6(\mathrm{~d}, J=238.9 \mathrm{~Hz}),-116.9(\mathrm{dt}, J=15.1,238.5 \mathrm{~Hz}) ; \mathrm{UV}(\mathrm{MeOH}) \lambda \max 262.41 \mathrm{~nm}$; HRMS (ESI+) found 279.0801 [calcd for $\mathrm{C}_{10} \mathrm{H}_{13} \mathrm{~F}_{2} \mathrm{~N}_{2} \mathrm{O}_{5}{ }^{+}(\mathrm{M}+\mathrm{H})^{+}$279.0793]; Anal. Calcd for $\mathrm{C}_{10} \mathrm{H}_{12} \mathrm{~F}_{2} \mathrm{~N}_{2} \mathrm{O}_{5}: \mathrm{C}, 43.17 ; \mathrm{H}, 4.35 ; \mathrm{N}, 10.07$. Found: $\mathrm{C}, 43.34 ; \mathrm{H}, 4.67 ; \mathrm{N}, 9.94$.

\section{General procedure for the synthesis of $2 \mathbf{i}$ and $2 \mathbf{j}$.}

Benzoylation. To a cooled $\left(0{ }^{\circ} \mathrm{C}\right)$ solution of $\mathbf{2 f}$ or $\mathbf{2 h}\left(1\right.$ equiv) in $\mathrm{CH}_{2} \mathrm{Cl}_{2}(0.07 \mathrm{M})$, benzoyl chloride ( 6 equiv) and pyridine ( 6.7 equiv) were added in a $\mathrm{N}_{2}$ atmosphere. After being stirred for $15 \mathrm{~h}$ at room temperature, the reaction mixture was quenched with $\mathrm{H}_{2} \mathrm{O}$ and extracted with $\mathrm{CH}_{2} \mathrm{Cl}_{2}$. The organic layers were combined and washed with $\mathrm{H}_{2} \mathrm{O}$ followed by brine, dried over $\mathrm{MgSO}_{4}$, filtered and evaporated. The residue was purified with column chromatography (silica gel, hexane/EtOAc, 1/1) to give the benzoylated intermediate. 
Introduction of Triazole. To a cooled $\left(0^{\circ} \mathrm{C}\right)$ suspension of $1,2,4-$ triazole (10 equiv) in anhydrous $\mathrm{MeCN}$ (0.6 M), phosphoryl chloride (10 equiv) was added dropwise in a $\mathrm{N}_{2}$ atmosphere. After stirring, the benzoylated intermediate (1 equiv) in $\operatorname{MeCN}(0.14 \mathrm{M})$, followed by trimethylamine (10 equiv), were added to the reaction mixture. After additional stirring at room temperature for $15 \mathrm{~h}$, the reaction mixture was evaporated. The reaction mixture was diluted with $\mathrm{CH}_{2} \mathrm{Cl}_{2}$ and $\mathrm{H}_{2} \mathrm{O}$. The layers were separated, and the organic layers were washed with $\mathrm{H}_{2} \mathrm{O}$, dried over $\mathrm{MgSO}_{4}$, filtered and evaporated.

Amination. In the sealed glass tube, above-generated intermediate in 1,4-dioxane $(0.06 \mathrm{M})$ was added excess saturated aqueous ammonia at room temperature. After being stirred at the same temperature for $2 \mathrm{~h}$, the reaction mixture was evaporated and purified with flash chromatography (silica gel, $\mathrm{CH}_{2} \mathrm{Cl}_{2} / \mathrm{MeOH}, 7 / 1$ ) to give the benzoyl protected cytosine intermediate.

Benzoyl deprotection. In a sealed glass tube, the above-generated benzoyl protected cytosine intermediate in $\mathrm{MeOH}(0.2 \mathrm{M})$ was added saturated ammonia in $\mathrm{MeOH}(0.2 \mathrm{M})$. After being stirred at the same temperature for $2 \mathrm{~d}$, the reaction mixture was evaporated and diluted with $\mathrm{H}_{2} \mathrm{O}$ and $\mathrm{CH}_{2} \mathrm{Cl}_{2}$. The layers were separated, and the $\mathrm{H}_{2} \mathrm{O}$ layers were washed with $\mathrm{CH}_{2} \mathrm{Cl}_{2} 10$ times and evaporated to give $\mathbf{2} \mathbf{i}$ and $\mathbf{2} \mathbf{j}$, respectively.

\section{4-Amino-1-((1S,2R,3R,4R,5S)-2-fluoro-4,5-dihydroxy-3-}

(hydroxymethyl)cyclopentyl)pyrimidin-2(1H)-one (2i). Yield = 17\%; white solid; mp 230$233^{\circ} \mathrm{C} ;[\alpha]_{\mathrm{D}}{ }^{25}=-84.26(c 0.20, \mathrm{MeOH}) ;{ }^{1} \mathrm{H}$ NMR $\left(800 \mathrm{MHz}, \mathrm{CD}_{3} \mathrm{OD}\right) \delta 7.67(\mathrm{dd}, J=1.3,7.5$ $\mathrm{Hz}, 1 \mathrm{H}), 5.88(\mathrm{~d}, J=7.4 \mathrm{~Hz}, 1 \mathrm{H}), 5.23(\mathrm{dt}, J=3.7,55.4 \mathrm{~Hz}, 1 \mathrm{H}), 4.93$ (ddd, $J=3.4,10.3$, $30.4 \mathrm{~Hz}, 1 \mathrm{H}), 4.44(\mathrm{dd}, J=6.6,10.3 \mathrm{~Hz}, 1 \mathrm{H}), 3.92(\mathrm{dd}, J=4.5,6.3 \mathrm{~Hz}, 1 \mathrm{H}), 3.71-3.78$ (m, 2 $\mathrm{H}), 2.31-2.40(\mathrm{~m}, 1 \mathrm{H}) ;{ }^{13} \mathrm{C} \mathrm{NMR}\left(200 \mathrm{MHz}, \mathrm{CDCl}_{3}\right) \delta 168.3,160.3,145.7(\mathrm{~d}, J=3.1 \mathrm{~Hz})$, 96.2, $93.0(\mathrm{~d}, J=179.9 \mathrm{~Hz}), 72.5,71.8,65.3(\mathrm{~d}, J=16.6 \mathrm{~Hz}), 60.7(\mathrm{~d}, J=11.3 \mathrm{~Hz}), 53.9(\mathrm{~d}, J$ 
$=17.9 \mathrm{~Hz}) ;{ }^{19} \mathrm{~F} \mathrm{NMR}\left(376 \mathrm{MHz}, \mathrm{CD}_{3} \mathrm{OD}\right) \delta-209.4(\mathrm{dt}, J=29.3,53.4 \mathrm{~Hz}) ; \mathrm{UV}(\mathrm{MeOH}) \lambda_{\max }$ $274.67 \mathrm{~nm}$; HRMS (ESI+) found 260.1041 [calcd for $\mathrm{C}_{10} \mathrm{H}_{15} \mathrm{FN}_{3} \mathrm{O}_{4}{ }^{+}(\mathrm{M}+\mathrm{H})^{+} 260.1047$; ; Anal. Calcd for $\mathrm{C}_{10} \mathrm{H}_{14} \mathrm{FN}_{3} \mathrm{O}_{4}$ : C, 46.33; H, 5.44; N, 16.21. Found: C, 46.71; H, 5.12; N, 15.99.

\section{4-Amino-1-((1S,3R,4R,5S)-2,2-difluoro-4,5-dihydroxy-3}

(hydroxymethyl)cyclopentyl)pyrimidin-2(1H)-one (2j). Yield = 20\%; white solid; mp 242$245{ }^{\circ} \mathrm{C} ;[\alpha]_{\mathrm{D}}^{25}=-39.85(c 0.30, \mathrm{MeOH}) ;{ }^{1} \mathrm{H}$ NMR $\left(500 \mathrm{MHz}, \mathrm{CD}_{3} \mathrm{OD}\right) \delta 7.62(\mathrm{dd}, J=7.45$, $2.35 \mathrm{~Hz}, 1 \mathrm{H}), 5.90$ (d, $J=7.40 \mathrm{~Hz}, 1 \mathrm{H}), 5.51(\mathrm{dt}, J=18.2,10.0 \mathrm{~Hz}, 1 \mathrm{H}), 4.37(\mathrm{dd}, J=10.6$, $5.25 \mathrm{~Hz}, 1 \mathrm{H}), 4.06(\mathrm{~m}, 1 \mathrm{H}), 3.73-3.83(\mathrm{~m}, 2 \mathrm{H}), 2.54(\mathrm{~m}, 1 \mathrm{H}) ;{ }^{13} \mathrm{C} \mathrm{NMR}\left(150 \mathrm{MHz}, \mathrm{CD}_{3} \mathrm{OD}\right)$ $\delta 168.2,160.1,145.7(\mathrm{~d}, J=3.6 \mathrm{~Hz}), 126.9(\mathrm{dd}, J=252.1,259.2 \mathrm{~Hz}), 96.8,72.9(\mathrm{~d}, J=8.6$ Hz), $71.7(\mathrm{~d}, J=3.6 \mathrm{~Hz}), 65.1(\mathrm{dd}, J=18.7,23.0 \mathrm{~Hz}), 59.6(\mathrm{~d}, J=10.8 \mathrm{~Hz}), 56.3(\mathrm{t}, J=20.1$ $\mathrm{Hz}) ;{ }^{19} \mathrm{~F}$ NMR $\left(378 \mathrm{MHz}, \mathrm{CD}_{3} \mathrm{OD}\right) \delta-97.4(\mathrm{~d}, J=235.9 \mathrm{~Hz}),-117.4(\mathrm{dt}, J=14.7,238.9 \mathrm{~Hz})$; $\mathrm{UV}(\mathrm{MeOH}) \lambda_{\max } 272.27,237.93 \mathrm{~nm}$; HRMS (ESI+) found 278.0954 [calcd for $\mathrm{C}_{10} \mathrm{H}_{14} \mathrm{~F}_{2} \mathrm{~N}_{3} \mathrm{O}_{4}{ }^{+}$ $(\mathrm{M}+\mathrm{H})^{+}$278.0952]; Anal. Calcd for $\mathrm{C}_{10} \mathrm{H}_{13} \mathrm{~F}_{2} \mathrm{~N}_{3} \mathrm{O}_{4}: \mathrm{C}, 43.32 ; \mathrm{H}, 4.73 ; \mathrm{N}, 15.16$. Found: $\mathrm{C}$, 43.56; H, 4.56; N, 15.44 .

\section{General procedure for the synthesis of 24, 27a and $27 \mathrm{~b}$.}

To a cooled $\left(0{ }^{\circ} \mathrm{C}\right)$ suspension of $\mathbf{2 c}, \mathbf{2} \mathbf{f}$ and $\mathbf{2 h}(1$ equiv) in acetone $(0.005 \mathrm{M})$ was added $1-2$ drops of $\mathrm{CH}_{2} \mathrm{SO}_{4}$ in $\mathrm{N}_{2}(\mathrm{~g})$. After being stirred at room temperature for $4 \mathrm{~h}$, the reaction mixture was neutralized with solid $\mathrm{NaHCO}_{3}$, filtered, and evaporated under reduced pressure. The residue was further purified by silica gel column chromatography to give $\mathbf{2 4}, \mathbf{2 7}$ a and $\mathbf{2 7 b}$, respectively.

((3a $R, 4 R, 6 S, 6 a S)-6-(6-A m i n o-9 H-p u r i n-9-y l)-5,5-d i f l u o r o-2,2-d i m e t h y l t e t r a h y d r o-4 H-$ cyclopenta[d][1,3]dioxol-4-yl)methanol (24). Yield = 96\%; colorless syrup; ${ }^{1} \mathrm{H}$ NMR (500 $\left.\mathrm{MHz}, \mathrm{CD}_{3} \mathrm{OD}\right) \delta 8.31(\mathrm{~s}, 1 \mathrm{H}), 8.21(\mathrm{~s}, 1 \mathrm{H}), 5.30-5.40(\mathrm{~m}, 2 \mathrm{H}), 4.70$ (br s, $\left.1 \mathrm{H}\right), 3.94$ (dd, $J=$ 
6.8, $11.4 \mathrm{~Hz}, 1 \mathrm{H}), 3.86(\mathrm{dd}, J=6.8,11.4 \mathrm{~Hz}, 1 \mathrm{H}), 2.81-2.90(\mathrm{~m}, 1 \mathrm{H}), 1.58(\mathrm{~s}, 3 \mathrm{H}), 1.35$ (s, $3 \mathrm{H}) ;{ }^{13} \mathrm{C}$ NMR $\left(125 \mathrm{MHz}, \mathrm{CD}_{3} \mathrm{OD}\right) \delta 163.5(\mathrm{dd}, J=33.1,69.2 \mathrm{~Hz}), 156.5,152.2,152.0,143.4$, $128.0(\mathrm{dd}, J=251.7,263.6 \mathrm{~Hz}), 116.0,80.7(\mathrm{~d}, J=7.3 \mathrm{~Hz}), 79.6(\mathrm{~d}, J=8.3 \mathrm{~Hz}), 66.1(\mathrm{dd}, J=$ 19.2, 22.8 Hz), $\left.59.2(\mathrm{~d}, J=8.0 \mathrm{~Hz}), 53.8(\mathrm{t}, J=19.4 \mathrm{~Hz}), 28.2,25.9 ; \mathrm{HRMS}_{(\mathrm{ESI}}^{+}\right)(\mathrm{m} / \mathrm{z})$ found 342.1370, [calcd for $\mathrm{C}_{14} \mathrm{H}_{18} \mathrm{~F}_{2} \mathrm{~N}_{5} \mathrm{O}_{3}{ }^{+}(\mathrm{M}+\mathrm{H})^{+}$342.1372]; Anal. Calcd for $\mathrm{C}_{14} \mathrm{H}_{17} \mathrm{~F}_{2} \mathrm{~N}_{5} \mathrm{O}_{3}$ : C, 49.27; H, 5.02; N, 20.52. Found: C, 49.28; H, 4.98; N, 20.91.

1-((3aS,4S,5R,6R,6aR)-5-Fluoro-6-(hydroxymethyl)-2,2-dimethyltetrahydro-4Hcyclopenta[d][1,3]dioxol-4-yl)pyrimidine-2,4(1H,3H)-dione (27a). Yield = 98\%; colorless syrup; ${ }^{1} \mathrm{H}$ NMR $\left(500 \mathrm{MHz}, \mathrm{CD}_{3} \mathrm{OD}\right) \delta 7.75(\mathrm{dd}, J=1.4,8.1 \mathrm{~Hz}, 1 \mathrm{H}), 5.70(\mathrm{~d}, J=8.1 \mathrm{~Hz}, 1$ H), $5.20(\mathrm{dt}, J=3.1,54.1 \mathrm{~Hz}, 1 \mathrm{H}), 5.01-5.13(\mathrm{~m}, 2 \mathrm{H}), 4.58(\mathrm{~d}, J=6.3 \mathrm{~Hz}, 1 \mathrm{H}), 3.73-3.83(\mathrm{~m}$, $2 \mathrm{H}), 2.42-2.56(\mathrm{~m}, 1 \mathrm{H}), 1.50(\mathrm{~s}, 3 \mathrm{H}), 1.32(\mathrm{~s}, 3 \mathrm{H}) ;{ }^{13} \mathrm{C} \mathrm{NMR}\left(125 \mathrm{MHz}, \mathrm{CD}_{3} \mathrm{OD}\right) \delta$ 166.7, $153.7,145.3(\mathrm{~d}, J=5.9 \mathrm{~Hz}), 116.5,103.2,99.2(\mathrm{~d}, J=180.2 \mathrm{~Hz}), 82.2,82.0,65.0(\mathrm{~d}, J=15.7$ $\left.\mathrm{Hz}), 60.3(\mathrm{~d}, J=8.7 \mathrm{~Hz}), 53.2(\mathrm{~d}, J=17.7 \mathrm{~Hz}), 28.4,25.9 ; \mathrm{HRMS}_{(\mathrm{ESI}}{ }^{+}\right)(\mathrm{m} / \mathrm{z})$ found 301.1185, [calcd for $\mathrm{C}_{13} \mathrm{H}_{18} \mathrm{FN}_{2} \mathrm{O}_{5}{ }^{+}(\mathrm{M}+\mathrm{H})^{+}$301.1194]; Anal. Calcd for $\mathrm{C}_{13} \mathrm{H}_{17} \mathrm{FN}_{2} \mathrm{O}_{5}$ : C, 52.00; H, 5.71; N, 9.33. Found: C, 52.15; H, 5.47; N, 9.15.

\section{1-((3aS,4S,6R,6aR)-5,5-Difluoro-6-(hydroxymethyl)-2,2-dimethyltetrahydro-4H-}

cyclopenta[d][1,3]dioxol-4-yl)pyrimidine-2,4(1H,3H)-dione (27b). Yield = 97\%; ${ }^{1} \mathrm{H}$ NMR $\left(500 \mathrm{MHz}, \mathrm{CD}_{3} \mathrm{OD}\right) \delta 7.71(\mathrm{dd}, J=2.0,8.1 \mathrm{~Hz}, 1 \mathrm{H}), 5.73(\mathrm{~d}, J=8.1 \mathrm{~Hz}, 1 \mathrm{H}), 5.33(\mathrm{dt}, J=$ 6.8, 21.3 Hz, $1 \mathrm{H}), 4.94(\mathrm{~d}, J=6.8 \mathrm{~Hz}, 1 \mathrm{H}), 4.57-4.63(\mathrm{~m}, 1 \mathrm{H}), 3.88$ (dd, $J=6.7,11.4 \mathrm{~Hz}, 1$ H), $3.81(\mathrm{dd}, J=6.7,11.4 \mathrm{~Hz}, 1 \mathrm{H}), 2.68-2.79(\mathrm{~m}, 1 \mathrm{H}), 1.54(\mathrm{~s}, 3 \mathrm{H}), 1.34$ (s, $3 \mathrm{H})$; HRMS $\left(\mathrm{ESI}^{+}\right)(\mathrm{m} / \mathrm{z})$ found 319.1104, [calcd for $\mathrm{C}_{13} \mathrm{H}_{17} \mathrm{~F}_{2} \mathrm{~N}_{2} \mathrm{O}_{5}{ }^{+}(\mathrm{M}+\mathrm{H})^{+}$319.1100]; Anal. Calcd for $\mathrm{C}_{13} \mathrm{H}_{16} \mathrm{~F}_{2} \mathrm{~N}_{2} \mathrm{O}_{5}: \mathrm{C}, 49.06 ; \mathrm{H}, 5.07 ; \mathrm{N}, 8.80$. Found: C, 49.43; H, 5.47; N, 8.43.

Synthesis of tert-Butyl-(9-((3aS,4S,6R,6aR)-5,5-difluoro-6-(hydroxymethyl)-2,2dimethyltetrahydro-4H-cyclopenta[ $d][1,3]$ dioxol-4-yl)-9H-purin-6-yl)carbamate $\quad$ (25a) 
and its $\boldsymbol{N}^{6}$-di-Boc derivative (25b). To a suspension of $24(20 \mathrm{mg}, 0.058 \mathrm{mmol})$ and 4 dimethylaminopyridine $(1 \mathrm{mg}, 0.0058 \mathrm{mmol})$ in hexamethyldisilazane $(3 \mathrm{~mL})$, trimethylsilyl trifluoromethanesulfonate $(5 \mu \mathrm{L})$ was added dropwise at room temperature in a $\mathrm{N}_{2}$ atmosphere (g). After being heated to $75^{\circ} \mathrm{C}$ with stirring for $2 \mathrm{~h}$, the reaction mixture was evaporated, and anhydrous THF $(7 \mathrm{~mL})$ was added. To a cooled $\left(0{ }^{\circ} \mathrm{C}\right)$ reaction mixture, di- $t$-butyl dicarbonate (63 mg, $0.29 \mathrm{mmol}$ ) was added. After stirring for $4 \mathrm{~h}$ at room temperature, the reaction mixture was evaporated, and the residue was added to $\mathrm{MeOH} /$ trimethylamine $(6 \mathrm{~mL}, 5: 1(\mathrm{v} / \mathrm{v}))$. After heating to $55{ }^{\circ} \mathrm{C}$ with stirring for $16 \mathrm{~h}$, the reaction mixture was evaporated, and the residue was purified with column chromatography (silica gel, $\mathrm{CH}_{2} \mathrm{Cl}_{2} / \mathrm{MeOH}, 50 / 1$ ) to give 25a (13 $\mathrm{mg}, 52 \%)$ and $\mathbf{2 5 b}(8 \mathrm{mg}, 25 \%)$ as colorless syrup.

Compound 25a: ${ }^{1} \mathrm{H}$ NMR $\left(500 \mathrm{MHz}, \mathrm{CD}_{3} \mathrm{OD}\right) \delta 8.59(\mathrm{~s}, 1 \mathrm{H}), 8.49$ (s, $\left.1 \mathrm{H}\right), 5.36-5.50$ (m, 2 $\mathrm{H}), 4.72(\mathrm{~d}, J=5.6 \mathrm{~Hz}, 1 \mathrm{H}), 3.95(\mathrm{dd}, J=6.8,11.4 \mathrm{~Hz}, 1 \mathrm{H}), 3.87(\mathrm{dd}, J=6.8,11.4 \mathrm{~Hz}, 1 \mathrm{H})$, 2.83-2.95 (m, $1 \mathrm{H}), 1.57(\mathrm{~s}, 12 \mathrm{H}), 1.34(\mathrm{~s}, 3 \mathrm{H})$; HRMS $\left(\mathrm{ESI}^{+}\right)(\mathrm{m} / \mathrm{z})$ found 442.1899, [calcd for $\left.\mathrm{C}_{19} \mathrm{H}_{26} \mathrm{~F}_{2} \mathrm{~N}_{5} \mathrm{O}_{5}{ }^{+}(\mathrm{M}+\mathrm{H})^{+} 442.1897\right]$.

Compound 25b: ${ }^{1} \mathrm{H}$ NMR (500 MHz, $\left.\mathrm{CD}_{3} \mathrm{OD}\right) \delta 8.87$ (s, $\left.1 \mathrm{H}\right), 8.73(\mathrm{~d}, J=1.8 \mathrm{~Hz}, 1 \mathrm{H}), 5.46-$ $5.57(\mathrm{~m}, 2 \mathrm{H}), 4.75(\mathrm{~d}, J=5.4 \mathrm{~Hz}, 1 \mathrm{H}), 3.95(\mathrm{dd}, J=6.8,11.4 \mathrm{~Hz}, 1 \mathrm{H}), 3.88(\mathrm{dd}, J=6.8,11.4$ $\mathrm{Hz}, 1 \mathrm{H}), 2.84-2.95(\mathrm{~m}, 1 \mathrm{H}), 1.59(\mathrm{~s}, 3 \mathrm{H}), 1.37$ (s, $21 \mathrm{H}) ;{ }^{13} \mathrm{C} \mathrm{NMR}\left(125 \mathrm{MHz}, \mathrm{CD}_{3} \mathrm{OD}\right) \delta$ 156.2, 154.2, 152.2, $152.1(2 \times \mathrm{C}(\mathrm{O})$-Boc protection group $), 147.8(\mathrm{~d}, J=2.4 \mathrm{~Hz}), 130.6,128.1$ $(\mathrm{dd}, J=251.8,263.3 \mathrm{~Hz}), 116.0,86.1,80.4(\mathrm{~d}, J=7.4 \mathrm{~Hz}), 79.7(\mathrm{~d}, J=8.2 \mathrm{~Hz}), 72.7,66.5(\mathrm{dd}$, $J=19.1,23.1 \mathrm{~Hz}), 59.2(\mathrm{~d}, J=8.0 \mathrm{~Hz}), 53.8(\mathrm{t}, J=19.2 \mathrm{~Hz}), 28.7\left(6 \times \mathrm{CH}_{3}\right.$-tert-butyl), 28.3, 25.9; $\mathrm{HRMS}\left(\mathrm{ESI}^{+}\right)(\mathrm{m} / \mathrm{z})$ found 542.2411, [calcd for $\mathrm{C}_{24} \mathrm{H}_{34} \mathrm{~F}_{2} \mathrm{~N}_{5} \mathrm{O}_{7}^{+}(\mathrm{M}+\mathrm{H})^{+}$542.2421].

iso-Propyl ((S)-(((3aR,4R,6S,6aS)-6-(6-((tert-butoxycarbonyl)amino)-9H-purin-9-yl)-5,5difluoro-2,2-dimethyltetrahydro-4H-cyclopenta[d][1,3]dioxol-4-yl)methoxy)

(phenoxy)phosphoryl)- $L$-alaninate (26). To a stirred suspension of $\mathbf{2 5 a}$ (16 mg, $0.036 \mathrm{mmol}$ ), 
25b (7 mg, $0.012 \mathrm{mmol})$ and powdered molecular sieves (4 A, $62 \mathrm{mg})$ in anhydrous THF (20 $\mathrm{mL})$, tert-butylmagnesium chloride solution $(0.26 \mathrm{~mL}, 1.0 \mathrm{M}$ in THF, $0.26 \mathrm{mmol})$ was added at $0^{\circ} \mathrm{C}$ in a nitrogen atmosphere. After $10 \mathrm{~min}$, a solution of pentafluoro-phosphoramidate reagent A (47 mg, $0.10 \mathrm{mmol})$ in THF (12 mL) was slowly added, and the reaction mixture was stirred at room temperature for $36 \mathrm{~h}$. Then, it was quenched by the dropwise addition of methanol $(10 \mathrm{~mL})$, filtered, and evaporated. The residue was purified by column chromatography ( silica gel, $\mathrm{CH}_{2} \mathrm{Cl}_{2} / \mathrm{MeOH}, 9 / 1$ ) to give the phosphoramidate $\mathbf{2 6}$ as a colorless liquid (12 mg, 33\%): ${ }^{1} \mathrm{H}$ NMR (500 MHz, CD $\left.3 \mathrm{OD}\right) \delta 8.59(\mathrm{~s}, 1 \mathrm{H}), 8.45(\mathrm{~s}, 1 \mathrm{H}), 7.37$ (d, $J=$ $7.8 \mathrm{~Hz}, 2 \mathrm{H}), 7.25(\mathrm{~d}, J=8.1 \mathrm{~Hz}, 2 \mathrm{H}), 7.19(\mathrm{~d}, J=7.5 \mathrm{~Hz}, 1 \mathrm{H}), 5.50(\mathrm{dt}, J=5.9,22.3 \mathrm{~Hz}, 1$ H), 5.40-5.45 (m, $1 \mathrm{H}), 4.92-4.99$ (m, $1 \mathrm{H}), 4.73-4.80$ (m, $1 \mathrm{H}), 4.36-4.50$ (m, $2 \mathrm{H}), 3.86-3.98$ (m, $1 \mathrm{H}), 3.07-3.19(\mathrm{~m}, 1 \mathrm{H}), 1.58(\mathrm{~s}, 12 \mathrm{H}), 1.34(\mathrm{~s}, 6 \mathrm{H}), 1.21(\mathrm{~d}, J=6.2 \mathrm{~Hz}, 3 \mathrm{H}), 1.17(\mathrm{~d}, J$ $=6.2 \mathrm{~Hz}, 3 \mathrm{H})$; HRMS $\left(\mathrm{ESI}^{+}\right)(\mathrm{m} / \mathrm{z})$ found 711.2716, [calcd for $\mathrm{C}_{31} \mathrm{H}_{42} \mathrm{~F}_{2} \mathrm{~N}_{6} \mathrm{O}_{9} \mathrm{P}^{+}(\mathrm{M}+\mathrm{H})^{+}$ $711.2713]$

\section{iso-Propyl((S)-(((1R,3S,4S,5R)-3-(6-amino-9H-purin-9-yl)-2,2-difluoro-4,5-}

dihydroxycyclopentyl)methoxy)(phenoxy)phosphoryl)- $L$-alaninate (3a). A solution of 26 $(15 \mathrm{mg}, 0.021 \mathrm{mmol})$ in $10 \mathrm{~mL}$ of formic acid/ $\mathrm{H}_{2} \mathrm{O}(1: 1, \mathrm{v}: \mathrm{v})$ was stirred at room temperature for $8 \mathrm{~h}$. After evaporation, the crude product was purified by column chromatography (silica gel, $\left.\mathrm{CH}_{2} \mathrm{Cl}_{2} / \mathrm{MeOH}, 6 / 1\right)$ to give $3 \mathbf{a}(9.9 \mathrm{mg}, 82 \%)$ as a colorless solid: $\mathrm{mp} 95-100{ }^{\circ} \mathrm{C}$; UV $(\mathrm{MeOH}) \lambda_{\max } 259.6 \mathrm{~nm} ;[\alpha]_{\mathrm{D}}{ }^{25}=-38.06(c 0.001, \mathrm{MeOH}) ;{ }^{1} \mathrm{H}$ NMR $\left(400 \mathrm{MHz}, \mathrm{CD}_{3} \mathrm{OD}\right) \delta 8.18$ (s, $1 \mathrm{H}), 8.17(\mathrm{~d}, J=1.6 \mathrm{~Hz}, 1 \mathrm{H}), 7.35(\mathrm{~d}, J=8.4 \mathrm{~Hz}, 2 \mathrm{H}), 7.23(\mathrm{~d}, J=8.6 \mathrm{~Hz}, 2 \mathrm{H}), 7.18(\mathrm{~d}$, $J=8.0 \mathrm{~Hz}, 1 \mathrm{H}), 5.26-5.38(\mathrm{~m}, 1 \mathrm{H}), 4.81-4.98\left(\mathrm{~m}, \quad\right.$ merged with $\mathrm{H}_{2} \mathrm{O}$ peak, $\left.1 \mathrm{H}\right), 4.74(\mathrm{dd}, J$ $=4.8,10.0 \mathrm{~Hz}, 1 \mathrm{H}), 4.29-4.43(\mathrm{~m}, 2 \mathrm{H}), 7.17$ (br s, $1 \mathrm{H}), 3.82-3.93(\mathrm{~m}, 1 \mathrm{H}), 2.79-2.94(\mathrm{~m}, 1$ H), $1.32(\mathrm{~d}, J=6.8 \mathrm{~Hz}, 3 \mathrm{H}), 1.19(\mathrm{~d}, J=6.2 \mathrm{~Hz}, 3 \mathrm{H}), 1.14(\mathrm{~d}, J=6.2 \mathrm{~Hz}, 3 \mathrm{H}) ;{ }^{13} \mathrm{C} \mathrm{NMR}$ $\left(150 \mathrm{MHz}, \mathrm{CD}_{3} \mathrm{OD}\right) \delta 175.2(\mathrm{~d}, J=5.7 \mathrm{~Hz}), 158.1,154.7,153.0,152.9,152.6,142.6,131.6(2$ 
$\times$ CH-phenyl), 127.0, $124.4(\mathrm{dd}, J=253.5,260.6 \mathrm{~Hz}), 122.2(\mathrm{~d}, J=4.3 \mathrm{~Hz}), 120.6(2 \times \mathrm{CH}-$ phenyl), $73.3(\mathrm{~d}, J=7.1 \mathrm{~Hz}), 71.2(\mathrm{~d}, J=5.0 \mathrm{~Hz}), 70.9,64.6,64.1(\mathrm{dd}, J=5.0,10.7 \mathrm{~Hz}), 52.4$, $22.6\left(\mathrm{~d}, J=2.9 \mathrm{~Hz}, 2 \times \mathrm{CH}_{3}\right), 21.2(\mathrm{~d}, J=6.5 \mathrm{~Hz}) ;{ }^{19} \mathrm{~F} \mathrm{NMR}\left(376 \mathrm{MHz}, \mathrm{CD}_{3} \mathrm{OD}\right) \delta-98.71(\mathrm{~d}$, $J=238.4 \mathrm{~Hz}),-115.13(\mathrm{dt}, J=14.9,236.4 \mathrm{~Hz})$; HRMS $\left(\mathrm{ESI}^{+}\right)(\mathrm{m} / \mathrm{z})$ found 571.1889, [calcd for $\mathrm{C}_{23} \mathrm{H}_{30} \mathrm{~F}_{2} \mathrm{~N}_{6} \mathrm{O}_{7} \mathrm{P}^{+}(\mathrm{M}+\mathrm{H})^{+}$571.1876]; Anal. Calcd for $\mathrm{C}_{23} \mathrm{H}_{29} \mathrm{~F}_{2} \mathrm{~N}_{6} \mathrm{O}_{7} \mathrm{P}: \mathrm{C}, 48.42 ; \mathrm{H}, 5.12 ; \mathrm{N}$, 14.73. Found: C, 48.74; H, 4.98; N, 14.54.

iso-Propyl $\quad((S)-(((1 R, 2 R, 3 S, 4 S, 5 R)-3-(2,4-d i o x 0-3,4-d i h y d r o p y r i m i d i n-1(2 H)-y l)-2-$ fluoro-4,5-dihydroxycyclopentyl)methoxy)(phenoxy)phosphoryl)-L-alaninate (3b). Introduction of phosphoramidate. To a cooled $\left(0^{\circ} \mathrm{C}\right)$ suspension of $27 \mathbf{a}(21 \mathrm{mg}, 0.069 \mathrm{mmol})$ and molecular sieves $(4 \AA, 35 \mathrm{mg})$ in anhydrous THF $(15 \mathrm{~mL}, 0.005 \mathrm{M})$, tert-butylmagnesium chloride solution $(0.34 \mathrm{~mL}, 1.0 \mathrm{M}$ in THF, $0.34 \mathrm{mmol})$ was added dropwise in a $\mathrm{N}_{2}$ atmosphere(g). After being stirred for $5 \mathrm{~min}$, a solution of the phosphoramidate reagent $\mathbf{A}$ (31 $\mathrm{mg}, 0.069 \mathrm{mmol})$ in anhydrous THF $(7 \mathrm{~mL})$ was added dropwise, and the reaction mixture was stirred at room temperature for $36 \mathrm{~h}$, quenched with $\mathrm{MeOH}(5 \mathrm{~mL})$, filtered and evaporated, and the residue was purified by column chromatograph (silica gel, $\mathrm{CH}_{2} \mathrm{Cl}_{2} / \mathrm{MeOH}, 24 / 1$ ) to give phosphoramidate as a colorless liquid (13 mg, 33\%): ${ }^{1} \mathrm{H}$ NMR (500 MHz, $\left.\mathrm{CD}_{3} \mathrm{OD}\right) \delta 7.73$ $(\mathrm{dd}, J=1.3,8.1 \mathrm{~Hz}, 1 \mathrm{H}), 7.36(\mathrm{~d}, J=7.8 \mathrm{~Hz}, 2 \mathrm{H}), 7.24$ (d, $J=7.8 \mathrm{~Hz}, 2 \mathrm{H}), 7.19(\mathrm{~d}, J=7.4$ $\mathrm{Hz}, 1 \mathrm{H}), 5.70(\mathrm{~d}, J=8.1 \mathrm{~Hz}, 1 \mathrm{H}), 5.02-5.22(\mathrm{~m}, 3 \mathrm{H}), 4.93-5.01(\mathrm{~m}, 1 \mathrm{H}), 4.66(\mathrm{~d}, J=6.3 \mathrm{~Hz}$, $1 \mathrm{H}), 4.29(\mathrm{~d}, J=7.6 \mathrm{~Hz}, 2 \mathrm{H}), 3.87-3.95(\mathrm{~m}, 1 \mathrm{H}), 2.62-2.73(\mathrm{~m}, 1 \mathrm{H}), 1.51(\mathrm{~s}, 3 \mathrm{H}), 1.34(\mathrm{~d}$, $J=7.7 \mathrm{~Hz}, 3 \mathrm{H}), 1.32(\mathrm{~s}, 3 \mathrm{H}), 1.22(\mathrm{~d}, J=6.2 \mathrm{~Hz}, 6 \mathrm{H})$; HRMS $\left(\mathrm{ESI}^{+}\right)(\mathrm{m} / \mathrm{z})$ found 570.2003, [calcd for $\mathrm{C}_{25} \mathrm{H}_{34} \mathrm{FN}_{3} \mathrm{O}_{9} \mathrm{P}^{+}(\mathrm{M}+\mathrm{H})^{+} 570.2011$ ].

Hydrolysis. A solution of phosphoramidate $(13 \mathrm{mg}, 0.022 \mathrm{mmol})$ in a formic acid/ $\mathrm{H}_{2} \mathrm{O}$ solution $(1: 1, \mathrm{v} / \mathrm{v}, 7 \mathrm{~mL}$ total) was stirred at room temperature for $8 \mathrm{~h}$. The reaction mixture was evaporated and the residue was purified by column chromatography (silica gel, $\mathrm{CH}_{2} \mathrm{Cl}_{2} / \mathrm{MeOH}$, 
7/1) to give the phosphoramidate prodrug $3 \mathbf{b}(10.8 \mathrm{mg}, 90 \%)$ as a white solid: $\mathrm{mp} 107-110{ }^{\circ} \mathrm{C}$; $\mathrm{UV}(\mathrm{MeOH}) \lambda_{\max } 262.8 \mathrm{~nm} ;[\alpha]_{\mathrm{D}}{ }^{25}=-59.40(c 0.001, \mathrm{MeOH}) ;{ }^{1} \mathrm{H}$ NMR $\left(500 \mathrm{MHz}, \mathrm{CD}_{3} \mathrm{OD}\right)$ $\delta 7.64(\mathrm{~d}, J=8.1 \mathrm{~Hz}, 1 \mathrm{H}), 7.36(\mathrm{~d}, J=7.9 \mathrm{~Hz}, 2 \mathrm{H}), 7.23(\mathrm{~d}, J=7.9 \mathrm{~Hz}, 2 \mathrm{H}), 7.19(\mathrm{~d}, J=7.4$ Hz, $1 \mathrm{H}), 5.68(\mathrm{~d}, J=8.1 \mathrm{~Hz}, 1 \mathrm{H}), 5.04(\mathrm{dt}, J=4.1,55.4 \mathrm{~Hz}, 1 \mathrm{H}), 4.87-4.98$ (m, merged with $\mathrm{H}_{2} \mathrm{O}$ peak, $\left.2 \mathrm{H}\right), 4.45(\mathrm{dd}, J=6.6,9.7 \mathrm{~Hz}, 1 \mathrm{H}), 4.26(\mathrm{~d}, J=7.1 \mathrm{~Hz}, 2 \mathrm{H}), 3.99(\mathrm{~d}, J=5.4 \mathrm{~Hz}$, $1 \mathrm{H}), 3.85-3.93(\mathrm{~m}, 1 \mathrm{H}), 2.49-2.60(\mathrm{~m}, 1 \mathrm{H}), 1.33(\mathrm{~d}, J=7.0 \mathrm{~Hz}, 3 \mathrm{H}), 1.21(\mathrm{~d}, J=6.1 \mathrm{~Hz}, 6$ $\mathrm{H}) ;{ }^{13} \mathrm{C}$ NMR (125 MHz, CD $\left.3 \mathrm{OD}\right) \delta$ 175.2, 166.9, 154.0, 151.1, 145.4, 131.5 (2 × CH-phenyl), $126.9(2 \times$ CH-phenyl), $122.2(\mathrm{~d}, J=4.6 \mathrm{~Hz}), 102.8,93.3(\mathrm{~d}, J=184.5 \mathrm{~Hz}), 80.3,79.9(\mathrm{~d}, J=$ 32.5 Hz), 72.3, 71.2, 70.9, $64.2(\mathrm{~d}, J=16.0 \mathrm{~Hz}), 52.4,22.7\left(\mathrm{~d}, J=9.2 \mathrm{~Hz}, 2 \times \mathrm{CH}_{3}\right), 21.2(\mathrm{~d}, J$ $=6.8 \mathrm{~Hz}) ;{ }^{19} \mathrm{~F} \mathrm{NMR}\left(376 \mathrm{MHz}, \mathrm{CD}_{3} \mathrm{OD}\right) \delta-208.27(\mathrm{dt}, J=29.7,59.4 \mathrm{~Hz}) ; \mathrm{HRMS}\left(\mathrm{ESI}^{+}\right)(\mathrm{m} / \mathrm{z})$ found 530.1685, [calcd for $\mathrm{C}_{22} \mathrm{H}_{30} \mathrm{FN}_{3} \mathrm{O}_{9} \mathrm{P}^{+}(\mathrm{M}+\mathrm{H})^{+}$530.1698]; Anal. Calcd for $\mathrm{C}_{22} \mathrm{H}_{2}{ }_{2} \mathrm{FN}_{3} \mathrm{O} 9 \mathrm{P}$ : C, 49.91; H, 5.52; N, 7.94. Found: C, 50.03; H, 5.32; N, 7.54.

iso-Propyl ((S)-(((1R,3S,4S,5R)-3-(2,4-dioxo-3,4-dihydropyrimidin-1(2H)-yl)-2,2difluoro-4,5-dihydroxycyclopentyl)methoxy)(phenoxy)phosphoryl)- $L$-alaninate (3c).

Compound 3c was synthesized according the same procedure used in the preparation of $\mathbf{3 b}$ : Yield $=30 \%$; white solid; $\mathrm{mp} 174{ }^{\circ} \mathrm{C}($ decomp$) ; \mathrm{UV}(\mathrm{MeOH}) \lambda_{\max } 262.8 \mathrm{~nm} ;[\alpha]_{\mathrm{D}}{ }^{25}=-19.40$ (c $0.001, \mathrm{MeOH}) ;{ }^{1} \mathrm{H} \mathrm{NMR}\left(500 \mathrm{MHz}, \mathrm{CD}_{3} \mathrm{OD}\right) \delta 7.53(\mathrm{dd}, J=2.1,8.1 \mathrm{~Hz}, 1 \mathrm{H}), 7.36(\mathrm{~d}, J=$ $7.8 \mathrm{~Hz}, 2 \mathrm{H}), 7.25(\mathrm{~d}, J=7.8 \mathrm{~Hz}, 2 \mathrm{H}), 7.20(\mathrm{~d}, J=7.6 \mathrm{~Hz}, 1 \mathrm{H}), 5.70(\mathrm{~d}, J=8.1 \mathrm{~Hz}, 1 \mathrm{H})$, 5.29-5.39 (m, $1 \mathrm{H}), 4.93-5.02(\mathrm{~m}, 1 \mathrm{H}), 4.30-4.39(\mathrm{~m}, 2 \mathrm{H}), 4.23-4.29(\mathrm{~m}, 1 \mathrm{H}), 4.08$ (br s, 1 H), 3.84-3.92 (m, $1 \mathrm{H}), 2.69-2.80(\mathrm{~m}, 1 \mathrm{H}), 1.33(\mathrm{~d}, J=7.1 \mathrm{~Hz}, 3 \mathrm{H}), 1.22(\mathrm{~d}, J=6.2 \mathrm{~Hz}, 6 \mathrm{H})$; ${ }^{19} \mathrm{~F}$ NMR $\left(376 \mathrm{MHz}, \mathrm{CD}_{3} \mathrm{OD}\right) \delta-98.47(\mathrm{~d}, J=237.2 \mathrm{~Hz}),-116.91(\mathrm{dt}, J=17.6,237.2 \mathrm{~Hz})$; $\operatorname{HRMS}\left(\mathrm{ESI}^{+}\right)(\mathrm{m} / \mathrm{z})$ found 548.1619, [calcd for $\mathrm{C}_{22} \mathrm{H}_{29} \mathrm{~F}_{2} \mathrm{~N}_{3} \mathrm{O}_{9} \mathrm{P}^{+}(\mathrm{M}+\mathrm{H})^{+}$548.1604]; Anal. Calcd for $\mathrm{C}_{22} \mathrm{H}_{28} \mathrm{~F}_{2} \mathrm{~N}_{3} \mathrm{O} 9 \mathrm{P}: \mathrm{C}, 48.27 ; \mathrm{H}, 5.16 ; \mathrm{N}, 7.68$. Found: C, 48.12; H, 4.98; 8.01. 


\section{SAH hydrolase assay. ${ }^{18 \mathrm{e}-\mathrm{g}, 29}$}

The gene encoding human placental SAH hydrolase was cloned into expression plasmid pPROKcd20. Recombinant SAH hydrolase protein was produced in E. coli JM109 in $50 \mathrm{mM}$ Tris- $\mathrm{HCl}(\mathrm{pH} 7.5)$ containing $2 \mathrm{mM}$ EDTA and was purified by DEAE-cellulose column (2.8 $\mathrm{cm}$ x $6 \mathrm{~cm})$, ammonium sulfate fractionation (35-60\%), Sephacryl S-300HR $(1.0 \mathrm{~cm}$ x $105 \mathrm{~cm})$, and DEAE cellulose $(2.8 \mathrm{~cm} \times 24 \mathrm{~cm})$. The protein homogeneity was confirmed by $10 \%$ SDSPAGE. The protein concentration was determined by using Bradford method. Bovine serum albumin was a standard material for protein assay. Enzyme activity was determined in reaction mixtures $(250 \mu \mathrm{L})$ that contain $50 \mathrm{mM}$ sodium phosphate $(\mathrm{pH} 8.0), 2 \mu \mathrm{M}$ SAH hydrolase $(0.5$ $\mu \mathrm{M}$ tetrameric form) and varying concentrations of compounds. The reaction mixtures were first preincubated with the compounds for 10 min at $37^{\circ} \mathrm{C}$, after which the reaction was initiated by adding $100 \mu \mathrm{M}$ SAH. The reaction was allowed to proceed for $20 \mathrm{~min}$, followed by the addition of DNTB to a final concentration of $200 \mu \mathrm{M}$. The absorbance of the product 5thio-2-nitrobenzoic acid (TNB) was measured at $412 \mathrm{~nm}$ using a spectrophotometer (Varian, Cary100). The molar extinction coefficient for TNB $\left(\varepsilon_{412}=13700 \mathrm{M}^{-1} \mathrm{~cm}^{-1}\right)$ was used in calculations to quantify TNB formation.

\section{Cells, viruses and compounds}

Vero E6 and Vero CCL81 cells were maintained in Dulbecco's modified Eagle's medium (DMEM; Lonza), supplemented with 8\% fetal calf serum (FCS; PAA), 2 mM L-glutamine, 100 $\mathrm{IU} / \mathrm{ml}$ of penicillin and $100 \mu \mathrm{g} / \mathrm{ml}$ of streptomycin, and were grown at $37^{\circ} \mathrm{C}$ in a humidified incubator with 5\% CO2. Vero cells were maintained in Eagles Minimum Essential Medium (EMEM; Lonza) ), supplemented with $8 \%$ fetal calf serum (FCS; PAA), $100 \mathrm{IU} / \mathrm{ml}$ of penicillin and $100 \mu \mathrm{g} / \mathrm{ml}$ of streptomycin, and were grown at $37^{\circ} \mathrm{C}$ in a humidified incubator with $5 \%$ $\mathrm{CO} 2$ Infections were performed in EMEM with 25 mM HEPES (Lonza) supplemented with 
2\% FCS, L-glutamine, and antibiotics. Infectious clone-derived CHIKV(CHIKV-LS3) was generated as described by Scholte et al. ${ }^{29}$ The ZIKV strain SL0612 was isolated from an infected traveler returning from Suriname as described by Van Boheemen et al. ${ }^{31}$ The Sindbis virus (SINV) strain HR and Semliki Forest virus (SFV) strain SFV4 are part of the LUMC virus collection. The MERS-CoV strain EMC/2012 was isolated from patient material in the Dr. Soliman Fakeeh Hospital, Jeddah, Saudi Arabia and was obtained from Erasmus Medical Center, Rotterdam. ${ }^{32}$ The SARS-CoV strain Frankfurt 1 was provided by H. F. Rabenau and H. W. Doerr (Johann Wolfgang Goethe-Universität, Frankfurt am Main, Germany). ${ }^{33}$ The compounds were dissolved in DMSO to obtain $20 \mathrm{mM}$ stock solutions. All work with infectious CHIKV, MERS-CoV, SARS-CoV and ZIKV was performed inside biosafety cabinets in the BSL-3 facilities of the Leiden University Medical Center.

\section{Antiviral CPE-reduction assays}

VeroE6 cells were seeded at a density of 5,000 cells/well (CHIKV) or 10,000 cells/well (SARS$\mathrm{CoV}, \mathrm{SFV}$ and SINV) in a total volume of $100 \mu \mathrm{L}$ per well in 96 well plates. Vero cells were seeded at a density of 20,000 cells/well when used for MERS-CoV infections and Vero CCL81 cells were seeded at a density of 5,000 cells/well for ZIKV infections under the same conditions as described for Vero E6. The following day, compound dilutions with concentrations of 150, $50,16.7$ and $5.6 \mu \mathrm{M}$ were prepared in the infection medium by 3 -fold serial dilution of the 150 $\mu \mathrm{M}$ solution. After replacing the culture medium with the respective dilutions of the compound, the cells were infected with CHIKV (MOI 0.005), SFV (MOI 0.025), SINV (MOI 0.025), ZIKV (MOI 0.05), MERS-CoV (MOI 0.005) or SARS-CoV (MOI 0.01). Viability assays were conducted in parallel. Each compound was tested at each concentration in quadruplicate (4 biological replicates per concentration). An MTS colorimetric assay was conducted $40 \mathrm{~h}$ postinfection (hpi) for SFV, 76 hpi for SINV, 72 h hpi for MERS- and SARS-CoV, and 96 hpi for 
CHIKV and ZIKV by adding $20 \mu \mathrm{l} /$ well of the CellTiter $96{ }^{\circledR}$ AQueous One Solution Cell Proliferation Assay (MTS) reagent (Promega). The assay was stopped after 2-2.5 h by fixing the cells with $37 \%$ formaldehyde. The absorbance was measured at $495 \mathrm{~nm}$ in a Berthold Mithras LB 940 plate reader, and the values were expressed relative to uninfected (infection) or untreated (viability) samples. The results represent the average of quadruplicate samples expressed as the mean $\pm \mathrm{SD}$. Compounds that were found to be protective were further evaluated in CPE reduction assays by testing 8 different concentrations to determine the $\mathrm{EC}_{50}$ as previously described. ${ }^{30,33}$ The cytotoxicity $\left(\mathrm{CC}_{50}\right)$ of the compounds was determined in parallel, and all experiments were performed in quadruplicate. Graph-Pad Prism 8.0.1 was used for $\mathrm{EC}_{50}$ and $\mathrm{CC}_{50}$ determination by non-linear regression.

\section{Viral load reduction assays}

VeroE6 (CHIKV, ZIKV) cells were seeded at a density of $7.5 \times 10^{4}$ cells/well in $0.5 \mathrm{ml}$ DMEM/8\%FCS in 24-well cell culture plates and allowed to adhere overnight. For MERS-CoV and SARS-CoV a cell density of or $6.0 \times 10^{4}$ cells/well of Vero E6 and Vero cells was used, respectively, under the same conditions as described above. The next day, compound dilutions $(0-1.5 \mu \mathrm{M})$ were prepared in EMEM/2\%FCS to which virus was added to yield inocula for infecting the cells with a $\mathrm{MOI}$ of 0.1 for CHIKV, MOI of 1 for ZIKV and an MOI of 0.01 for SARS- and MERS-CoV. Cells were incubated at $37^{\circ} \mathrm{C}$ with $250 \mu \mathrm{l} /$ well of the inoculum for $1 \mathrm{hr}$ (CHIKV, SARS- and MERS-CoV) or $2 \mathrm{hrs}$ (ZIKV). After the infection, the cells were washed twice with $1 \mathrm{ml} /$ well warm PBS and $0.5 \mathrm{ml} /$ well fresh EMEM/2\%FCS with different concentrations of compound $(0-1.5 \mu \mathrm{M})$ was added. The cells were incubated for $30 \mathrm{hrs}$ (CHIKV) or 48 hrs (ZIKV, SARS- and MERS-CoV) at $37^{\circ} \mathrm{C}$, after which supernatants were harvested and stored at $-80^{\circ} \mathrm{C}$ for determination of the infectious virus titer by plaque assay. Viability assays were conducted in parallel as described in the previous paragraph. Plaque assays with CHIKV and SARSCoV on VeroE6 cells, MERS-CoV on Vero cells, and ZIKV on Vero CCL81 cells were performed as described previously (). Compound $2 \mathrm{c}$ was tested at each concentration in duplicate in two independent experiments $(n=4)$. Graph-Pad Prism 8.0.1 was used for statistical analysis with one-way ANOVA 
multiple comparison test.

ASSOCIATED CONTENT

\section{Supporting Information}

The Supporting Information is available free of charge via the Internet at http://pubs.acs.org.

${ }^{1} \mathrm{H}$ and ${ }^{13} \mathrm{C}$ NMR copies of all final compounds $\mathbf{2 a - j}$ and $\mathbf{3 a - c}$ (PDF).

Molecular formula strings (CSV)

\section{AUTHOR INFORMATION}

\section{Corresponding Author}

Lak Shin Jeong, Ph.D., Research Institute of Pharmaceutical Sciences, College of Pharmacy,

Seoul National University, Seoul 151-742, Korea. Phone: 82-2-880-7850. E-mail: lakjeong@snu.ac.kr

\section{Author Contributions}

\#J. Y. and G.K. contributed equally to this work.

All authors have contributed to the manuscript and given approval to the final version of the 
manuscript.

\section{Notes}

The authors declare no competing financial interest.

\section{Acknowledgments}

This research was supported by grants from Mid-career Research Program (2016R1A2B3010164) and the Ministry of Science, ICT \& Future Planning (2017M3A9A8032086) of the National Research Foundation (NRF), Korea. The work in Leiden (NSO and KK) was supported by the EU Marie Skłodowska-Curie ETN 'ANTIVIRALS' (Grant Agreement No. 642434).

\section{ABBREVIATIONS USED}

RdRp, RNA-dependent RNA polymerase; SAH, $S$-adenosyl-homocysteine; SARS-CoV, severe acute respiratory syndrome coronavirus; CHIKV, chikungunya virus; ZIKV, Zika virus; nsps, nonstructural proteins; MTase, methyltransferase; NTP, nucleoside triphosphate; SAM, $S$ adenosyl-L-methionine; AK, adenosine kinase; LiHMDS, lithium hexamethyldisilazide; TESCl, triethylsilyl chloride; NFSI, $N$-fluorobenzenesulfonimide; NFOBS, $N$-fluoro- $O$ benzenedisulfonimide; $\mathrm{NaBH}_{4}$, sodium borohydride; $\mathrm{LiBH}_{4}$, lithium borohydride; $\mathrm{NMO}, \mathrm{N}$ methylmorpholine- $N$-oxide; TBS, $t$-butyldimethylsilyl; TBAF, tetra- $n$-butylammonium fluoride; DAST, $N, N$-diethylaminosulfur trifluoride; $\mathrm{AlMe}_{3}$, trimethylaluminum; $\mathrm{SOCl}_{2}$, thionyl chloride; DIPEA, N,N-diisopropylethylamine; TFA, trifluoroacetic acid; $\mathrm{Boc}_{2} \mathrm{O}$, ditert-butyl dicarbonate; DNTB, 5,5'-dithiobis-2-nitrobenzoate; CPE, cytopathic; TMSOTf, trimethylsilyl trifluoromethanesulfonate; DMEM, Dulbecco's modified Eagle's medium; FCS, fetal calf serum; NEAA, non-essential amino acid; EMEM, Eagle's minimum essential 
medium; SINV, Sindbis virus; SFV, Semliki forest virus.

\section{References}

(1) (a) Baltimore, D. Expression of animal virus genomes. Bacteriological Rev. 1971, 35, 235 241. (b) Modrow, S.; Falke, D.; Truyen, U.; Schätzl, H. Viruses with single-stranded, positivesense RNA genomes. Molecular virology. Berlin, Heidelberg: Springer Berlin Heidelberg. 2013, pp. 185-349.

(2) Thiel, V. (editor). (2007). Coronaviruses: Molecular and cellular biology (1st ed.). Caister Academic Press.

(3) Zumla, A.; Hui, D. S.; Perlman, S. Middle east respiratory syndrome. Lancet 2015, 386, 995-1007.

(4) Caglioti, C; Lalle, E.; Castilletti, C.; Carletti, F.; Capobianchi, M. R.; Bordi, L. Chikungunya virus infection: an overview. New Microbiol. 2013, 36, 211-27.

(5) (a) Musso, D.; Gubler, D. J. Zika virus. Clin. Microbiol. Rev. 2016, 29, 487-524. (b) Agumadu, V. C.; Ramphul, K. Zika virus: A review of literature. Cureus 2018, 10, e3025. (6) (a) Forgie, S.; Marrie, T. J. Healthcare-associated atypical pneumonia. Semin. Respir. Crit. Care Med. 2009, 30, 67-85. (b) Chan-Yeung, M.; Xu, R. H. SARS: epidemiology. Respirology 2003, 8 (Suppl), S9-S14. (c) Hui, D. S.; Azhar, E. I.; Kim, Y.-J.; Memish, Z. A.; Oh, M.-d.; Zumla, A. Middle east respiratory syndrome coronavirus: risk factors and determinants of primary, household, and nosocomial transmission. Lancet Infect. Dis. 2018, 
http://dx.doi.org/10.1016/S1473-3099(18)30127-0.

(7) (a) Schwartz, O.; Albert, M. L. Biology and pathogenesis of chikungunya virus. Nat. Rev. Microbiol. 2010, 8, 491-500. (b) Presti, A. L.; Lai, A.; Cella, E.; Zehender, G.; Ciccozzi, M. Chikungunya virus, epidermiology, clinics, and pathogenesis: A review. Asian Pac. J. Trop. Med. 2014, 7, 925-932. (c) Ng, L. F. P. Immunopathology of chikungunya virus infection: Lessons learned from patients and animal models. Ann. Rev. Virol. 2017, 4, 413-427.

(8) Abushouk, A. I.; Negida, A.; Ahmed, H. An updated review of Zika virus. J. Clin. Virol. 2016, 84, 53-58.

(9) (a) Musso, D.; Roche, C.; Robin, E.; Nhan, T.; Teissier, A.; Cao-Lormeau, V. M. Potential sexual transmission of Zika virus. Emerg. Infect. Dis. 2015, 21, 359-361. (b) Oster, A. M.; Russell, K. Stryker, J. E.; Friedman, A.; Kachur, R. E.; Peterson, E. E.; Jamieson, D. J.; Cohn, A. C.; Brooks, J. T. Update: Interim guidance for prevention of sexual transmission of Zika virus. Morb. Mortal.Wkly Rep. 2016, 65, 23-325.

(10) Ahlquist, P. RNA-dependent RNA polymerases, viruses, and RNA silencing. Science 2002, 296, 1270-1273.

(11) (a) Coutard, B.; Barral, K.; Lichiere, J.; Selisko, B.; Martin, B.; Aouadi, W.; Lombardia, M. O.; Debart, F.; Vasseur, J.-J.; Guillemot, J. C.; Canard, B.; Decroly, E. Zika virus methyltransferase: Structure and functions for drug design perspectives. J. Virol. 2017, 91, e02202-16. (b) Case, J. B.; Ashbrook, A. W.; Dermody, T. S.; Denison, M. R. Mutagenesis of $S$-adenosyl-L-methionine-binding residues in coronavirus nsp14 N7-methyltransferase demonstrates differing requirements for genome translation and resistance to innate immunity. J. Virol. 2016, 90, 7248e 7256.

(12) (a) Decroly, E.; Ferron, F.; Lescar, J.; Canard, B. Conventional and unconventional mechanisms for capping viral mRNA. Nat. Rev. Microbiol. 2011, 10, 51-65. (b) Cougot, N.; 
Van Dijk, E.; Babajko, S.; Seraphin, B. Cap-tabolism. Trends Biochem. Sci. 2004, 29, 436e444.

(c) Ferron, F.; Decroly, E.; Selisko, B.; Canard, B. The viral RNA capping machinery as a target for antiviral drugs. Antiviral Res. 2012, 96, $21 \mathrm{e} 31$.

(13) (a) Turner, M. A.; Yang, X.; Yin, D.; Kuczera, K.; Borchardt, R. T.; Howell, P. L. Structure and function of $S$-adenosylhomocysteine hydrolase. Cell Biochem. Biophys. 2000, 33, 101-125. (b) Cantoni, G. L. The Centrality of $S$-Adenosylhomocysteinase in the Regulation of the Biological Utilization of S-Adenosylmethionine. In Biological Methylation and Drug Design; Borchardt, R. T., Creveling, C. R., Ueland, P. M., Eds.; Humana Press: Clifton, NJ, 1986; pp 227-238.

(14) (a) Wolfe, M. S.; Borchardt, R. T. S-Adenosyl-L-homocysteine hydrolase as a target for antiviral chemotherapy. J. Med. Chem. 1991, 34, 1521-1530. (b) De Clercq, E. Strategies in the design of antiviral drugs. Nat. Rev. Drug Discov. 2002, 1, 13-25.

(15) Jordheim, L. P.; Durantel, D.; Zoulim, F.; Dumontet, C. Advances in the development of nucleoside and nucleotide analogues for cancer and viral diseases. Nat. Rev. Drug Discov. 2013, $12,447-464$.

(16) (a) Kusaka, T.; Yamamoto, H.; Shibata, M.; Muro, M.; Kishi, T.; Mizuno, K. Streptomyces citricolor nov. sp. and a new antibiotic. J. Antibiot. (Tokyo) 1968, 21, 255-263.

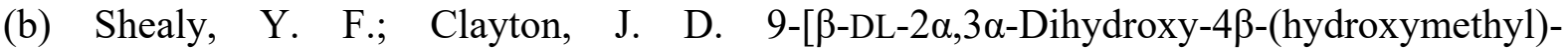
cyclopentyl]adenine, the carbocyclic analog of adenosine. J. Am. Chem. Soc. 1966, 88, 38853887. (c) Shealy, Y. F.; Clayton, J. D. Synthesis of carbocyclic analogs of purine ribonucleosides. J. Am. Chem. Soc. 1969, 91, 3075-3083. (d) Shealy, Y. F.; Thorpe, M. C.; Coburn, Jr. W. C.; Clayton, J. D. Identity of the synthetic carbocylic analog of adenosine and 
aristeromycin. Chem. Pharm. Bull. 1980, 28, 3114-3117. (e) Arita, M.; Adachi, K.; Ito, Y.; Sawai, H.; Ohno, M. Enantioselective synthesis of the carbocyclic nucleosides (-)aristeromycin and (-)-neplanocin A by a chemicoenzymatic approach. J. Am. Chem. Soc. 1983, 105, 4049-4055. (f) Yoshikawa, M.; Okaichi, Y.; Cha, B. C.; Kitagawa, I. Synthesis of (-)aristeromycin from D-glucose. Tetrahedron, 1990, 46, 7459-7470. (g) Wolfe, M. S.; Lee, Y.; Bartlett, W. J.; Borcherding, D. R.; Borchardt, R. T. 4'-Modified analogs of aristeromycin and neplanocin A: synthesis and inhibitory activity toward $S$-adenosyl-L-homocysteine hydrolase. J. Med. Chem. 1992, 35, 1782-1791. (h) Madhavan, G. V.; Martin, J. C. A novel and stereospecific synthesis of $( \pm)$ - and (-)-aristeromycin. J. Org. Chem. 1986, 51, 1287-1293.

(17) (a) Bennett, L. L., Jr.; Allan, P. W.; Rose, L. M.; Comber, R. N.; Secrist, J. A., III. Differences in the metabolism and metabolic effects of the carbocyclic adenosine analogs, neplanocin A and aristeromycin. Mol. Pharmacol. 1986, 29, 383-390. (b) Bennett, L. L.; Bowdon, B. J.; Allan, P. W.; Rose, L. M. Evidence that the carbocyclic analog of adenosine has different mechanisms of cytotoxicity to cells with adenosine kinase activity and to cells lacking this enzyme. Biochem. Pharmacol. 1986, 35, 4106-4109.

(18) (a) Madhavan, G. V. B.; McGee, D. P. C.; Rydzewski, R. M.; Boehme, R.; Martin, J. C.; Prisbe, E. J. Synthesis and antiviral evaluation of 6'-substituted aristeromycins: potential mechanism-based inhibitors of $S$-adenosylhomocysteine hydrolase. J. Med. Chem. 1988, 31, 1798-1804. (b) Verheyden, J. P.; Martin, J. C.; Madhaven, B.; McGee, D. P. C.; Prisbe, E. J. Purinyl or pyrimidinyl substituted hydroxycyclopentane compounds useful as antivirals. U.S. Patent 4,605,659, Aug 12, 1986. (c) Yin, X. -Q.; Schneller, S. W. Chiral syntheses of 6 - $\beta$ fuoroaristeromycin, 6 - $\beta$-fuoro-5 -noraristeromycin and aristeromycin. Tetrahedron Lett. 2005, 46, 7535-7538. (d) Jeong, L. S.; Moon, H. R.; Park, J. G.; Shin, D. H.; Choi, W. J.; Lee, K. M.; 
Kim, H. O.; Chun, M. W.; Kim, H. D.; Kim, J. H. Synthesis and biological evaluation of haloneplanocin A as novel mechanism-based inhibitors of $S$-adenosylhomocysteine hydrolase. Nucleosides, Nucleotides Nucleic Acids 2003, 22, 589-592. (e) Jeong, L. S.; Yoo, S. J.; Lee, K. M.; Koo, M. J.; Choi, W. J.; Kim, H. O.; Moon, H. R.; Lee, M. Y.; Park, J. G.; Lee, S. K.; Chun, M. W. Design, synthesis, and biological evaluation of fluoroneplanocin A as the novel mechanism-based inhibitor of $S$-adenosylhomocysteine hydrolase. J. Med. Chem. 2003, 46, 201-203. (f) Lee, K. M.; Choi, W. J.; Lee, Y.; Lee, H. J.; Zhao, L. X.; Lee, H. W.; Park, J. G.; Kim, H. O.; Hwang, K. Y.; Heo, Y. X-ray crystal structure and binding mode analysis of human $S$-adenosylhomocysteine hydrolase complexed with novel mechanism-based inhibitors, haloneplanocin A analogues. J. Med. Chem. 2011, 54, 930-938. (g) Chandra, G.; Moon, Y. W.; Lee, Y.; Jang, J. Y.; Song, J.; Nayak, A.; Oh, G.; Mulamoottil, V. A.; Sahu, P. K.; Kim, G.; Chang, T.-S.; Noh, N.; Lee, S. K.; Choi, S.; Jeong, L. S. Structure-activity relationships of neplanocin A analogues as $S$-adenosylhomocysteine hydrolase inhibitors and their antiviral and antitumor activities. $J$. Med. Chem. 2015, 58, 5108-5120.

(19) Kim, G.; Yoon, J.-s.; Jarhad, D. B.; Shin, Y. S.; Majik, M. S.; Mulamoottil, V. A.; Hou, X.; Qu, S.; Park, J.; Baik, M.-H.; Jeong, L. S. Asymmetric synthesis of (-)-6'-fluoroaristeromycin via stereoselective electrophilic fluorination. Org. Lett. 2017, 19, 5732-5735. (20) (a) Siddiqui, A. Q.; Balatore, C.; McGuigan, C.; Pathirana, T. N.; Balzarini, J.; De Clercq, E. The presence of substituents on the aryl moiety of the aryl phosphoramidate derivative of d4T enhances anti-HIV efficacy in cell culture: a structure-activity relationship. J. Med. Chem. 1999, 42, 393-399. (b) Mehellou, Y.; Rattan, H.S.; Balzarini, J. The ProTide prodrug technology: from the concept to the clinic. J. Med. Chem. 2018, 61, 2211-2226. (c) Mehellou, Y.; Balzarini, J.; McGuigan C. Aryloxy phosphoramidate triesters: a technology for delivering monophosphorylated nucleosides and sugars into cells. Chem. Med. Chem. 2009, 4, 1779-1791. 
(d) McGuigan, C.; Pathirana, R. N.; Balzarini, J.; De Clercq, E. Intracellular delivery of bioactive AZT nucleotides by aryl phosphate derivatives of AZT. J. Med. Chem. 1993, 36, 1048-1052. (e) McGuigan, C.; Harris, S. A.; Daluge, S. M.; Gudmundsson, K. S.; McLean, E. W.; Burnette, T. C.; Marr, H.; Hazen, R.; Condreay, L. D.; Johnson, L.; De Clercq, E.; Balzarini, J. Application of phosphoramidate pronucleotide technology to abacavir leads to a significant enhancement of antiviral potency. J. Med. Chem. 2005, 48, 3504-3515. (f) McGuigan, C.; Hassan-Abdallah, A.; Srinivasan, S.; Wang, Y.; Siddiqui, A.; Daluge, S. M.; Gudmundsson, K. S.; Zhou, H.; McLean, E. W.; Peckham, J. P.; Burnette, T. C.; Marr, H.; Hazen, R.; Condreay, L. D.; Johnson, L.; Balzarini, J. Application of phosphoramidate proTide technology significantly improves antiviral potency of carbocyclic adenosine derivatives. J. Med. Chem. 2006, 49, 7215-7226. (g) Sofia, M. J.; Bao, D.; Chang, W.; Du, J.; Nagarathnam, D.; Rachakonda, S.; Reddy, P. G.; Ross, B. S.; Wang, P.; Zhang, H.-R.; Bansal, S.; Espiritu, C.; Keilman, M.; Lam, A. M.; Steuer, H. M. M.; Niu, C.; Otto, M. J.; Furman, P. A. Discovery of a $\beta$-D-2 -deoxy-2 - $\alpha$-fluoro-2 - $\beta$ - $C$-methyluridine nucleotide prodrug (PSI-7977) for the treatment of hepatitis C virus. J. Med. Chem. 2010, 53, 7202-7218. (h) Slusarczyk, M.; Lopez, M. H.; Balzarini, J.; Mason, M.; Jiang, W. G.; Blagden, S.; Thompson, E.; Ghazaly, E.; McGuigan, C. Application of ProTide technology to gemcitabine: a successful approach to overcome the key cancer resistance mechanisms leads to a new agent (NUC-1031) in clinical development. J. Med. Chem. 2014, 57, 1531-1542.

(21) (a) Choi, W. J.; Park, J. G.; Yoo, S. J.; Kim, H. O.; Moon, H. R.; Chun, M. W.; Jung, Y. H.; Jeong, L. S. Syntheses of D- and L-Cyclopentenone derivatives using ring-closing metathesis: Versatile intermediates for the synthesis of D- and L-carbocyclic nucleosides. J. Org. Chem. 2001, 66, 6490-6494. (b) Moon, H. R.; Choi, W. J.; Kim, H. O.; Jeong, L. S. Improved and alternative synthesis of D- and L-cyclopentenone derivatives, the versatile intermediates for the 
synthesis of carbocyclic nucleosides. Tetrahedron:Asymmetry 2002, 13, 1189-1193. (c) Mulamoottil, V. A.; Nayak, A.; Jeong, L. S. Recent advances in the synthesis of carbocyclic nucleosides via ring closing metathesis. Asian J. Org. Chem. 2014, 3, 748-761.

(22) (a) Gilman, H.; Jones, R. G.; Woods, L. A. The preparation of methylcopper and some observations on the decomposition of organocopper compounds. J. Org. Chem. 1952, 17, 1630-1634. (b) Song, G. Y.; Paul, V.; Choo, H.; Morrey, J.; Sidwell, R. W.; Schinazi, R. F.; Chu, C. K. Enantiomeric synthesis of D- and L-cyclopentenyl nucleosides and their antiviral activity against HIV and West Nile virus. J. Med. Chem. 2001, 44, 3985-3993.

(23) Rubottom, G. M.; Gruber, J. M.; Boeckman, R. K., Jr; Ramaiah, M.; Medwid, J. B. Clarification of the mechanism of rearrangement of enol silyl ether epoxides. Tetrahedron Lett. 1978, 19, 4603-4606.

(24) Montgomery, J. A.; Temple, Jr., C. Synthesis of potential anticancer agents. IX. 9-Ethyl6-substituted-purines. J. Am. Chem. Soc., 1957, 79, 5238-5242.

(25) (a) Shaw, G.; Warrener, R. N. Purines, pyrimidines, and glyoxalines. Part VIII. New synthesis of uracil and thymine. J. Chem. Soc. 1958, 157-159. (b) Jeong, L. S.; Buenger, G.; McCormack, J. J.; Cooney, D. A.; Hao, Z.; Marquez, V. E. Carbocyclic analogues of the potent cytidine deaminase inhibitor 1-( $\beta$-D-ribofuranosyl)-1,2-dihydropyrimidin-2-one (zebularine). J. Med. Chem. 1998, 41, 2572-2578.

(26) Crystal structure data for $\mathrm{C}_{10} \mathrm{H}_{13} \mathrm{FN}_{2} \mathrm{O}_{5}(\mathbf{2 g})$ are as follows: $\mathrm{M}_{\mathrm{r}}=260.22, T=295.71$ (13) $\mathrm{K}$, trigonal, space group P3221, $a=6.6465(2) \AA ̊ ., b=6.6465(2) \AA ̊ ., c=43.3632(14) \AA, \alpha=$ $90^{\circ}, \beta=90^{\circ}, \gamma=120^{\circ}, V=1658.97(13) \AA^{3}, Z=6, \rho_{\text {calc }}=1.563 \mathrm{gcm}^{-3}, \mu=1.183 \mathrm{~mm}^{-1}, F(000)$ $=816.0$, crystal dimension $0.242 \times 0.067 \times 0.034 \mathrm{~mm}^{3}$, radiation $\mathrm{CuK}_{\alpha}(\lambda=1.54184)$. Of 29371 reflections collected in the $2 \theta$ range from 12.246 to $154.882^{\circ}$ using an $\omega$ scan on a SuperNova, 
Dual, $\mathrm{Cu}$ at zero, AtlasS2 diffractometer, 2346 were unique reflections $\left(\mathrm{R}_{\text {int }}=0.0654, \mathrm{R}_{\text {sigma }}=\right.$ 0.0230). Using Olex2, the structure was solved with the ShelXT structure solution program using Direct Methods and refined with the ShelXL refinement package using Least Squares minimization. Final $\mathrm{R}$ indexes [all data] $R 1=0.0273, w R 2=0.0779$, GOF $=1.062$, and $\operatorname{maxmin}^{-1}$ residual electron density $0.14 /-0.16 \mathrm{e}^{-3}$. Flack $\times$ parameter $=0.13(10)$. Further details of the crystal structure investigation(s) may be obtained from the Cambridge Crystallographic Data Centre (CCDC, 12 Union Road, Cambridge, CB2 1EZ (UK); Tel: (+44)1223-336-408, Fax: (+44)1223-336-033, e-mail: deposit@ccdc.cam.ac.kr) using no. CCDC 1871331. (c) Crystal structure data for $\mathrm{C}_{10} \mathrm{H}_{13} \mathrm{~F}_{2} \mathrm{~N}_{2} \mathrm{O}_{5}$ (2h) are as follows: $\mathrm{M}_{\mathrm{r}}=278.21$, $T=293.55$ (10) K, orthorhombic, space group $\mathrm{P} 2{ }_{1} 2{ }_{1}{ }_{1}, a=5.8735(2) \AA ⿻$, $b=13.5166(2) \AA$, $c=14.1374(14) \AA, \alpha=90^{\circ}, \beta=90^{\circ}, \gamma=90^{\circ}, V=1122.36$ (7) $\AA^{3}, Z=4, \rho_{\text {calc }}=1.6463 \mathrm{gcm}^{-3}$, $\mu=1.343 \mathrm{~mm}^{-1}, F(000)=578.6$, crystal dimension $0.261 \times 0.21 \times 0.074 \mathrm{~mm}^{3}$, radiation $\mathrm{CuK}_{\alpha}$ $(\lambda=1.54184)$. Of 3965 reflections collected in the $2 \theta$ range from 9.06 to $147.32^{\circ}$ using an $\omega$ scan on a SuperNova, Dual, $\mathrm{Cu}$ at zero, AtlasS2 diffractometer, 2190 were unique reflections $\left(R_{\text {int }}=0.0191, R_{\text {sigma }}=0.0258\right)$. Using Olex2, the structure was solved with the ShelXT structure solution program using Direct Methods and refined with the ShelXL refinement package using Least Squares minimization. Final $\mathrm{R}$ indexes [all data] $R 1=0.0318, w R 2=0.0813$, $\mathrm{GOF}=1.065$, and $\operatorname{maxmin}^{-1}$ residual electron density $0.17 /-0.19$ e $\AA^{-3}$. Flack $x$ parameter $=$ 0.02(13). Further details of the crystal structure investigation(s) may be obtained from the Cambridge Crystallographic Data Centre (CCDC, 12 Union Road, Cambridge, CB2 1EZ(UK); Tel: (+44)1223-336-408, Fax: (+44)1223-336-033, e-mail: deposit@ccdc.cam.ac.kr) using no. CCDC 1871332.

(27) Divaker, K. J.; Reese, C. B. 4-(1,2,4-Triazol-1-yl)- and 4-(3-nitro-1,2,4-triazol-1-yl)-1-( $\beta$ - 
D-2,3,5-tri- $O$-acetylarabinofuranosyl)pyrimidin-2(1H)-ones. Valuable intermediates in the synthesis of derivatives of 1- $\beta$-D-arabinofuranosyl)cytosine (Ara-C), J. Chem. Soc. Perkin I 1982, $1171-1176$.

(28) Ross, B. S.; Reddy, P. G.; Zhang, H.-R.; Rachakonda, S.; Sofia, M. J. Synthesis of diatereomerically pure nucleotide phosphoramidates. J. Org. Chem. 2011, 76, 8311-8319.

(29) Lozada-Ramírez, J. D.; Martínez-Martínez, I.; Sánchez-Ferrer, A.; García-Carmona, F. A colorimetric assay for $S$-adenosylhomocysteine hydrolase. J. Biochem. Biophys. Methods 2006, $67,131-140$.

(30) Scholte, F. E. M.; Tas, A.; Martina, B. E. E.; Cordioli, P.; Narayanan, K.; Makino, S.; Snijder, E. J.; van Hemert, M. J. Characterization of synthetic chikungunya viruses based on the consensus sequence of recent E1-226V isolates. PLoS One. 2013, 8, e71047.

(31) van Boheemen, S.; Tas, A.; Anvar, S. Y.; van Grootveld, R.; Albulescu, I. C.; Bauer, M. P.; Feltkamp, M. C.; Bredenbeek, P. J.; van Hemert, M. J. Quasispecies composition and evolution of a typical zika virus clinical isolate from suriname. Sci Rep. 2017, 7, 2368.

(32) van Boheemen, S.; de Graaf, M.; Lauber, C.; Bestebroer, T. M.; Raj, V.S.; Zaki, A. M.; Osterhaus, A. D.; Haagmans, B. L.; Gorbalenya, A. E.; Snijder, E. J.; Fouchier, R. A. Genomic characterization of a newly discovered coronavirus associated with acute respiratory distress syndrome in humans. mBio 2012, 3, e00473-12.

(33) (a) Albulescu, I. C.; Kovacikova, K.; Tas, A.; Snijder, E. J.; van Hemert, M. J. Suramin inhibits Zika virus replication by interfering with virus attachment and release of infectious particles. Antiviral. Res. 20017, 143, 230-236. (b) de Wilde, A. H.; Jochmans, D.; Posthuma, C. C.; Zevenhoven-Dobbe, J. C.; van Nieuwkoop, S.; Bestebroer, T. M.; van den Hoogen, B. G.; Neyts, J.; Snijder, E. J. Screening of an FDA-approved compound library identifies four small-molecule inhibitors of Middle East respiratory syndrome coronavirus replication in cell 
culture. Antimicrob. Agents Chemother. 2014, 58, 4875-4884.

Table of Contents graphic

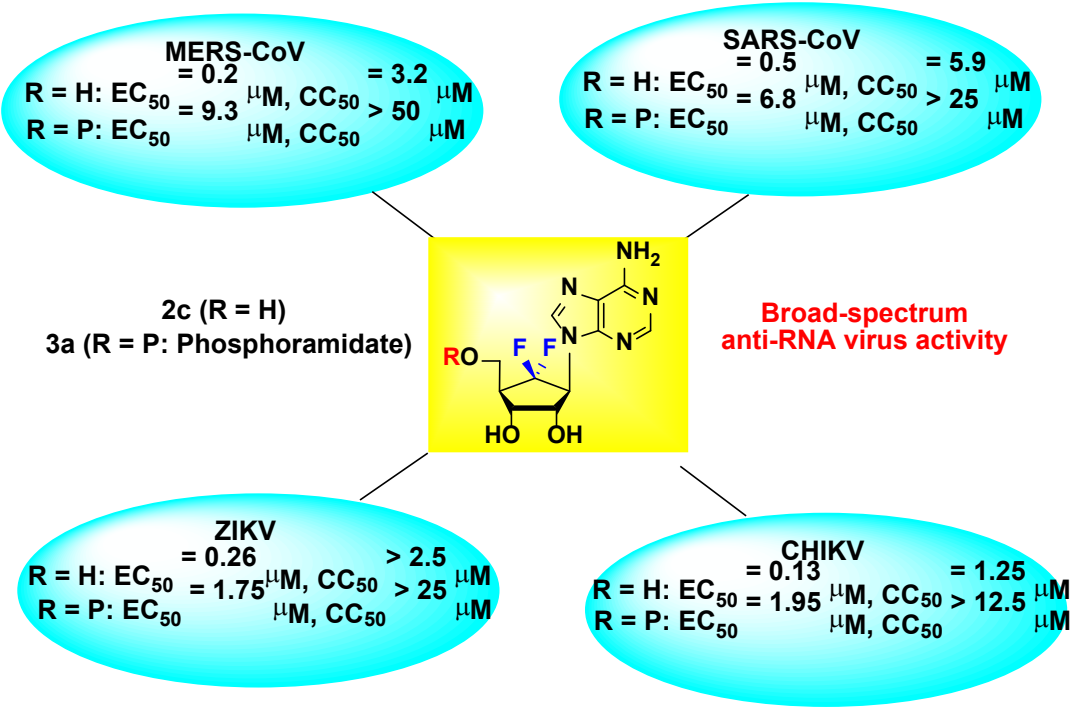


